\title{
Structure of an Unusual Tetracyclic Deoxyguanosine Adduct: Implications for Frameshift Mutagenicity by Ortho-Cyano Nitroanilines.
}

Trevor W. Manning, Sameer Al-Abdul-Wahid, Richard A. Manderville,* P. David Josephy,* Ryan W. Kung and Stacey D. Wetmore*

\section{Table of Contents:}

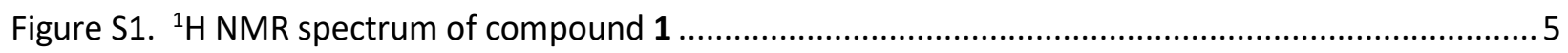

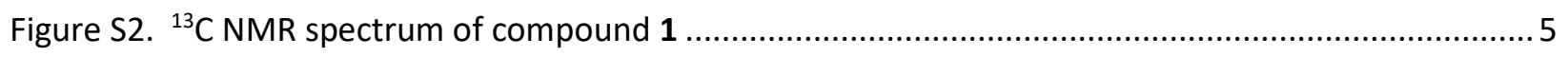

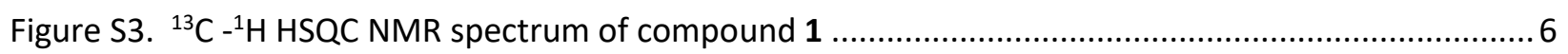

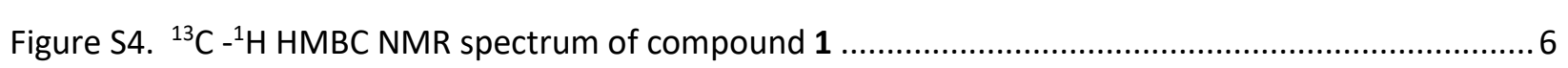

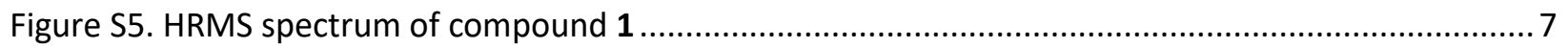

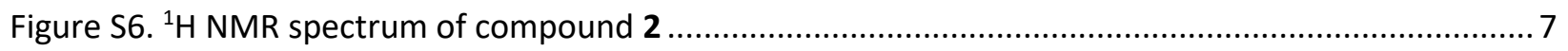

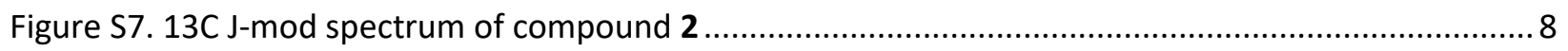

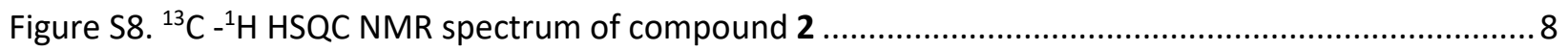

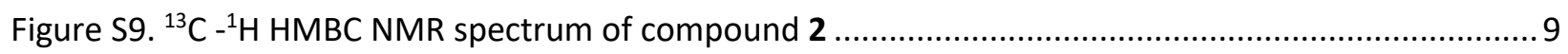

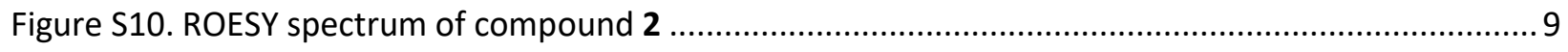

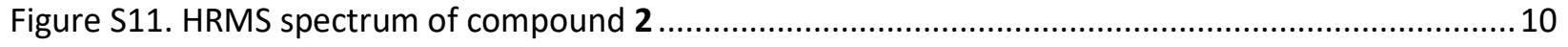

Figure S12. Mass spectrum of compound 2 in DMSO stock solution .................................................... 10

Figure S13. Mass spectrum of compound 2 following exposure to $0.1 \mathrm{M} \mathrm{HCl}$ at $37.2^{\circ} \mathrm{C} \ldots \ldots \ldots \ldots \ldots \ldots \ldots . . . . . . . . .11$

Figure S14. Mass spectrum of compound 1 in DMSO stock solution ...................................................11

Figure S15. Mass spectrum of compound 1 following exposure to $0.1 \mathrm{M} \mathrm{HCl}$ at $37.2^{\circ} \mathrm{C}$

Figure S16: Structures and relative stabilities of the 1 nucleobase minima as calculated at the B3LYPD3(BJ)/6-31G(d,p) level of theory. Zero-point vibrational energy corrected B3LYP-D3(BJ)/6$311++G(2 d f, 2 p)$ relative energies are provided in parentheses $(\mathrm{kJ} / \mathrm{mol})$. 
Figure S17: Select dihedrals ( $\theta$ and $\phi$, deg) for the $\mathbf{2}$ nucleobase minima as calculated at the B3LYPD3(BJ)/6-31G(d,p) level of theory. Zero-point vibrational energy corrected B3LYP-D3(BJ)/6$311++\mathrm{G}(2 \mathrm{df}, 2 \mathrm{p})$ relative energies are provided in parentheses $(\mathrm{kJ} / \mathrm{mol})$.

Figure S18: Select dihedral angles ( $\chi$, deg) for the 1 nucleoside minima and transition states (TS) as calculated at the B3LYP-D3(BJ)/6-31G(d,p) level of theory. Zero-point vibrational energy corrected B3LYP-D3(BJ)/6-311++G $(2 \mathrm{df}, 2 \mathrm{p})$ relative energies are provided in parentheses $(\mathrm{kJ} / \mathrm{mol})$.

Figure S19: Select dihedral angles ( $\chi$, deg) for the 1 nucleoside minima and transition states (TS) as calculated at the B3LYP-D3(BJ)/6-31G(d,p) level of theory with the $5^{\prime}$-hydroxyl group fixed away from the adduct. Zero-point vibrational energy corrected B3LYP-D3(BJ)/6-311++G(2df,2p) relative energies are provided in parentheses $(\mathrm{kJ} / \mathrm{mol})$.

Figure S20: Select dihedral angles ( $\chi, \theta$ and $\phi, \mathrm{deg}$ ) for the $\mathbf{2}$ nucleoside minima and transition states (TS) as calculated at the B3LYP-D3(BJ)/6-31G(d,p) level of theory. Zero-point vibrational energy corrected B3LYP-D3(BJ)/6-311++G(2df,2p) relative energies are provided in parentheses $(\mathrm{kJ} / \mathrm{mol}) \ldots \ldots \ldots \ldots \ldots \ldots \ldots \ldots . .16$

Figure S21: Select dihedral angles ( $\chi, \theta$ and $\phi, \mathrm{deg}$ ) for the $\mathbf{2}$ nucleoside minima and transition states (TS) as calculated at the B3LYP-D3(BJ)/6-31G(d,p) level of theory with the $5^{\prime}$-hydroxyl group fixed away from the adduct. Zero-point vibrational energy corrected B3LYP-D3(BJ)/6-311++G(2df,2p) relative energies are provided in parentheses $(\mathrm{kJ} / \mathrm{mol})$.

Figure S22: Potential energy surface for the rotation about the $\chi$ dihedral angle (deg) in the 1 nucleoside with the $5^{\prime}$-hydroxyl group constrained (orange) or unconstrained (blue). Calculated every $10^{\circ}$ at the B3LYP-D3(BJ)/6-31G(d,p) level of theory and report in $\mathrm{kJ} / \mathrm{mol}$.

Figure S23: Potential energy surface for the rotation about the $\chi$ dihedral angle (deg) in the $\mathbf{2}$ nucleoside with the $5^{\prime}$-hydroxyl group constrained (orange) or unconstrained (blue). Calculated every $10^{\circ}$ at the B3LYP-D3(BJ)/6-31G(d,p) level of theory and report in $\mathrm{kJ} / \mathrm{mol}$.

Figure S24: Histograms of the $\chi$ dihedral angle sampled during umbrella sampling for the $\mathbf{1}$ (top) and $\mathbf{2}$ (bottom) free nucleosides with a $30 \mathrm{kcal} /\left(\mathrm{mol} \mathrm{rad}^{2}\right)$ restraint.

Figure S25: Representative structures obtained from MD simulations for the five $1 \mu$ s replicas of the distorted $\mathbf{1}$ adducted SMI duplex in the anti orientation. The adducted base and unpaired $\mathrm{C}$ are shown in cyan, and the flanking bases are shown in purple.

Figure S26: Representative structures obtained from MD simulations for the five $1 \mu$ s replicas of the distorted $\mathbf{2}$ adducted SMI duplex in the anti orientation. The adducted base and unpaired $\mathrm{C}$ are shown in cyan, and the flanking bases are shown in purple.

Figure S27: Example structure of a SMI helix with the adducted G3 and G2 bases hydrogen bonding to a single $C$. The adducted base and unpaired $C$ are shown in cyan, and the flanking bases are shown in purple.

Figure S28: Example structures of the distorted SMI helices highlighting observed helical distortions $5^{\prime}$ to the lesion site with the $\mathbf{1}$ (left) and $\mathbf{2}$ (right) adducts in the anti orientation. The adducted base and unpaired $\mathrm{C}$ are shown in cyan, and the flanking bases are shown in purple..... .22

Figure S29: SMI complex representative structures, highlighting the ability of both lesions to adopt planar and bent structures, for the (A) planar $\mathbf{1}$ adduct, (B) distorted bent $\mathbf{1}$ adduct, (C) planar $\mathbf{2}$ adduct 
and (D) distorted bent $\mathbf{2}$ adduct in the syn orientation. The unpaired nucleotides and flanking base-pairs are coloured cyan.

Figure S30: Representative structures obtained from MD simulations for the five $1 \mu$ s replicas of 1 adducted SMI duplex in the syn orientation. The adducted base and unpaired C are shown in cyan, and the flanking bases are shown in purple.

Figure S31: Representative structures obtained from MD simulations for the five $1 \mu$ s replicas of 2 adducted SMI duplex in the syn orientation. The adducted base and unpaired C are shown in cyan, and the flanking bases are shown in purple.

Figure S32: Interplanar angle between the base pairs flanking the lesion site in the SMI containing syn adduct 1 over the course of the five MD replicate simulations.

Figure S33: Interplanar angle between the base-pairs flanking the lesion site in the SMI containing syn adduct $\mathbf{2}$ over the course of the five MD replicate simulations.

Figure S34: Representative structures obtained from MD simulations for the five $1 \mu$ s replicas of 1 adducted FP duplex in the $\mathrm{B}$ conformation. The adducted base and pairing $\mathrm{C}$ are shown in cyan and the flanking bases are shown in purple.

Figure S35: Representative structures obtained from MD simulations for the five $1 \mu$ s replicas of 2 adducted FP duplex in the $B$ conformation. The adducted base and pairing $C$ are shown in cyan and the flanking bases are shown in purple.

Figure S36: Representative structures obtained from MD simulations for the five $1 \mu$ s replicas of 1 adducted FP duplex in the $\mathrm{S}$ conformation. The adducted base and pairing $\mathrm{C}$ are shown in cyan and the flanking bases are shown in purple.

Figure S37: Representative structures obtained from MD simulations for the five $1 \mu$ s replicas of 2 adducted FP duplex in the $\mathrm{S}$ conformation. The adducted base and pairing $\mathrm{C}$ are shown in cyan and the flanking bases are shown in purple.

Figure S38: Representative structures obtained from MD simulations for the five $1 \mu$ s replicas of 1 adducted FP duplex in the $\mathrm{W}$ conformation. The adducted base and pairing $\mathrm{C}$ are shown in cyan and the flanking bases are shown in purple.

Figure S39: Representative structures obtained from MD simulations for the five $1 \mu$ s replicas of 2 adducted FP duplex in the $\mathrm{W}$ conformation. The adducted base and pairing $\mathrm{C}$ are shown in cyan and the flanking bases are shown in purple.

Figure S40: Positions of the bulky moieties (red) with respect to the flanking base-pairs in the FP duplexes in the $S$ conformation for $\mathbf{1}(A$ and $C$ ) and $\mathbf{2}(B$ and $D$ ). Figures were generated by overlaying 1000 frames across the trajectories based on the atoms of the flanking base pairs.

Figure S41: Histogram of the interplanar angles (deg) between the aromatic portion of the bulky moiety of syn 1 (blue) and 2 (orange) and the 5'- or 3'-base pairs from the five MD replicate simulations of the FP duplex.

Table S1. Comparisons between gas-phase and implicit solvent B3LYP-D3(BJ)/6-311++G(2df,2p) relative energies $(\mathrm{kJ} / \mathrm{mol})$ for the anti and syn conformations of the 1 and 2 nucleosides.

Table S2: Average and standard deviations (parentheses) of the sugar pucker occupancies over all windows during umbrella sampling on the adduct nucleosides. 


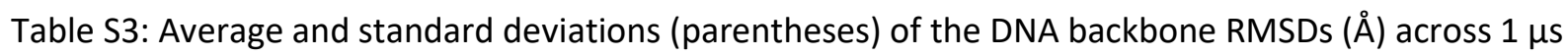
MD simulations.

Table S4: Average and standard deviations (parentheses) of the key dihedral angles (deg) for the positioning of the adduct with respect to the DNA backbone across $1 \mu \mathrm{s}$ MD simulations.

Table S5: Average and standard deviations (parentheses) of the sugar pucker occupancies over all replicas for each SMI and FP containing adducts 1 and $\mathbf{2}$.

Table S6: Occupancies (\%) of the hydrogen bonds of the adduct and unpaired $\mathrm{C}$ when the damaged $\mathrm{G}$ is in the anti conformation for the SMI models. ${ }^{\text {. }}$

Table S7: Occupancies (\%) of the hydrogen bonds of the flanking bases when the lesion is started from the anti conformation for the SMI models. ${ }^{\text {a }}$

Table S8: Occupancies (\%) of the hydrogen bonds of the adduct and unpaired $\mathrm{C}$ when the damaged $\mathrm{G}$ is in the syn conformation for the SMI models. ${ }^{\text {. }}$....

Table S9: Occupancies (\%) of the hydrogen bonds of the flanking bases when the lesion is started from the syn conformation for the SMI models. ${ }^{\text {a }}$

Table S10: Average residence times (ps, amount of time the helix adopts one conformation before switching conformations) for the planar and bent conformations of the syn SMI structures. ${ }^{\text {. }}$

Table S11: Histogram of residence times for the SMI adducts switching between the planar and bent conformations for all five replicas. ${ }^{a}$

Table S12: Occupancies (\%) of the hydrogen bonds at the lesion site containing the lesion pair in the B conformation for the FP models. ${ }^{\text {a }}$.

Table S13: Occupancies (\%) of the hydrogen bonds of the flanking bases in the B Conformation for the FP models. ${ }^{a}$

Table S14: Occupancies (\%) of the hydrogen bonds at the lesion site containing the lesion pair in the S conformation for the FP models. ${ }^{\text {. }}$

Table S15: Occupancies (\%) of the hydrogen bonds of the flanking bases when the helix containing a lesion is started from the $\mathrm{S}$ conformation for the FP models. ${ }^{a}$

Table S16: Occupancies (\%) of the hydrogen bonds at the lesion site containing the lesion pair in the W conformation for the FP models. ${ }^{\text {a }}$

Table S17: Occupancies (\%) of the hydrogen bonds of the flanking bases when the helix containing a lesion is started from the $\mathrm{W}$ conformation for the FP models. ${ }^{\mathrm{a}}$

Table S18: Average and standard deviations (in parenthesis) of the interplanar angle (deg) between the aromatic portion of the bulky moiety and the $5^{\prime}$ or $3^{\prime}$ base-pairs for the FP duplexes with the adduct in the syn orientation. ${ }^{\mathrm{a}}$

Table S19. MOL2 file containing partial charges and atom types of the 1 adduct used for MD simulations (atom numbers are provided in the associated figure).

Table S20. MOL2 file containing partial charges and atom types of the $\mathbf{2}$ adduct used for MD simulations (atom numbers are provided in the associated figure). 


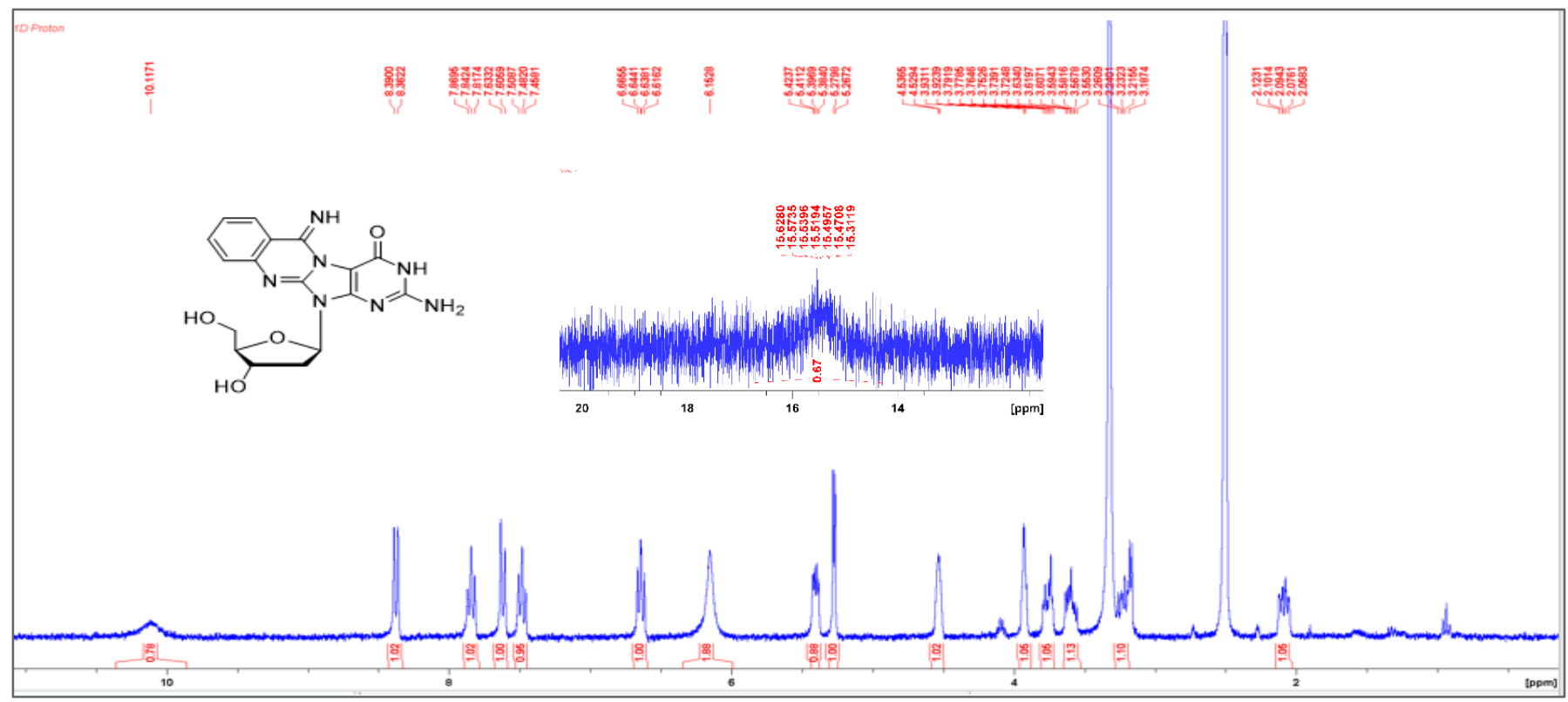

Figure S1. ${ }^{1} \mathrm{H}$ NMR spectrum of compound 1

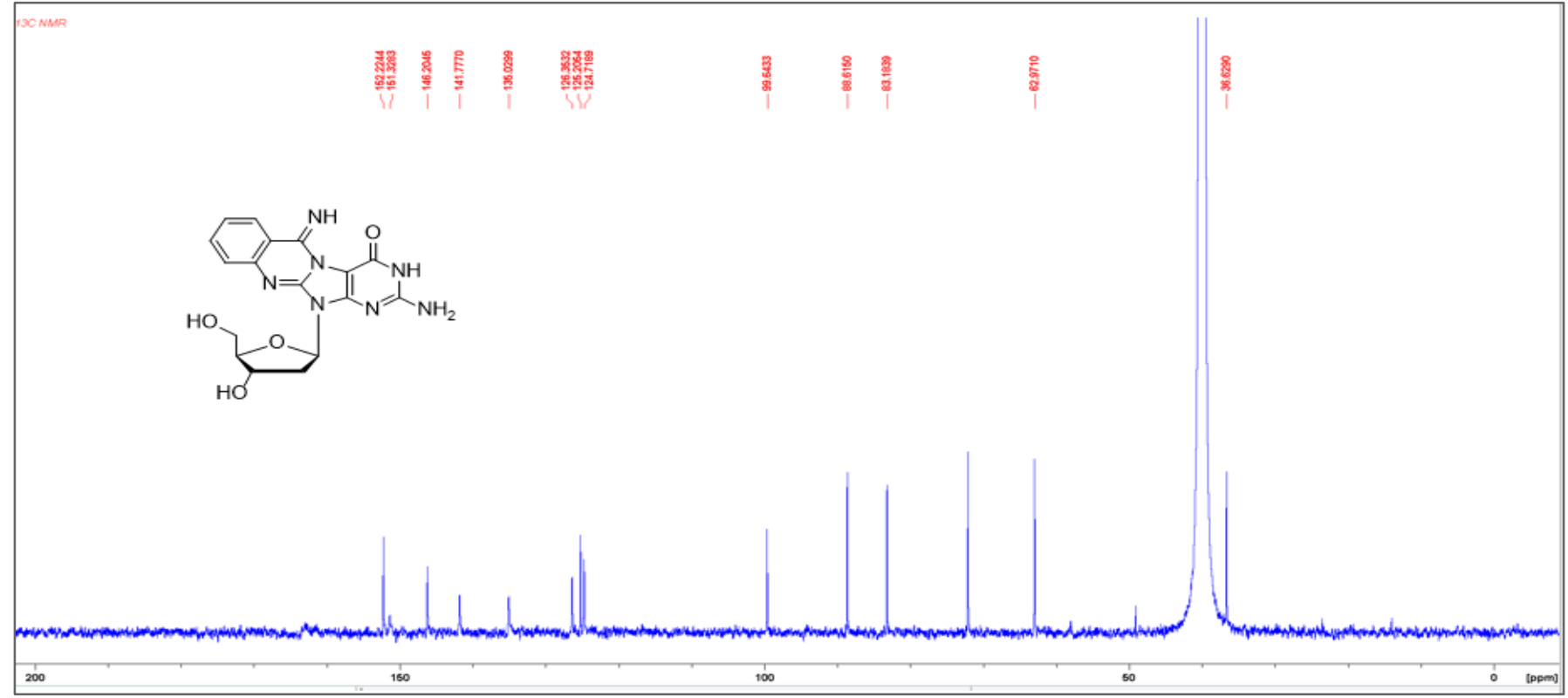

Figure S2. ${ }^{13} \mathrm{C}$ NMR spectrum of compound 1 


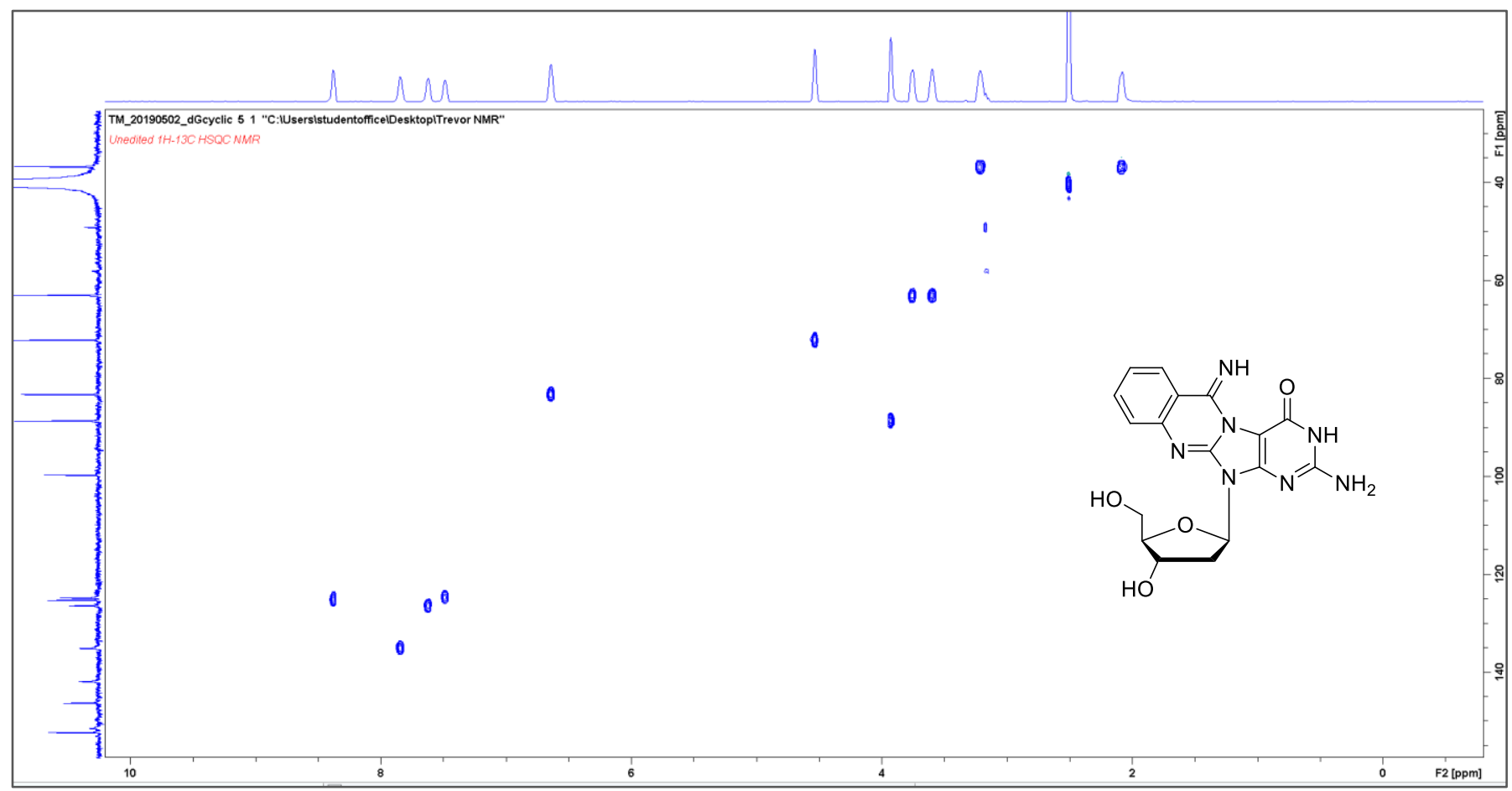

Figure S3. ${ }^{13} \mathrm{C}-{ }^{1} \mathrm{H}$ HSQC NMR spectrum of compound 1

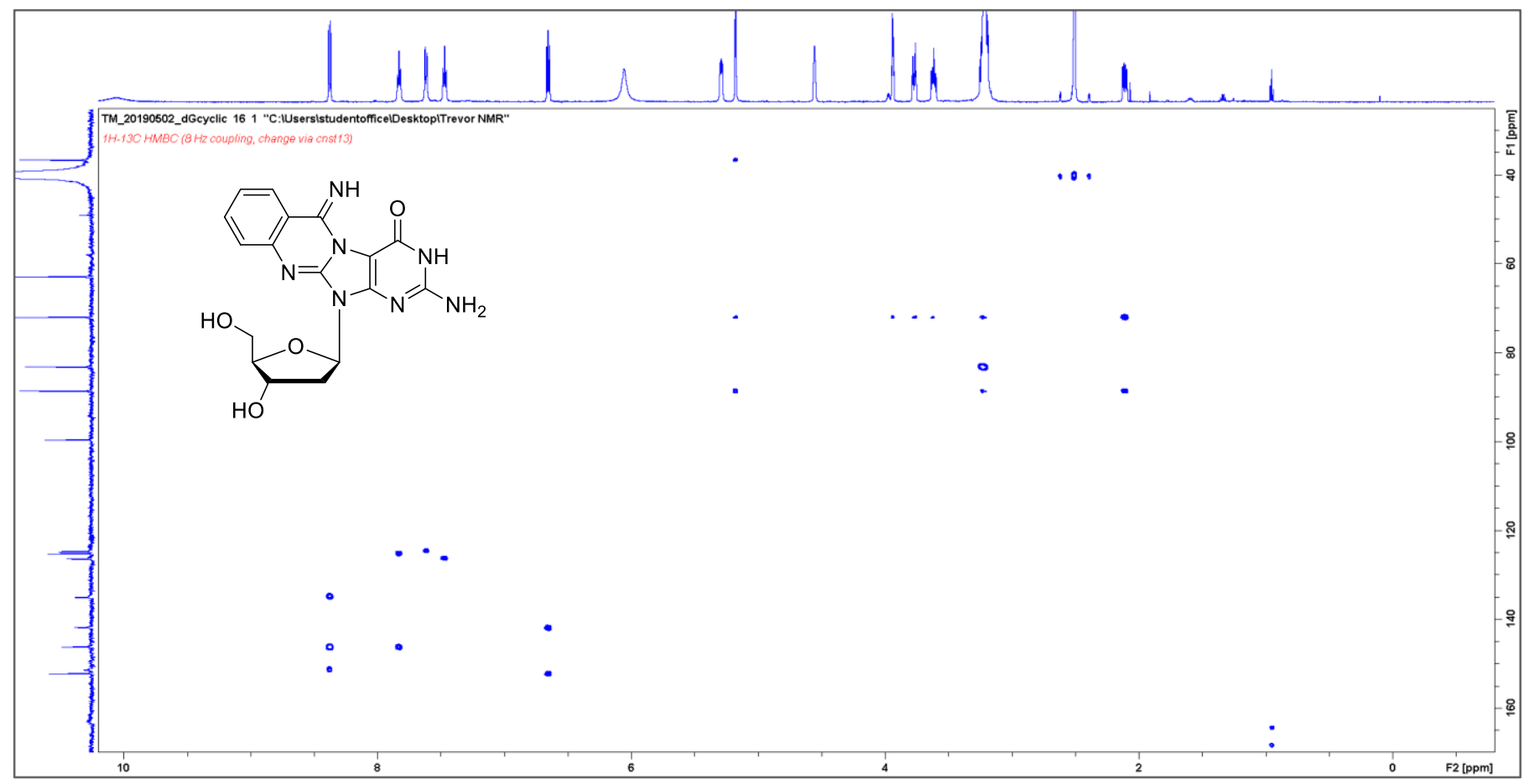

Figure S4. ${ }^{13} \mathrm{C}-{ }^{1} \mathrm{H}$ HMBC NMR spectrum of compound 1 


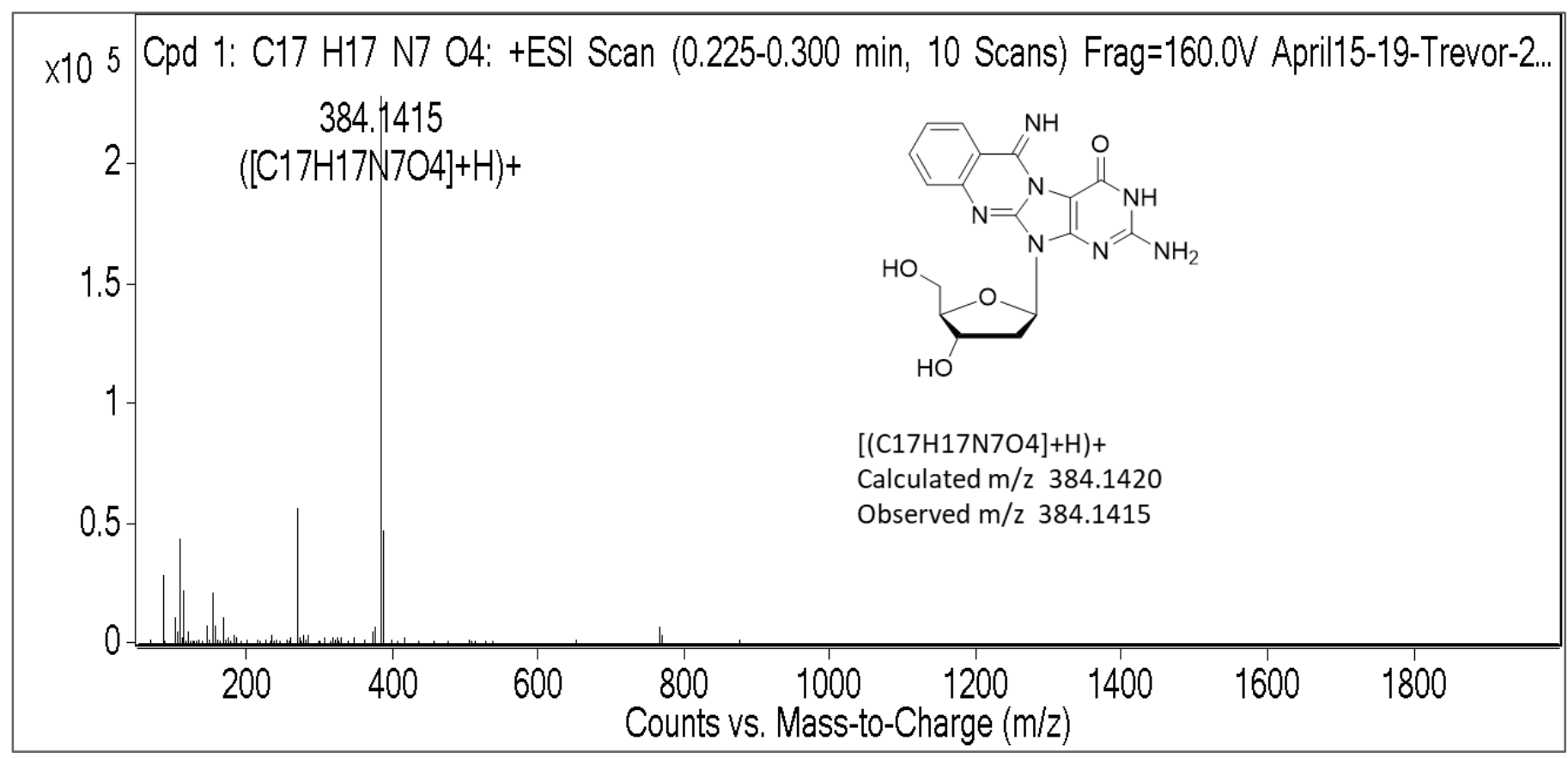

Figure S5. HRMS spectrum of compound 1

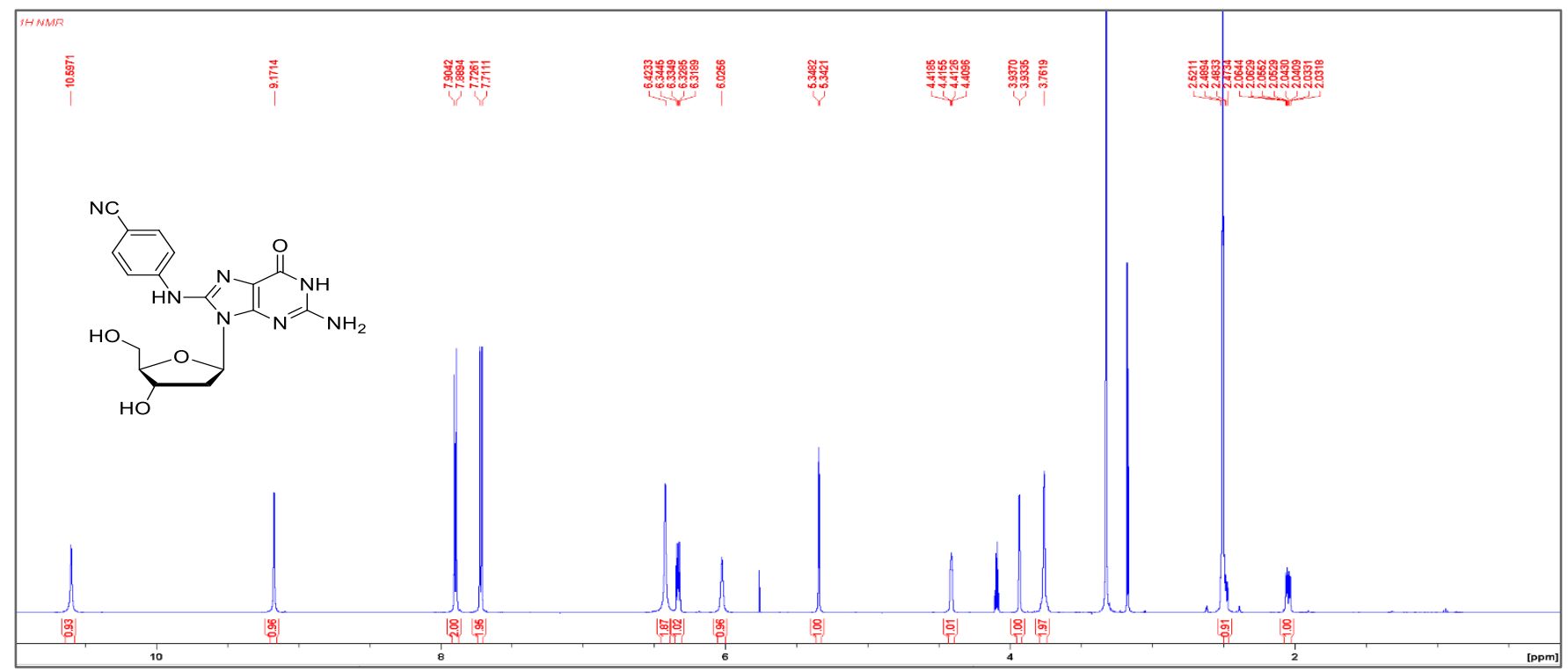

Figure S6. ${ }^{1} \mathrm{H}$ NMR spectrum of compound 2 


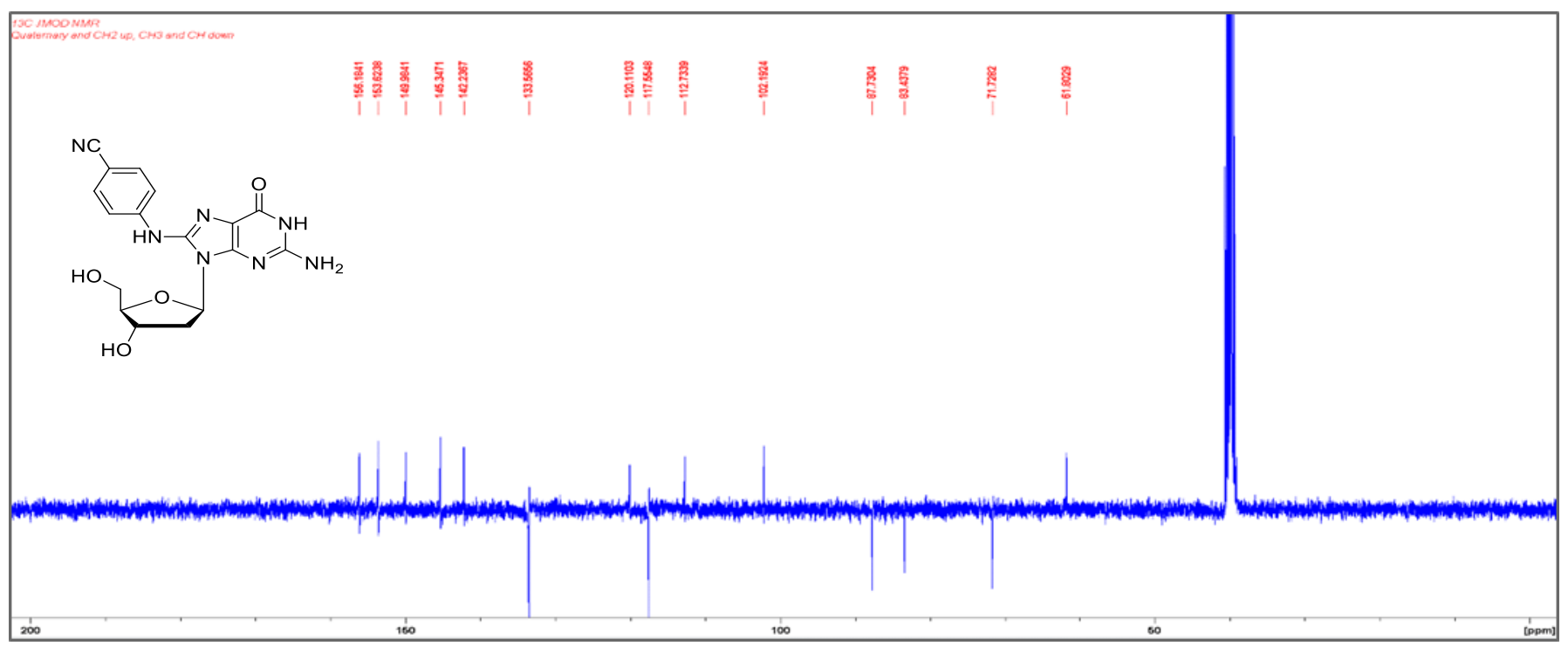

Figure S7. 13C J-mod spectrum of compound 2

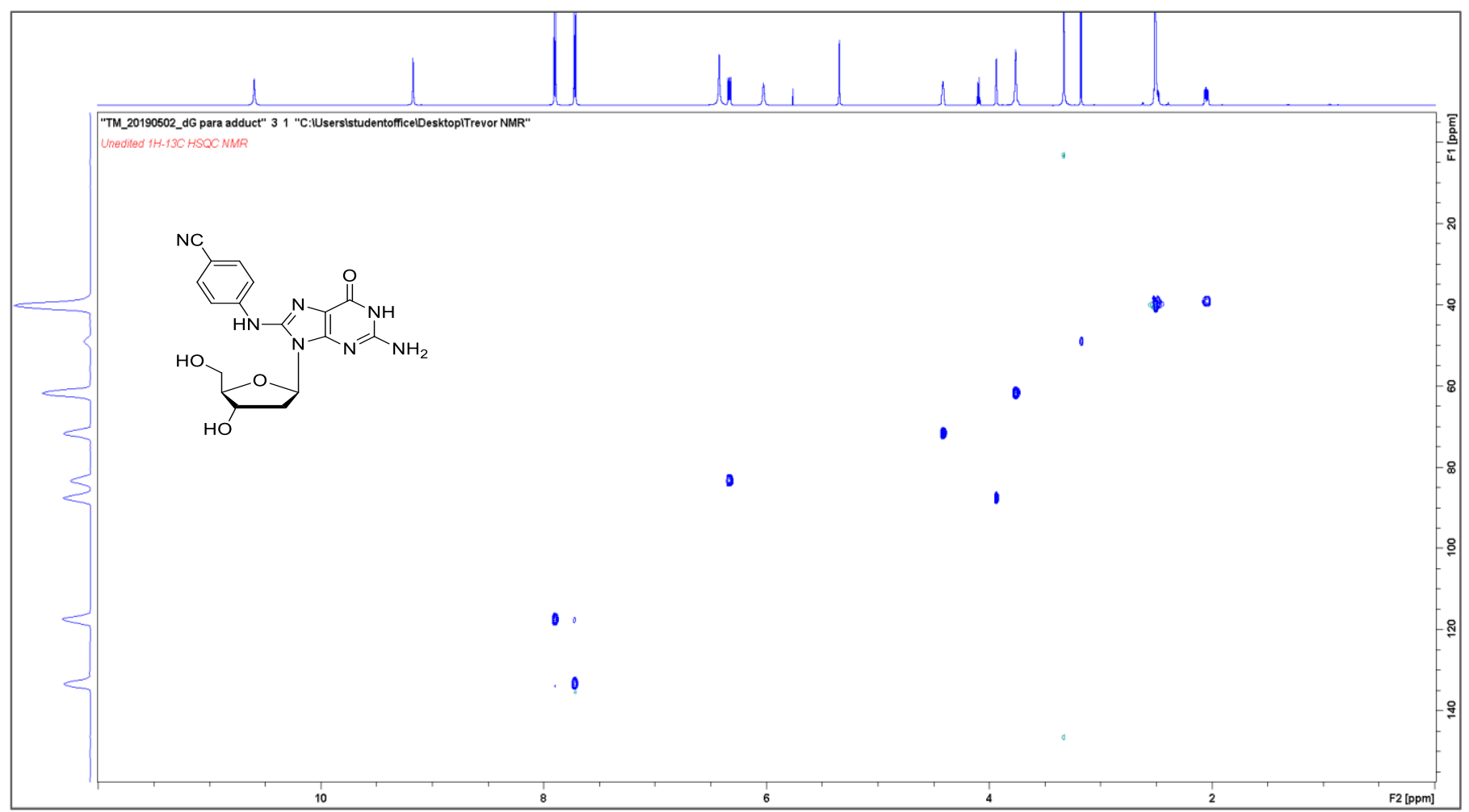

Figure S8. ${ }^{13} \mathrm{C}-{ }^{1} \mathrm{H}$ HSQC NMR spectrum of compound 2 


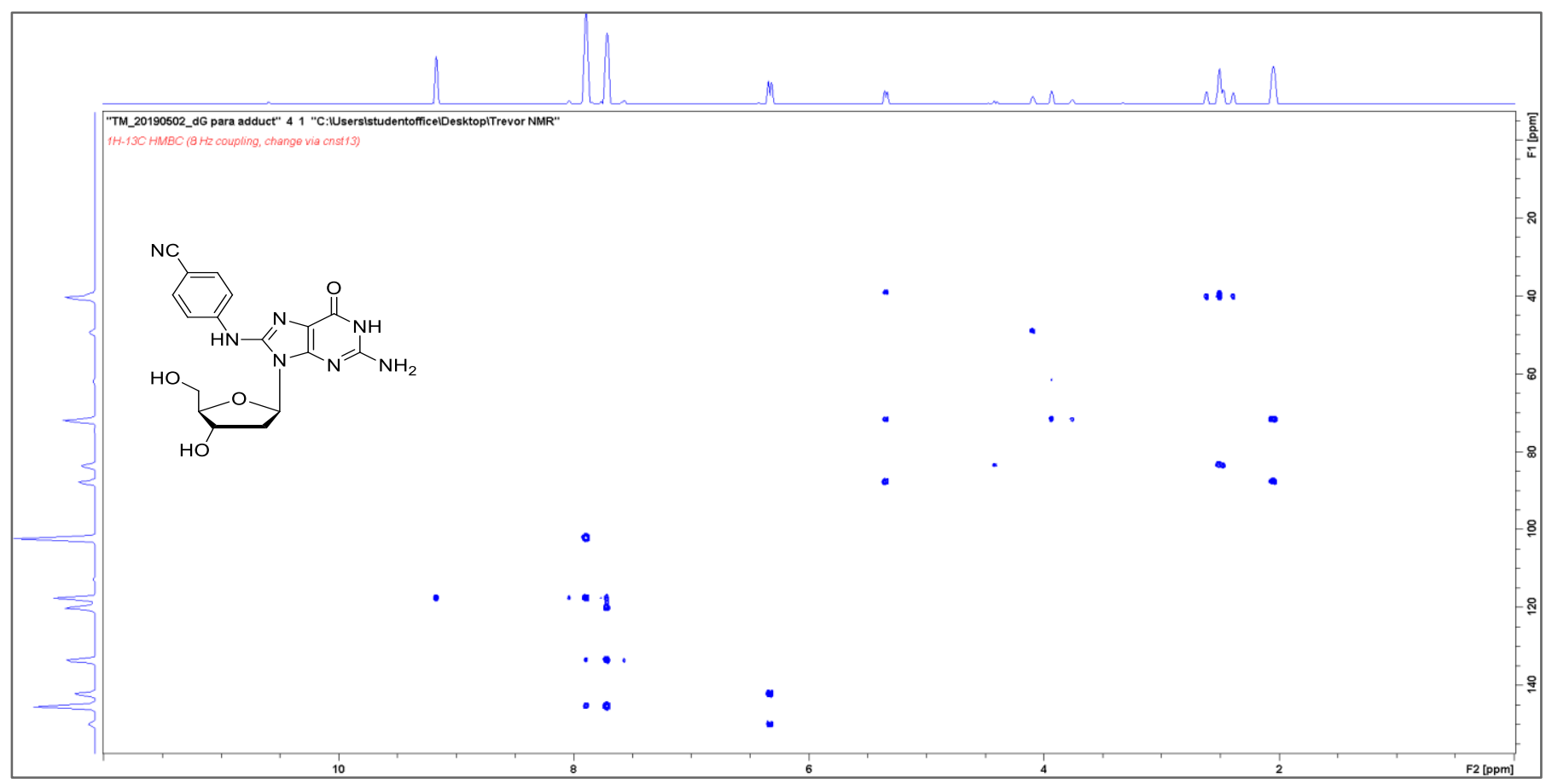

Figure S9. ${ }^{13} \mathrm{C}-{ }^{1} \mathrm{H}$ HMBC NMR spectrum of compound 2

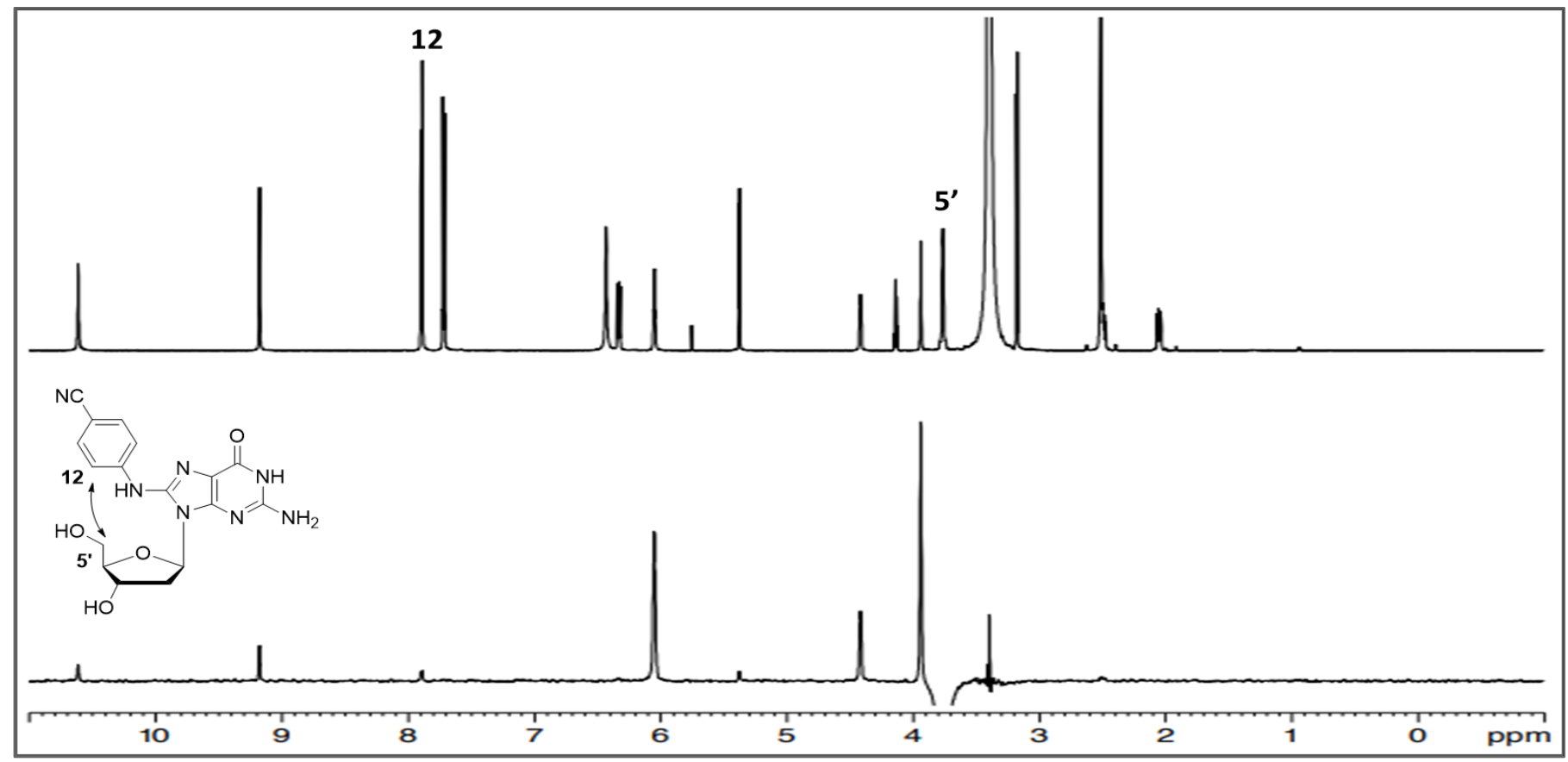

Figure S10. ROESY spectrum of compound 2 


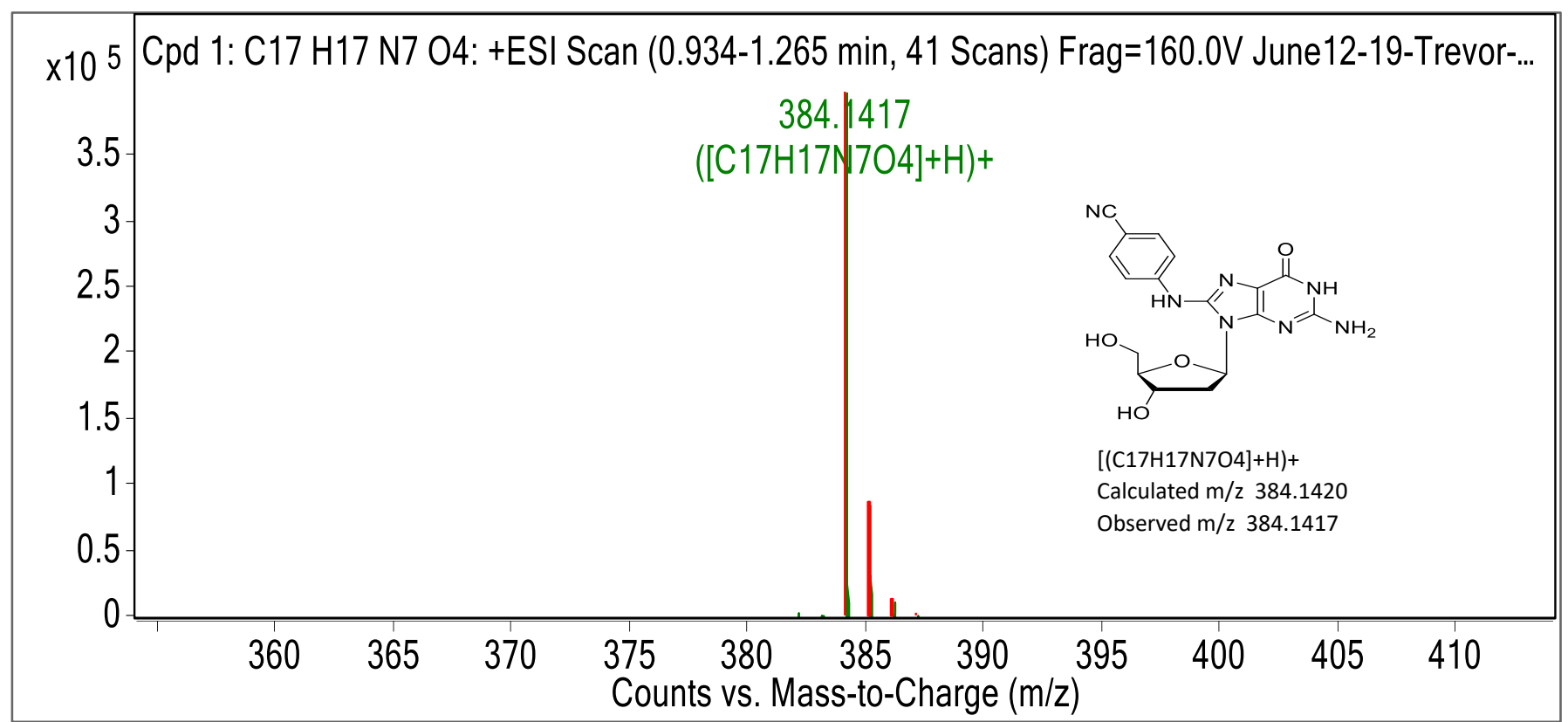

Figure S11. HRMS spectrum of compound 2

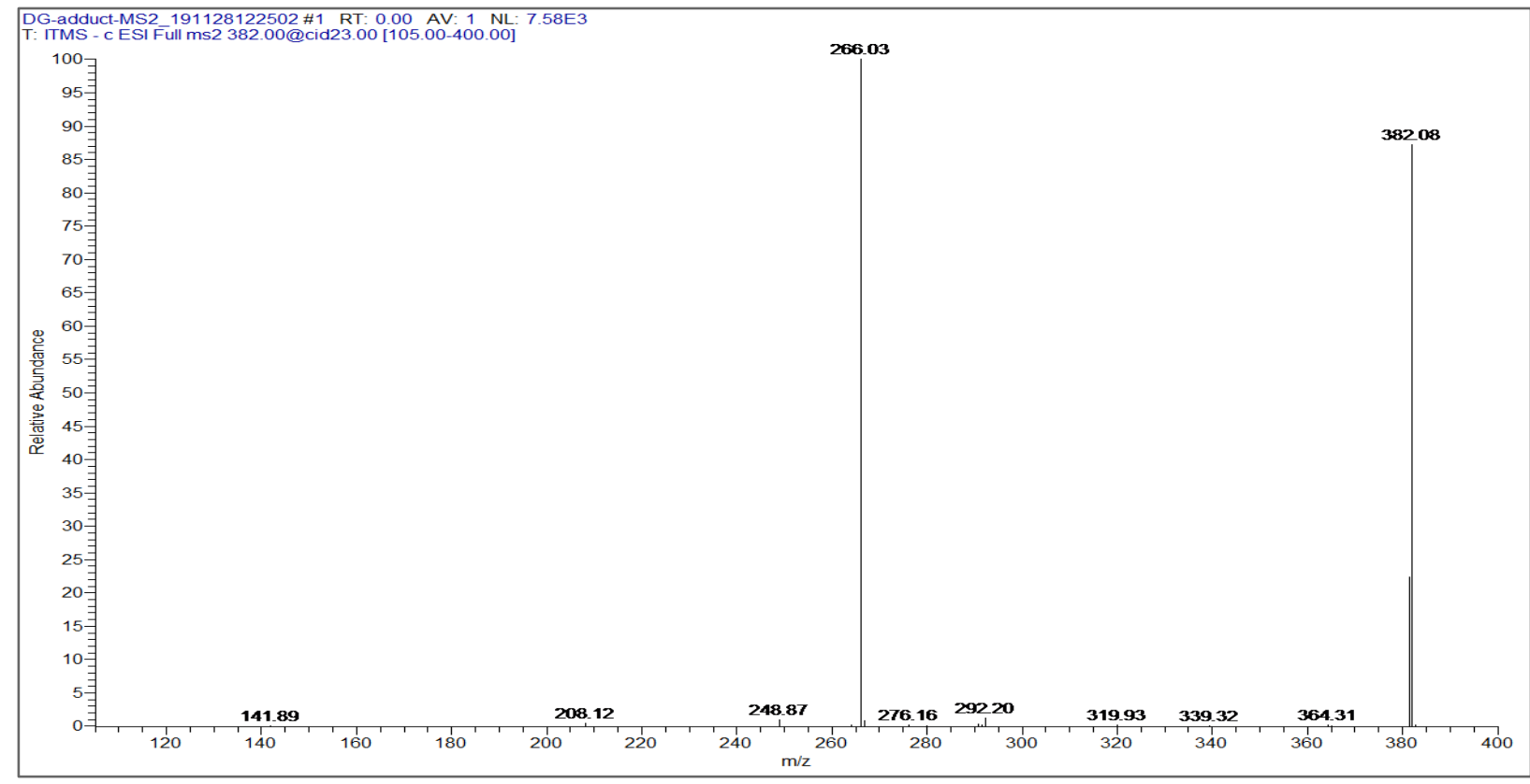

Figure S12. Mass spectrum of compound 2 in DMSO stock solution 


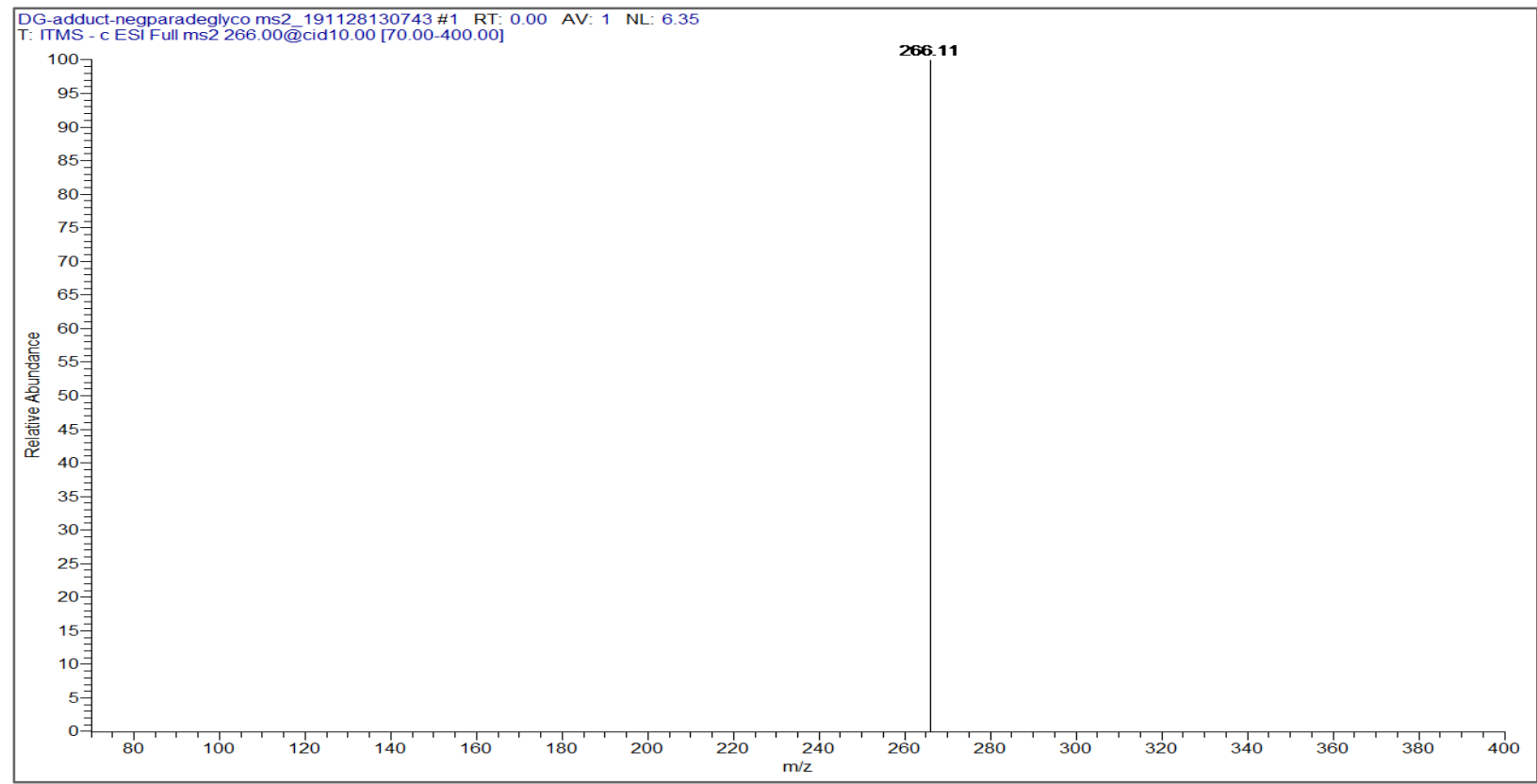

Figure S13. Mass spectrum of compound 2 following exposure to $0.1 \mathrm{M} \mathrm{HCl}$ at $37.2^{\circ} \mathrm{C}$

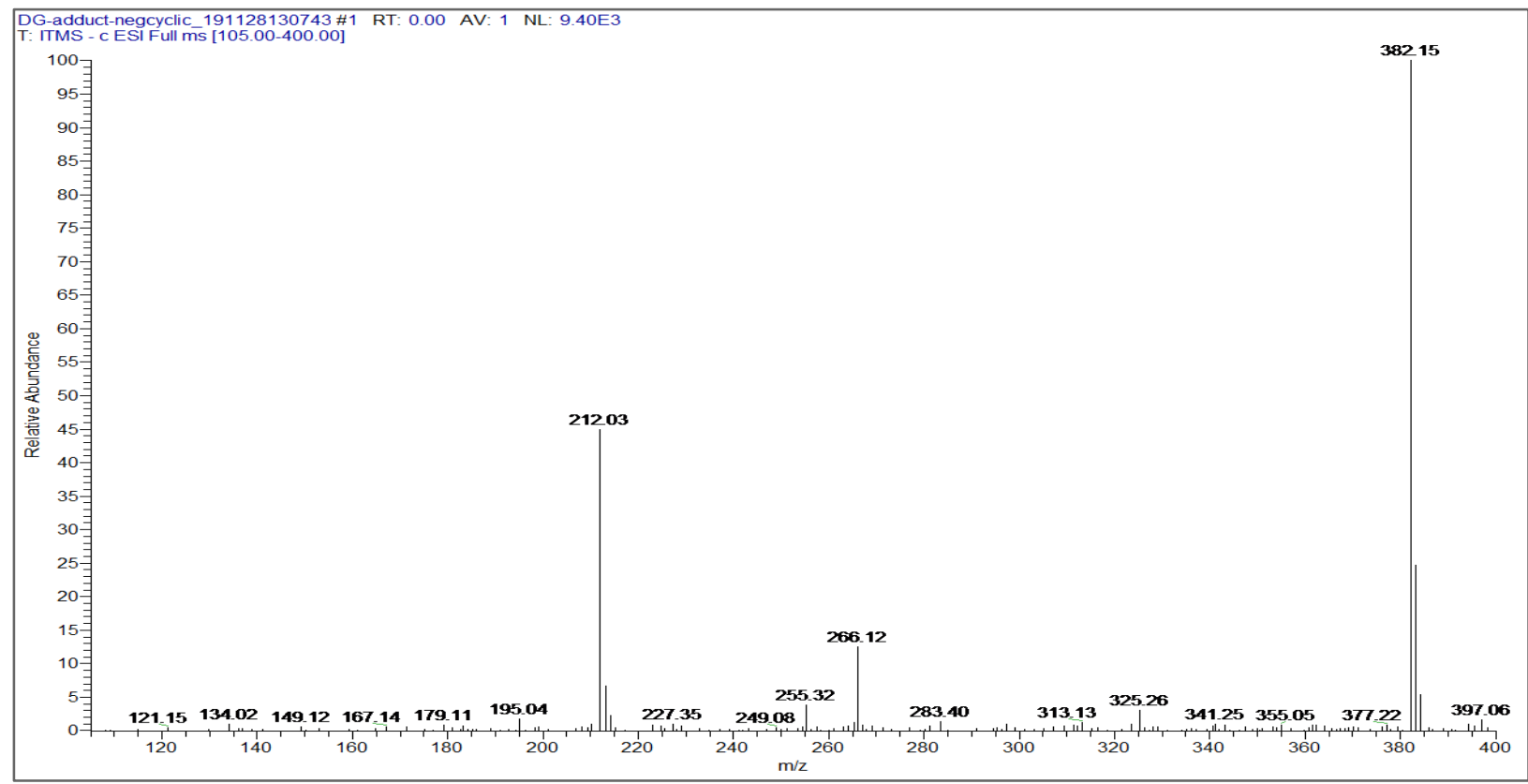

Figure S14. Mass spectrum of compound 1 in DMSO stock solution 


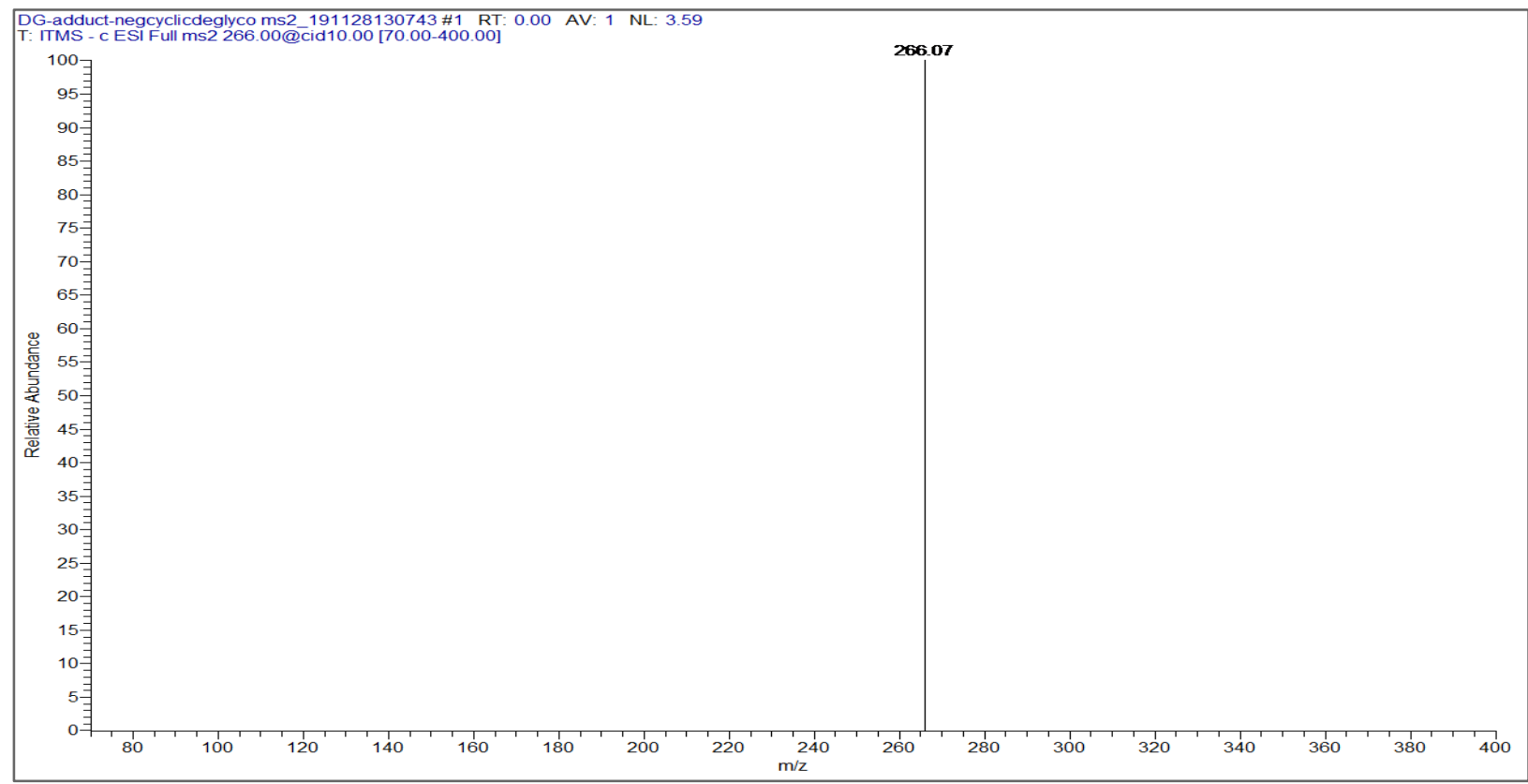

Figure S15. Mass spectrum of compound 1 following exposure to $0.1 \mathrm{M} \mathrm{HCl}$ at $37.2^{\circ} \mathrm{C}$

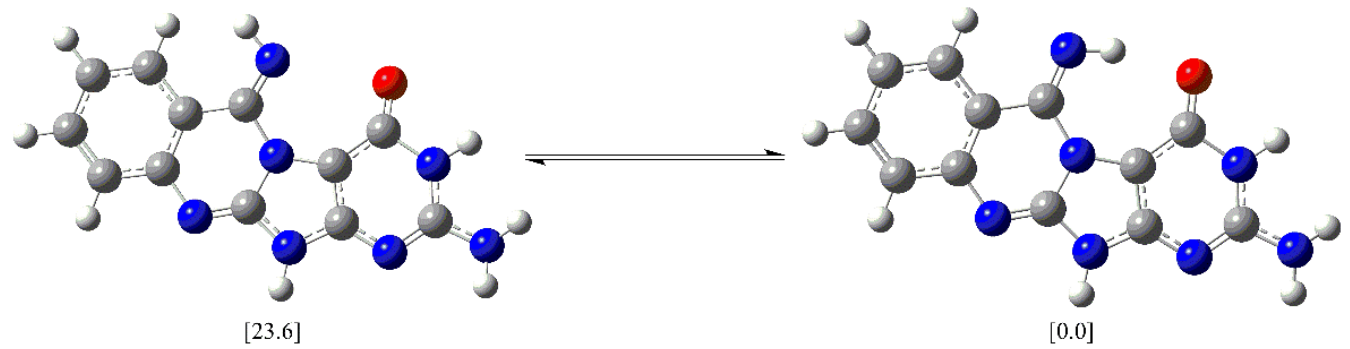

Figure S16: Structures and relative stabilities of the 1 nucleobase minima as calculated at the B3LYP-D3(BJ)/6-31G(d,p) level of theory. Zero-point vibrational energy corrected B3LYP$\mathrm{D} 3(\mathrm{BJ}) / 6-311++\mathrm{G}(2 \mathrm{df}, 2 \mathrm{p})$ relative energies are provided in parentheses $(\mathrm{kJ} / \mathrm{mol})$. 


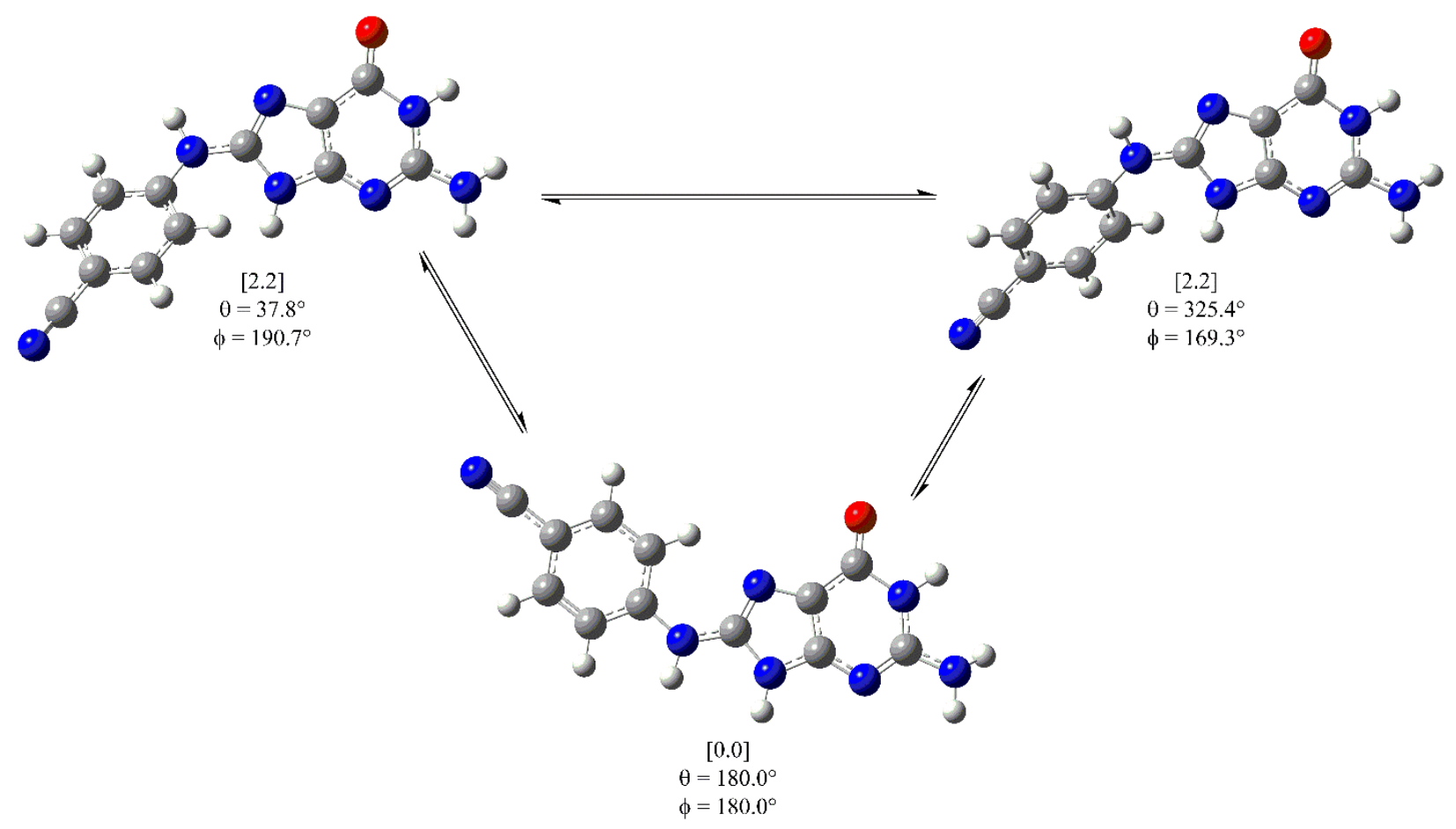

Figure S17: Select dihedrals ( $\theta$ and $\varphi$, deg) for the 2 nucleobase minima as calculated at the B3LYP-D3(BJ)/6-31G(d,p) level of theory. Zero-point vibrational energy corrected B3LYP$\mathrm{D} 3(\mathrm{BJ}) / 6-311++\mathrm{G}(2 \mathrm{df}, 2 \mathrm{p})$ relative energies are provided in parentheses $(\mathrm{kJ} / \mathrm{mol})$. 


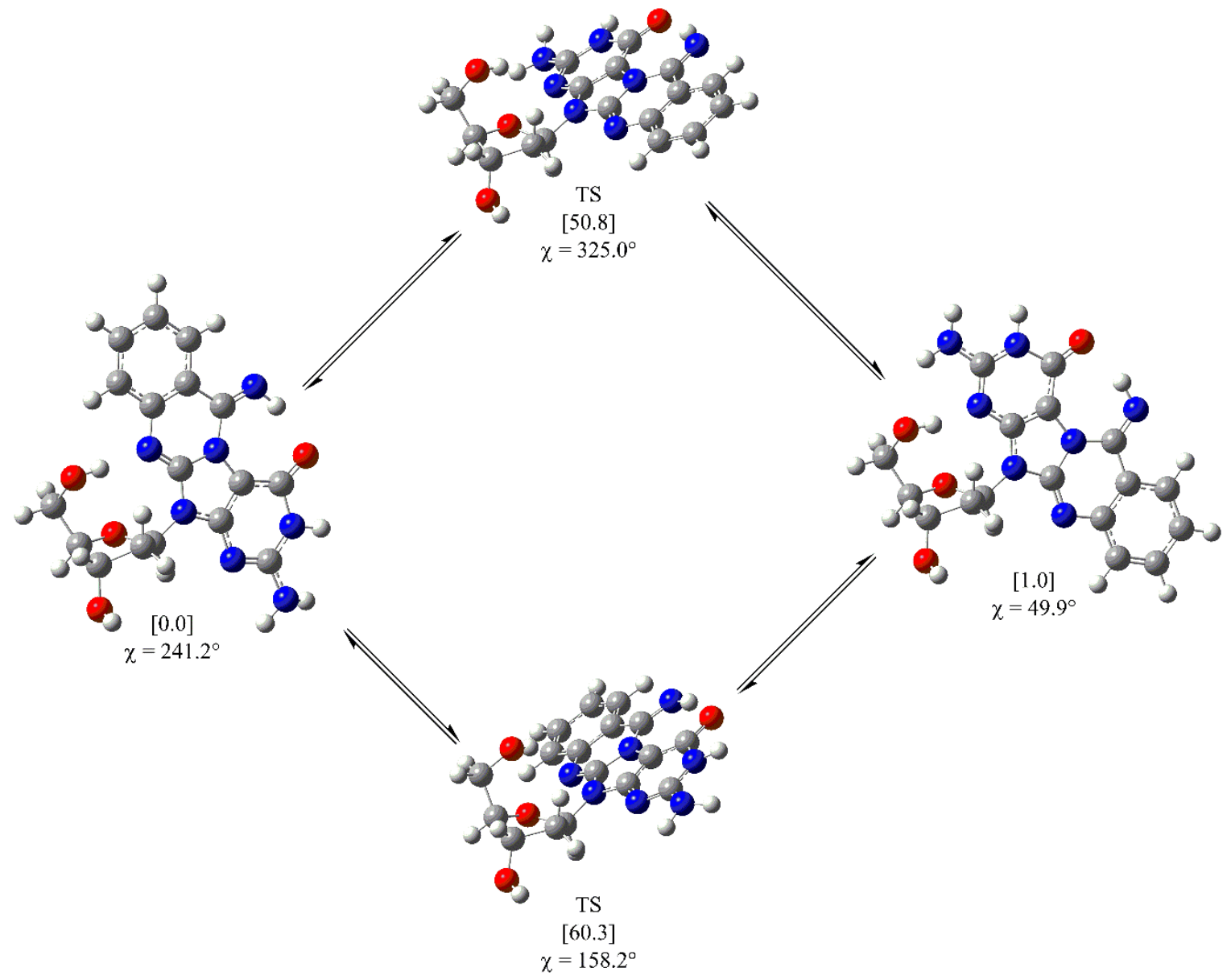

Figure S18: Select dihedral angles $(\mathrm{X}, \mathrm{deg})$ for the 1 nucleoside minima and transition states (TS) as calculated at the B3LYP-D3(BJ)/6-31G(d,p) level of theory. Zero-point vibrational energy corrected B3LYP-D3(BJ)/6-311++G(2df,2p) relative energies are provided in parentheses $(\mathrm{kJ} / \mathrm{mol})$. 


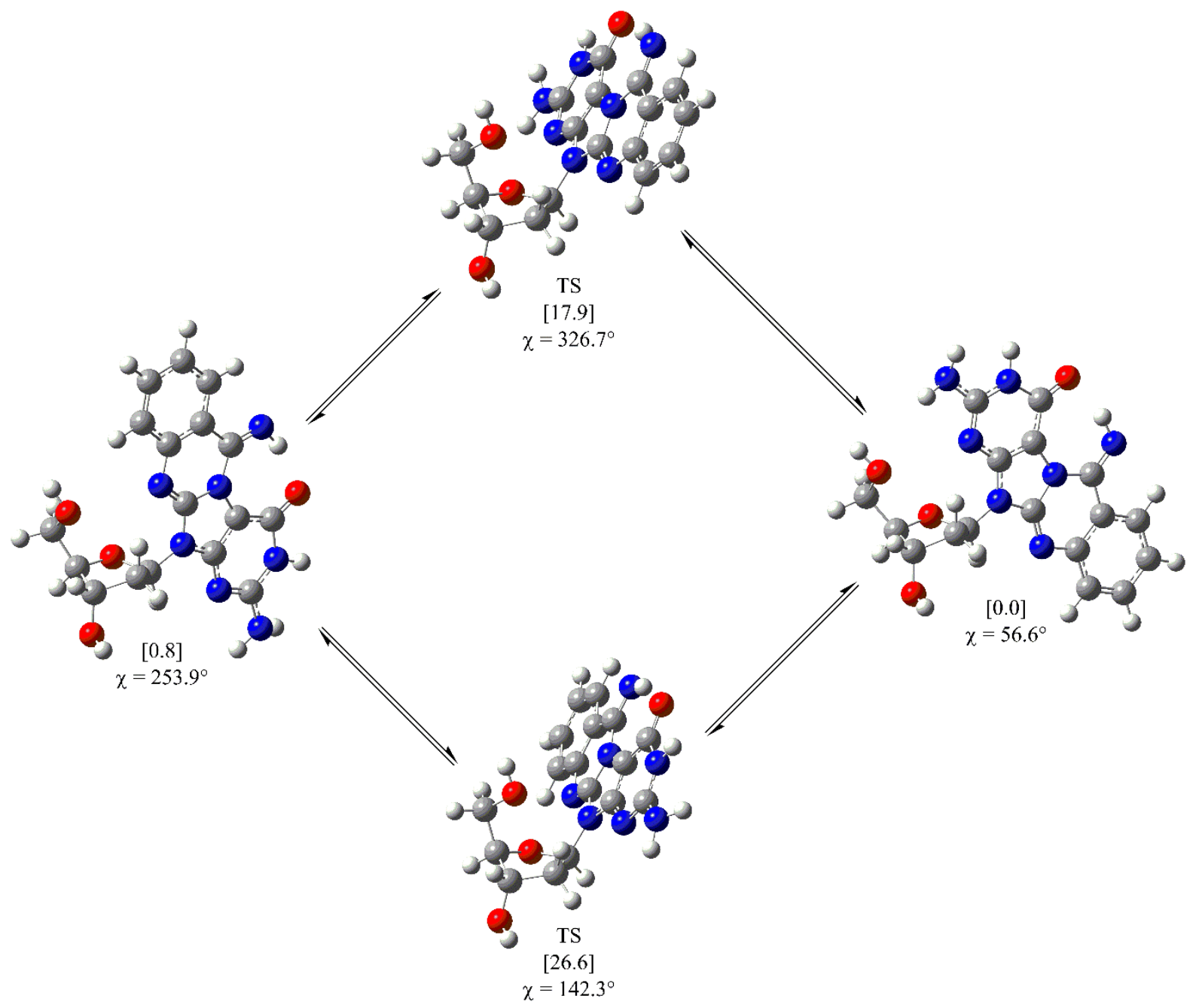

Figure S19: Select dihedral angles $(\mathrm{X}$, deg) for the 1 nucleoside minima and transition states (TS) as calculated at the B3LYP-D3(BJ)/6-31G(d,p) level of theory with the 5'-hydroxyl group fixed away from the adduct. Zero-point vibrational energy corrected B3LYP-D3(BJ)/6$311++\mathrm{G}(2 \mathrm{df}, 2 \mathrm{p})$ relative energies are provided in parentheses $(\mathrm{kJ} / \mathrm{mol})$. 


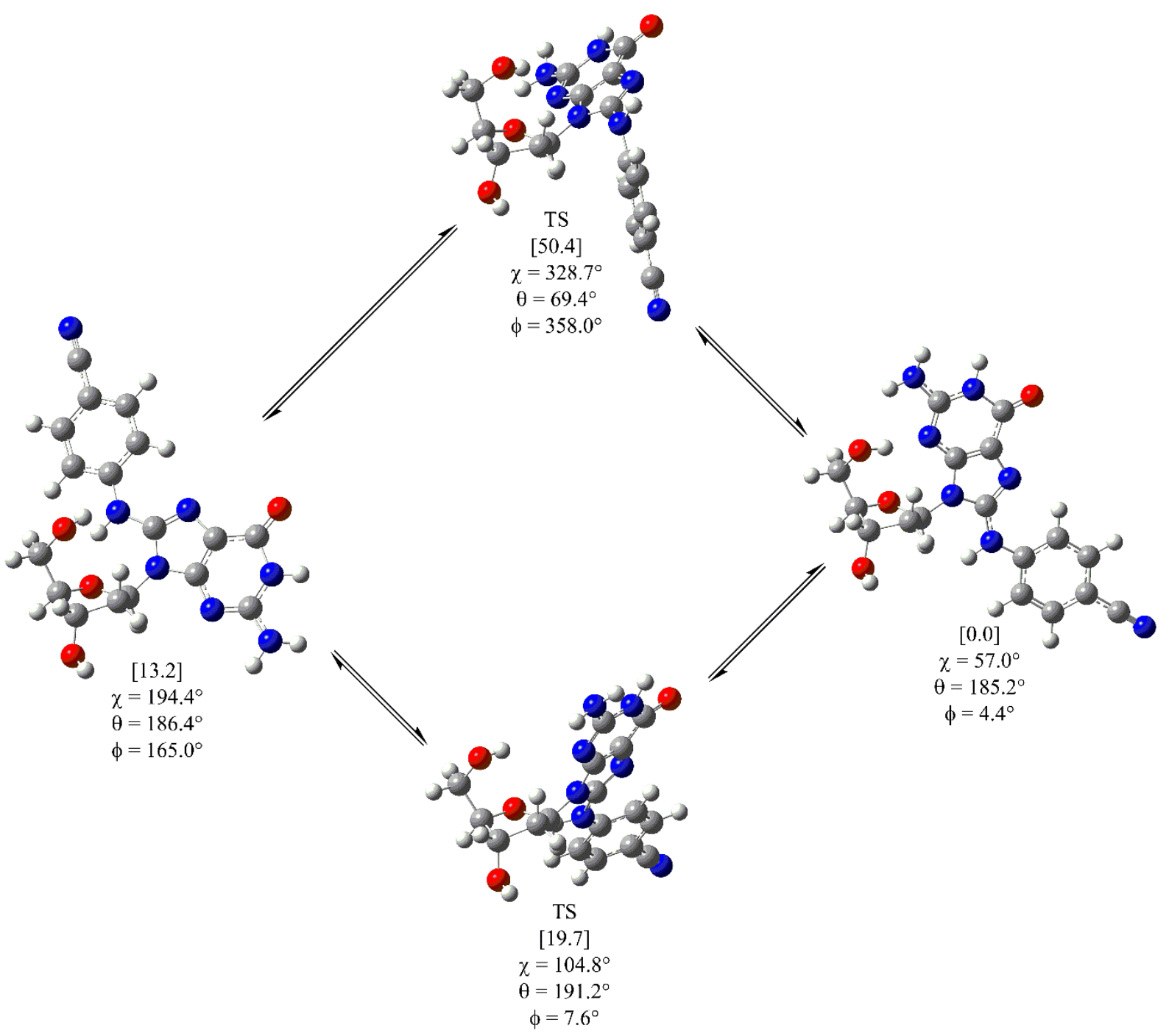

Figure S20: Select dihedral angles $(X, \theta$ and $\varphi$, deg) for the 2 nucleoside minima and transition states (TS) as calculated at the B3LYP-D3(BJ)/6-31G(d,p) level of theory. Zero-point vibrational energy corrected B3LYP-D3(BJ)/6-311++G(2df,2p) relative energies are provided in parentheses $(\mathrm{kJ} / \mathrm{mol})$. 


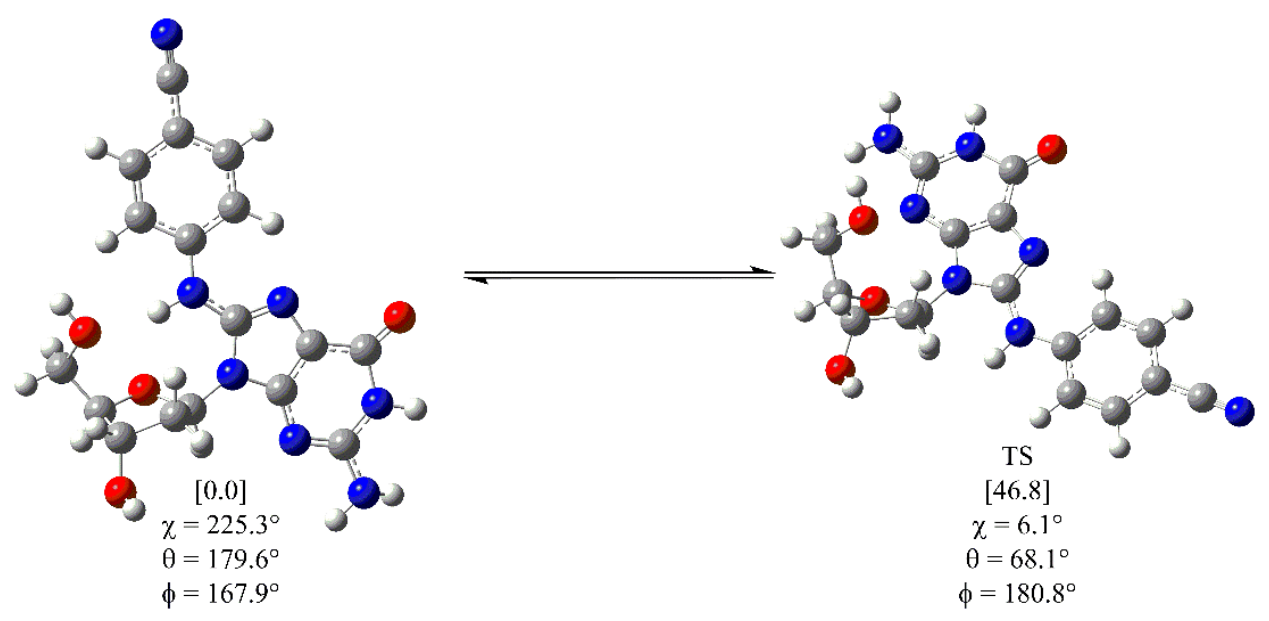

Figure S21: Select dihedral angles $(X, \theta$ and $\varphi$, deg) for the 2 nucleoside minima and transition states (TS) as calculated at the B3LYP-D3(BJ)/6-31G(d,p) level of theory with the 5'-hydroxyl group fixed away from the adduct. Zero-point vibrational energy corrected B3LYP-D3(BJ)/6$311++G(2 d f, 2 p)$ relative energies are provided in parentheses $(\mathrm{kJ} / \mathrm{mol})$. 


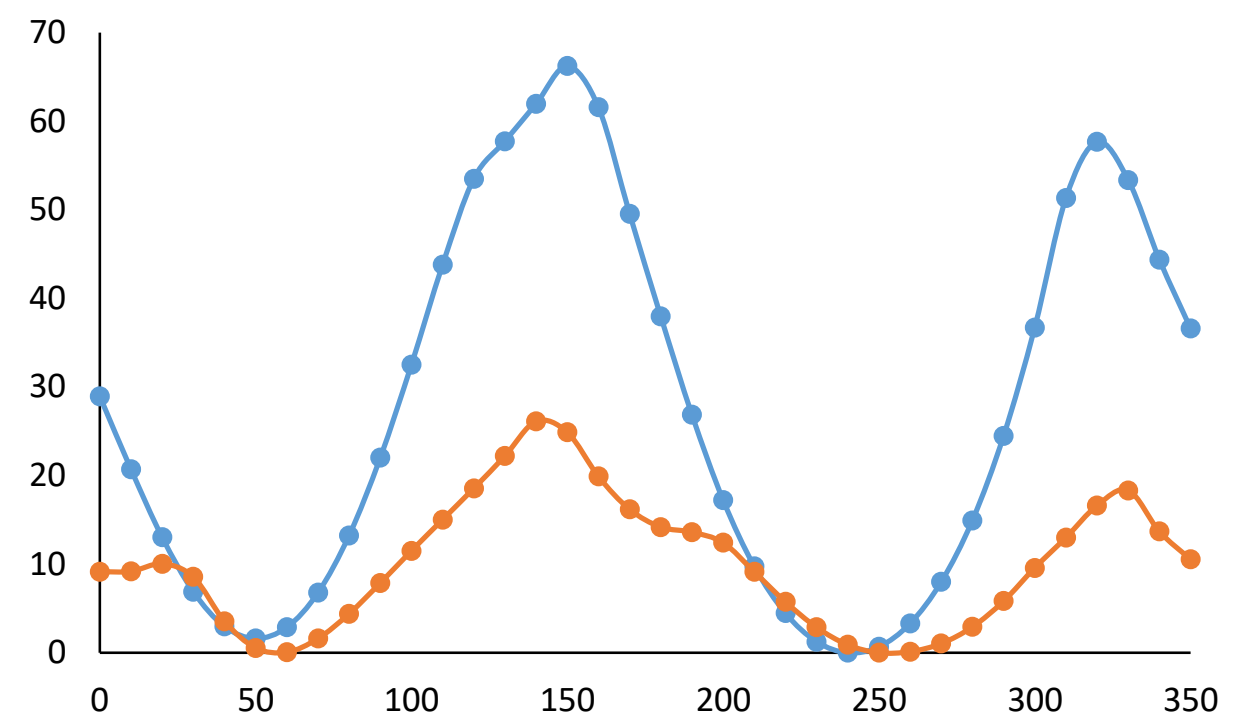

Figure S22: Potential energy surface for the rotation about the $x$ dihedral angle (deg) in the 1 nucleoside with the 5'-hydroxyl group constrained (orange) or unconstrained (blue). Calculated every $10^{\circ}$ at the B3LYP-D3(BJ)/6-31G(d,p) level of theory and report in $\mathrm{kJ} / \mathrm{mol}$.

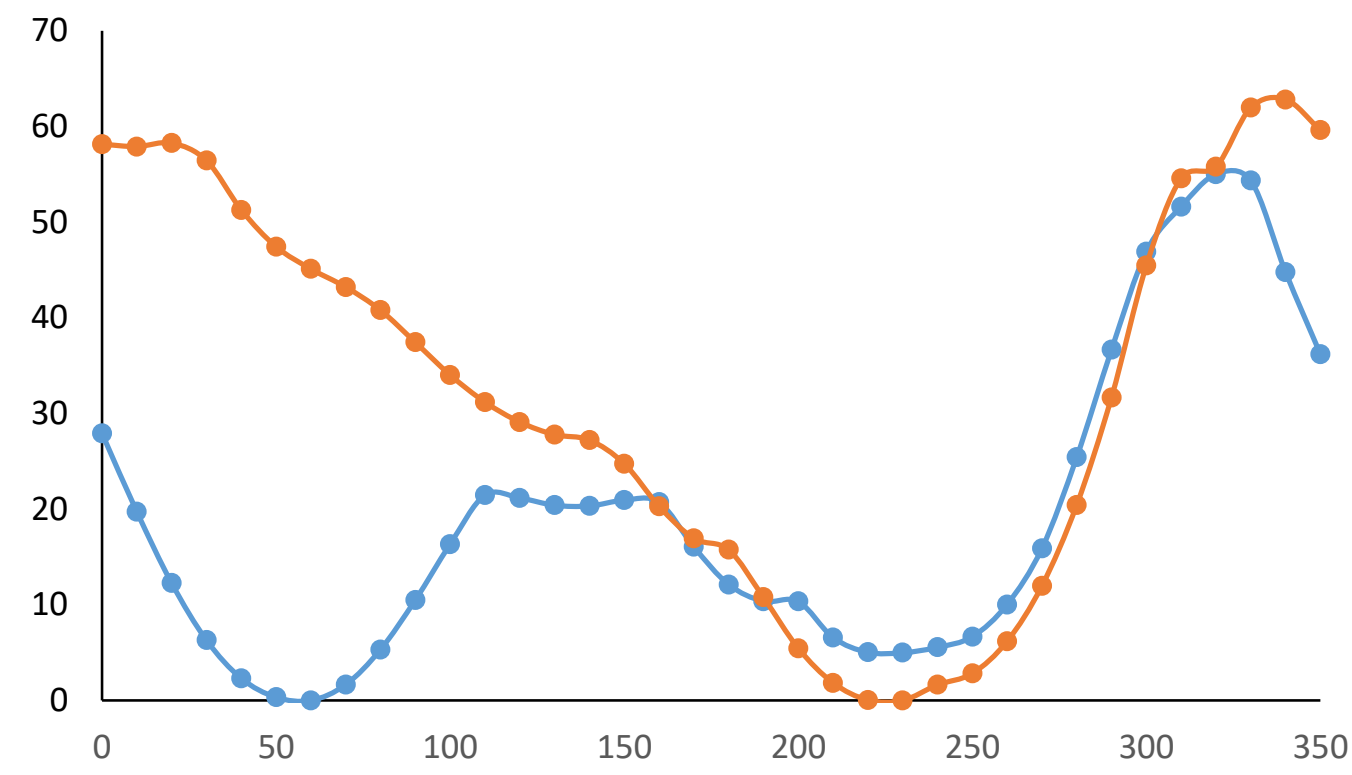

Figure S23: Potential energy surface for the rotation about the $x$ dihedral angle (deg) in the 2 nucleoside with the 5'-hydroxyl group constrained (orange) or unconstrained (blue). Calculated every $10^{\circ}$ at the B3LYP-D3(BJ)/6-31G(d,p) level of theory and report in $\mathrm{kJ} / \mathrm{mol}$. 


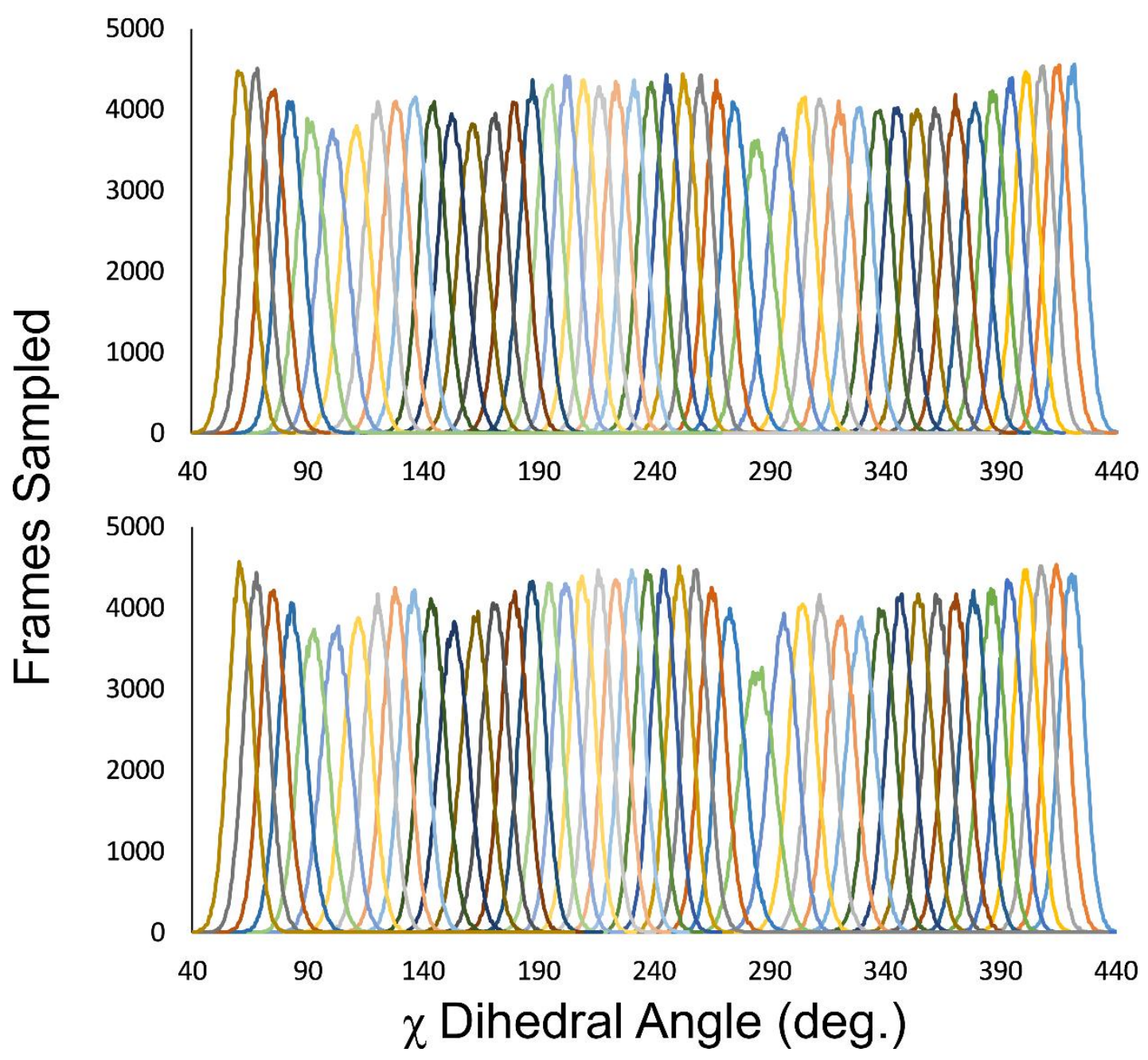

Figure S24: Histograms of the $x$ dihedral angle sampled during umbrella sampling for the 1 (top) and 2 (bottom) free nucleosides with a $30 \mathrm{kcal} /\left(\mathrm{mol} \mathrm{rad}^{2}\right)$ restraint. 

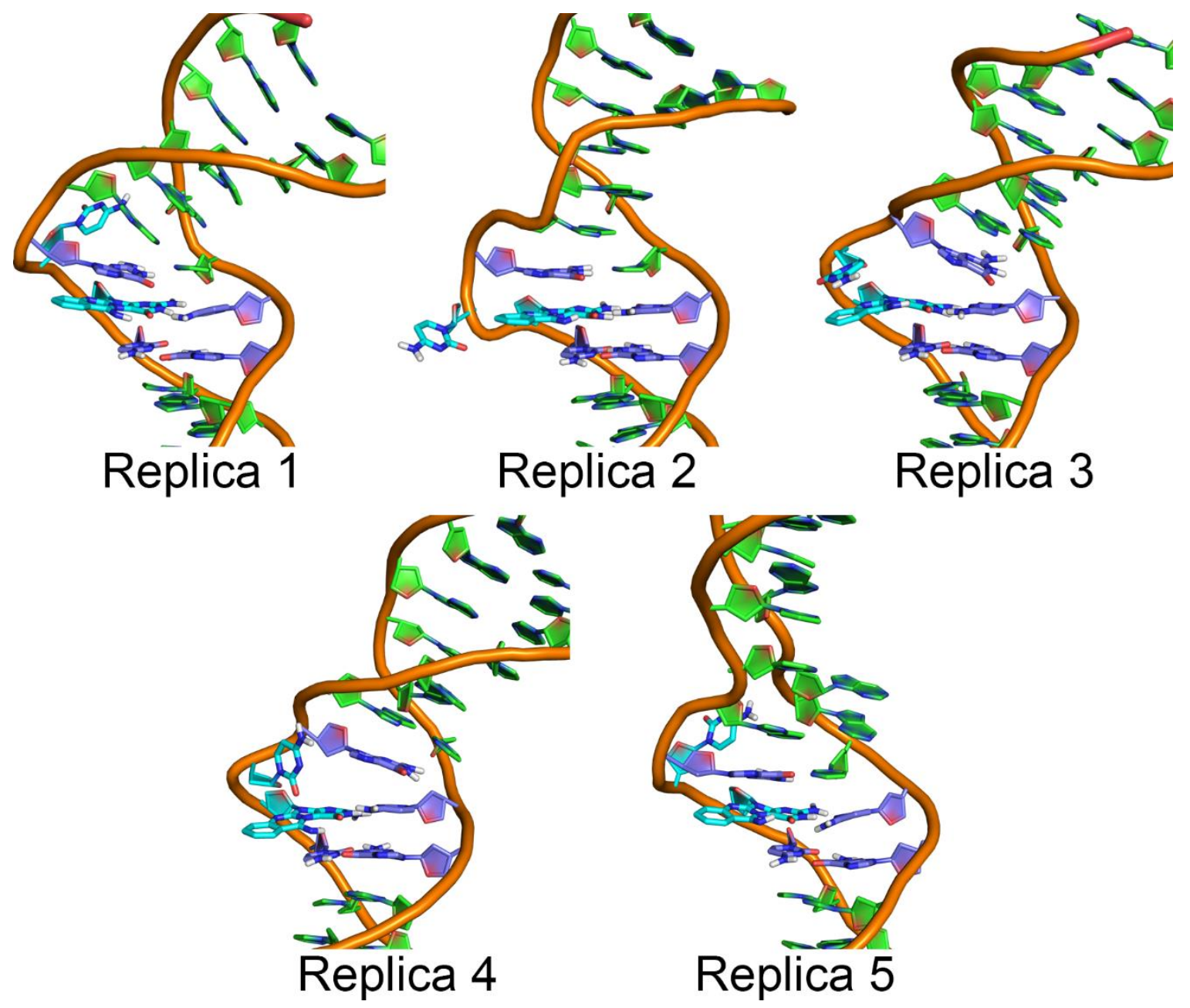

Figure S25: Representative structures obtained from MD simulations for the five $1 \mu$ seplicas of the distorted 1 adducted SMI duplex in the anti orientation. The adducted base and unpaired $\mathrm{C}$ are shown in cyan, and the flanking bases are shown in purple. 

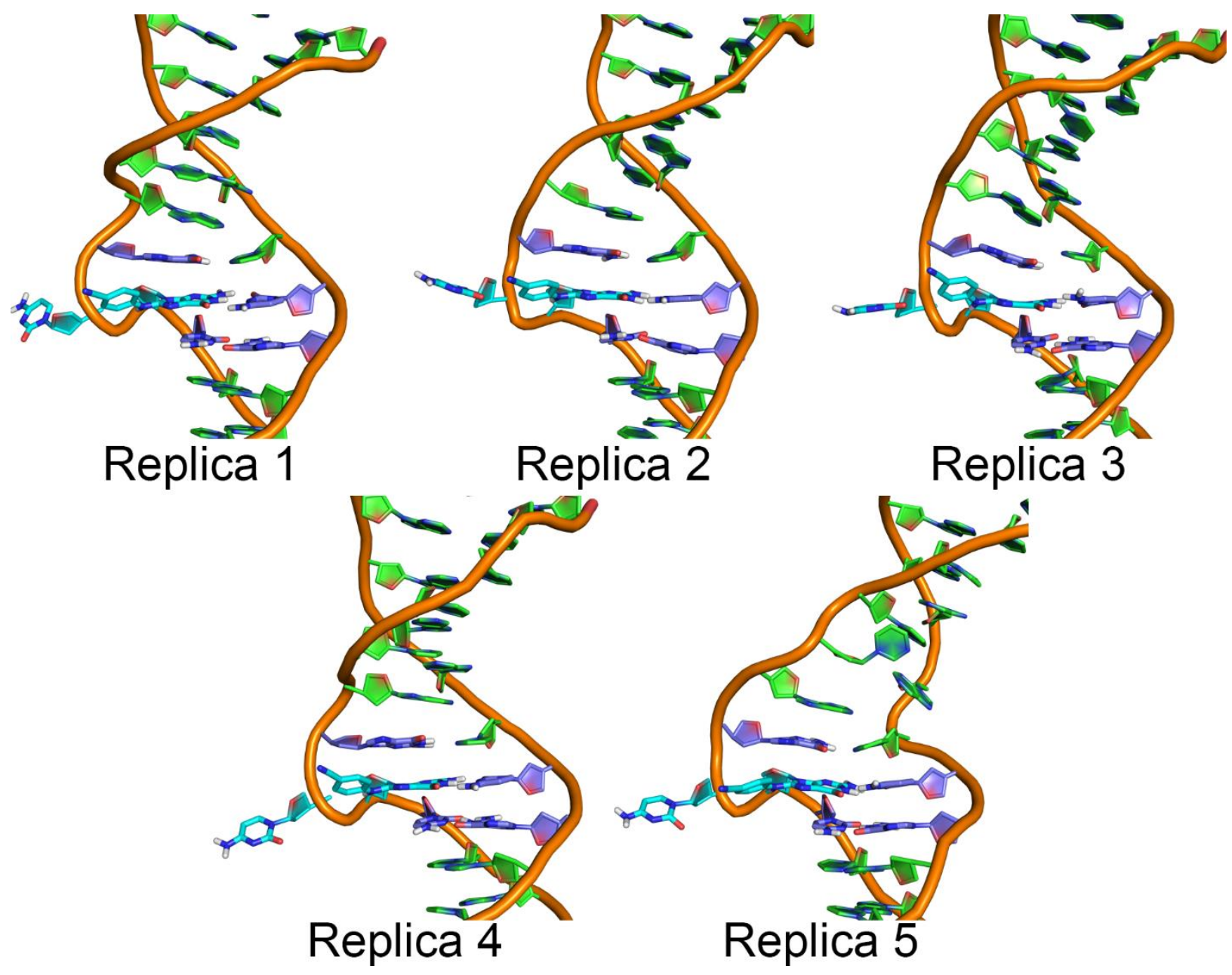

Figure S26: Representative structures obtained from MD simulations for the five $1 \mu$ s replicas of the distorted 2 adducted SMI duplex in the anti orientation. The adducted base and unpaired $\mathrm{C}$ are shown in cyan, and the flanking bases are shown in purple. 


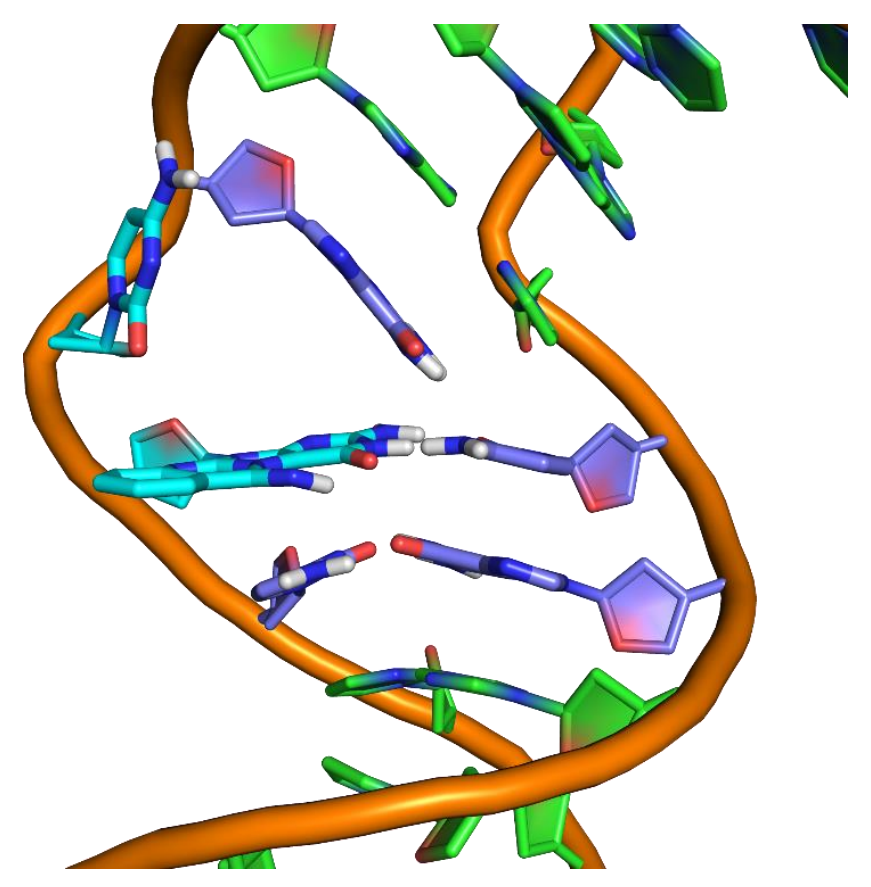

Figure S27: Example structure of a SMI helix with the adducted G3 and G2 bases hydrogen bonding to a single $\mathrm{C}$. The adducted base and unpaired $\mathrm{C}$ are shown in cyan, and the flanking bases are shown in purple.
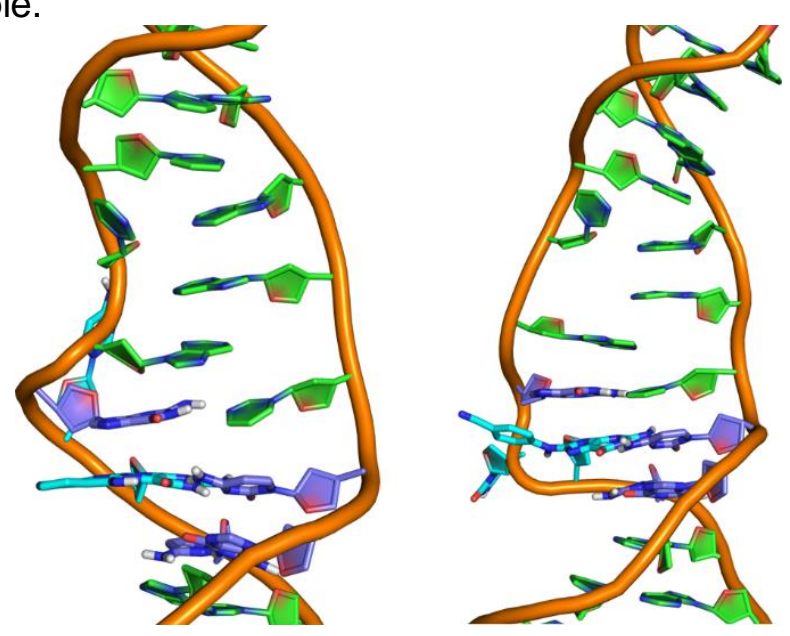

Figure S28: Example structures of the distorted SMI helices highlighting observed helical distortions $5^{\prime}$ to the lesion site with the $\mathbf{1}$ (left) and $\mathbf{2}$ (right) adducts in the antiorientation. The adducted base and unpaired $\mathrm{C}$ are shown in cyan, and the flanking bases are shown in purple. 

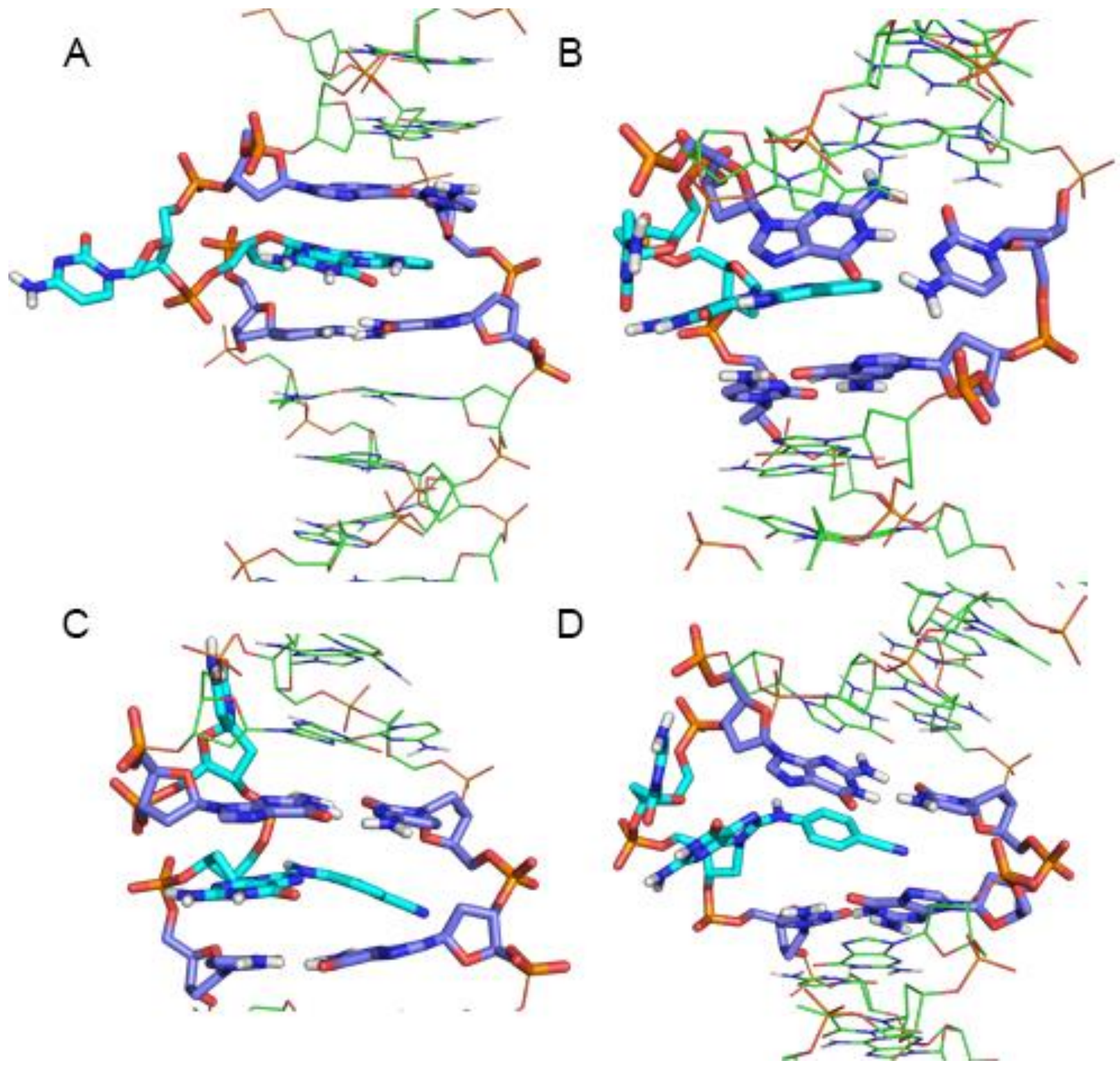

Figure S29: SMI complex representative structures, highlighting the ability of both lesions to adopt planar and bent structures, for the (A) planar 1 adduct, (B) distorted bent 1 adduct, (C) planar 2 adduct and (D) distorted bent 2 adduct in the syn orientation. The unpaired nucleotides and flanking base-pairs are coloured cyan. 


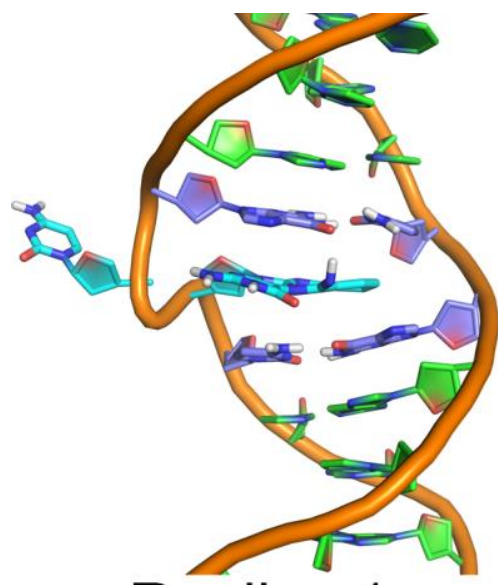

Replica 1

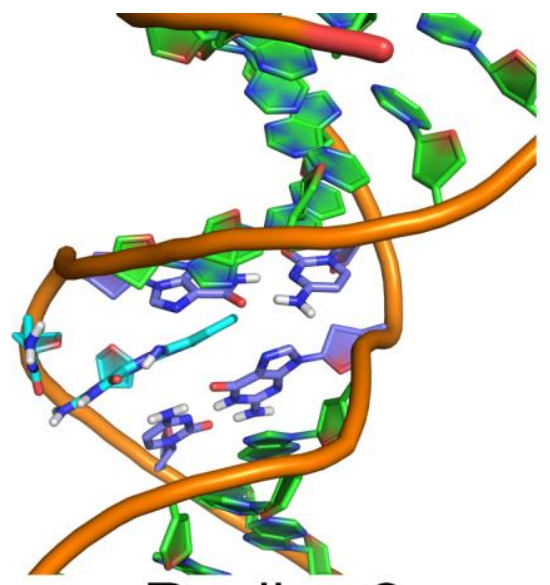

Replica 2

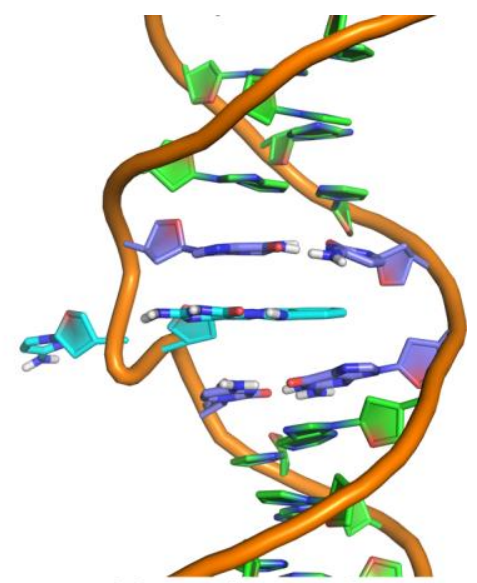

Replica 3
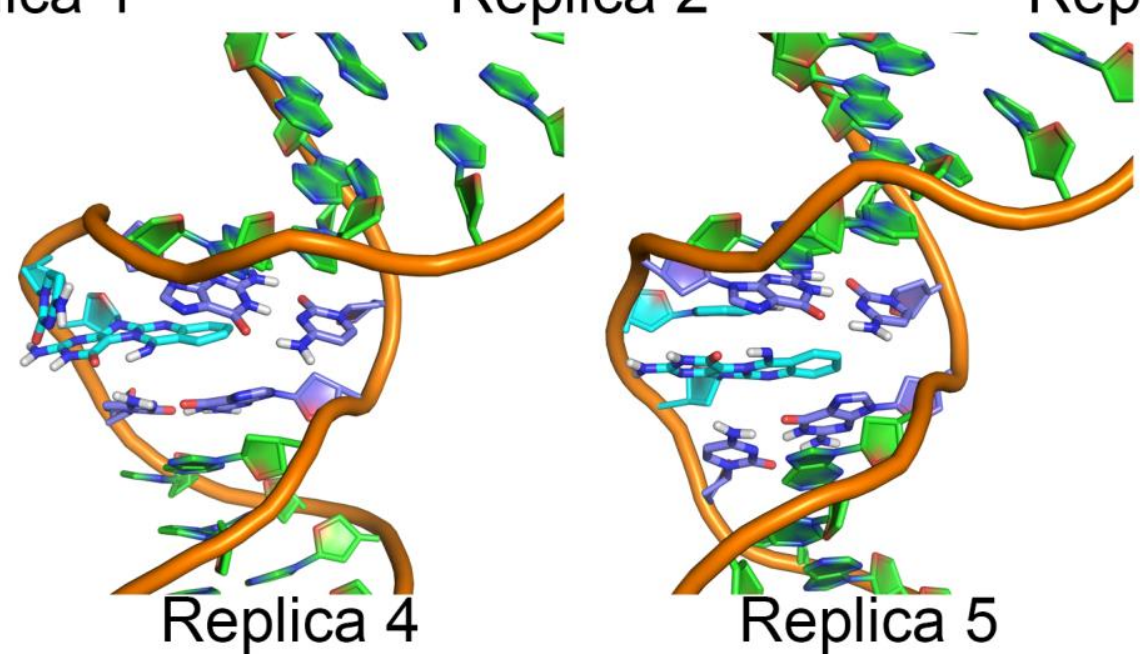

Figure S30: Representative structures obtained from MD simulations for the five $1 \mu$ s replicas of 1 adducted SMI duplex in the syn orientation. The adducted base and unpaired $\mathrm{C}$ are shown in cyan, and the flanking bases are shown in purple. 

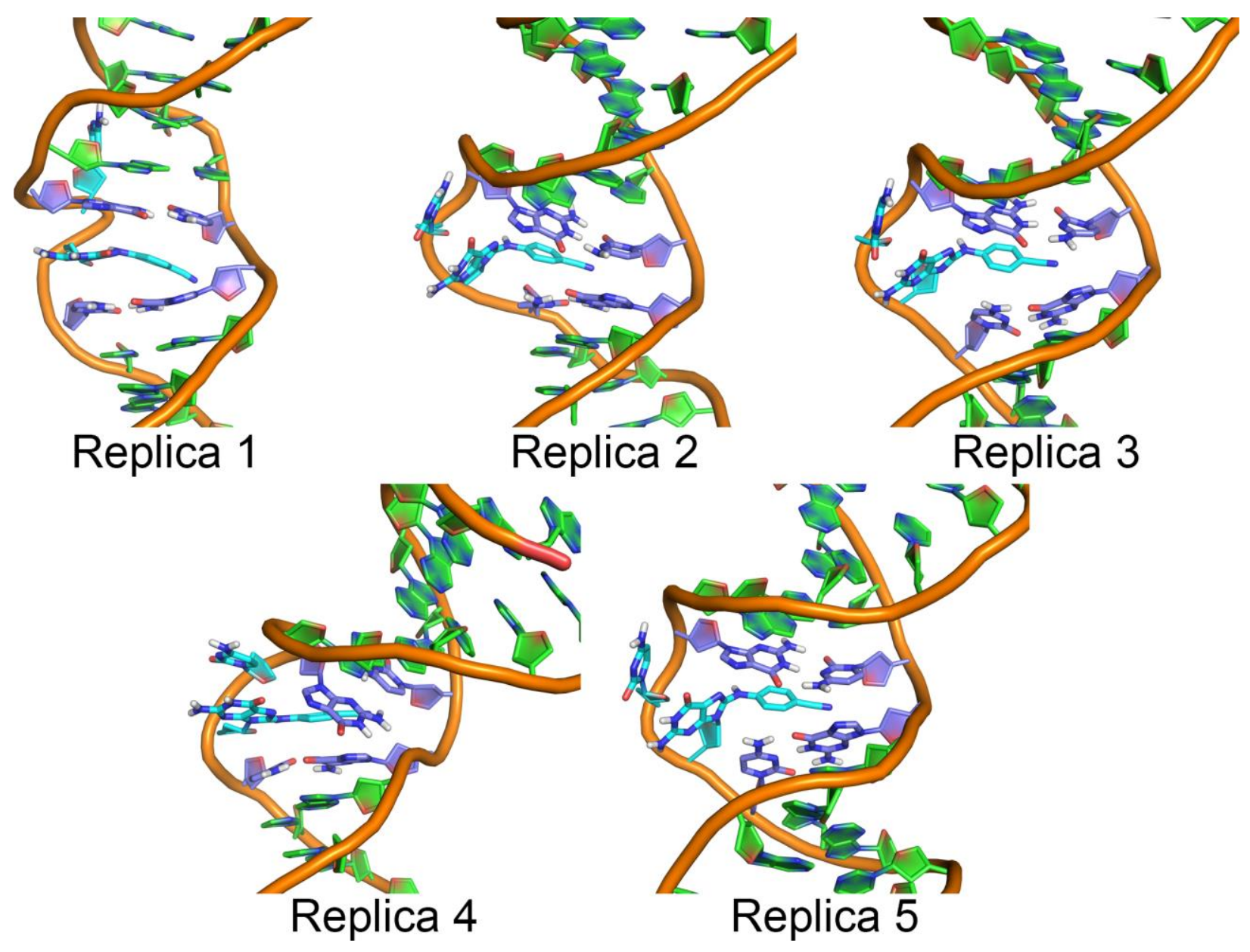

Figure S31: Representative structures obtained from MD simulations for the five $1 \mu$ s replicas of 2 adducted SMI duplex in the syn orientation. The adducted base and unpaired $\mathrm{C}$ are shown in cyan, and the flanking bases are shown in purple. 

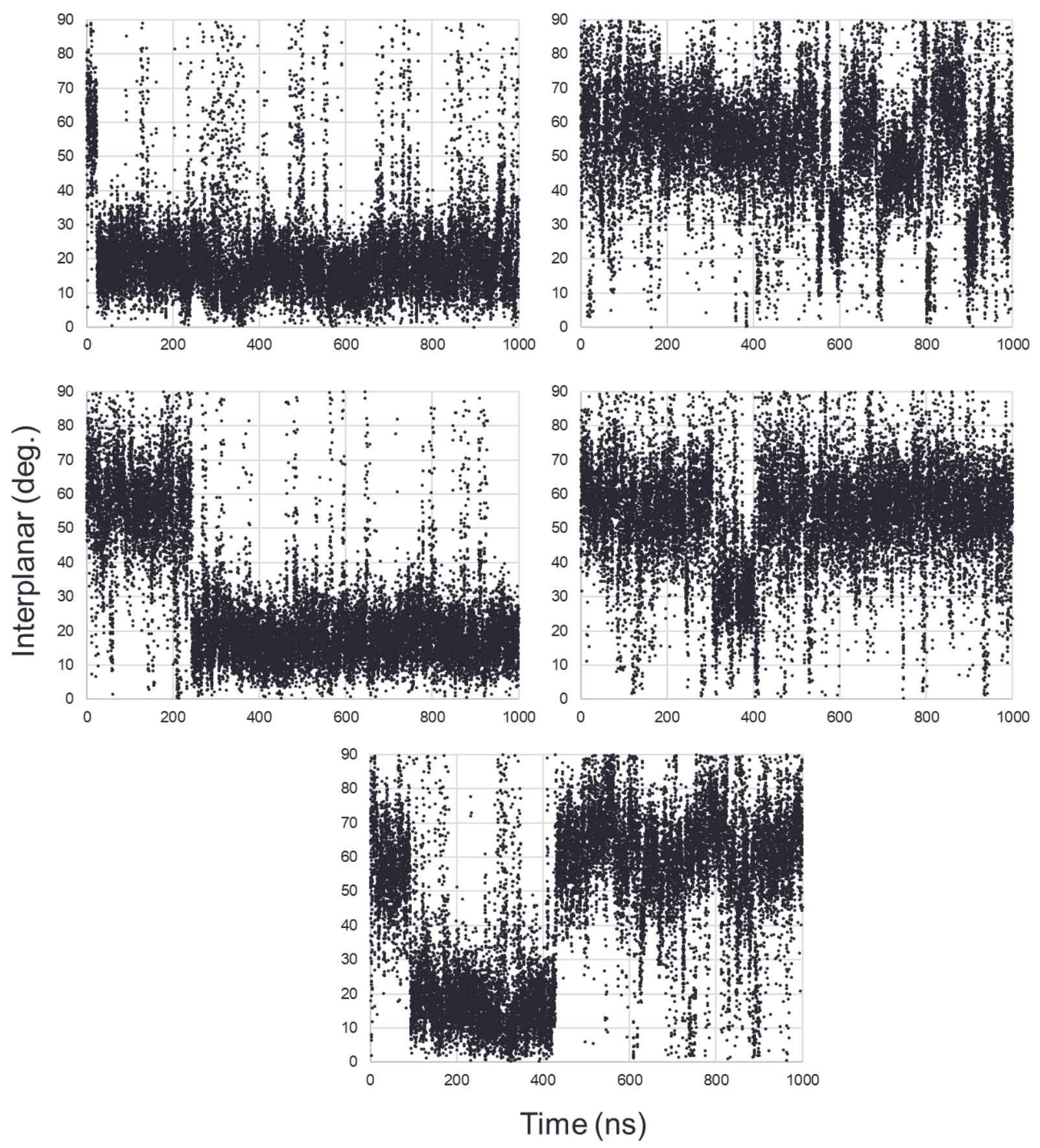

Figure S32: Interplanar angle between the base pairs flanking the lesion site in the SMI containing syn adduct 1 over the course of the five MD replicate simulations. 

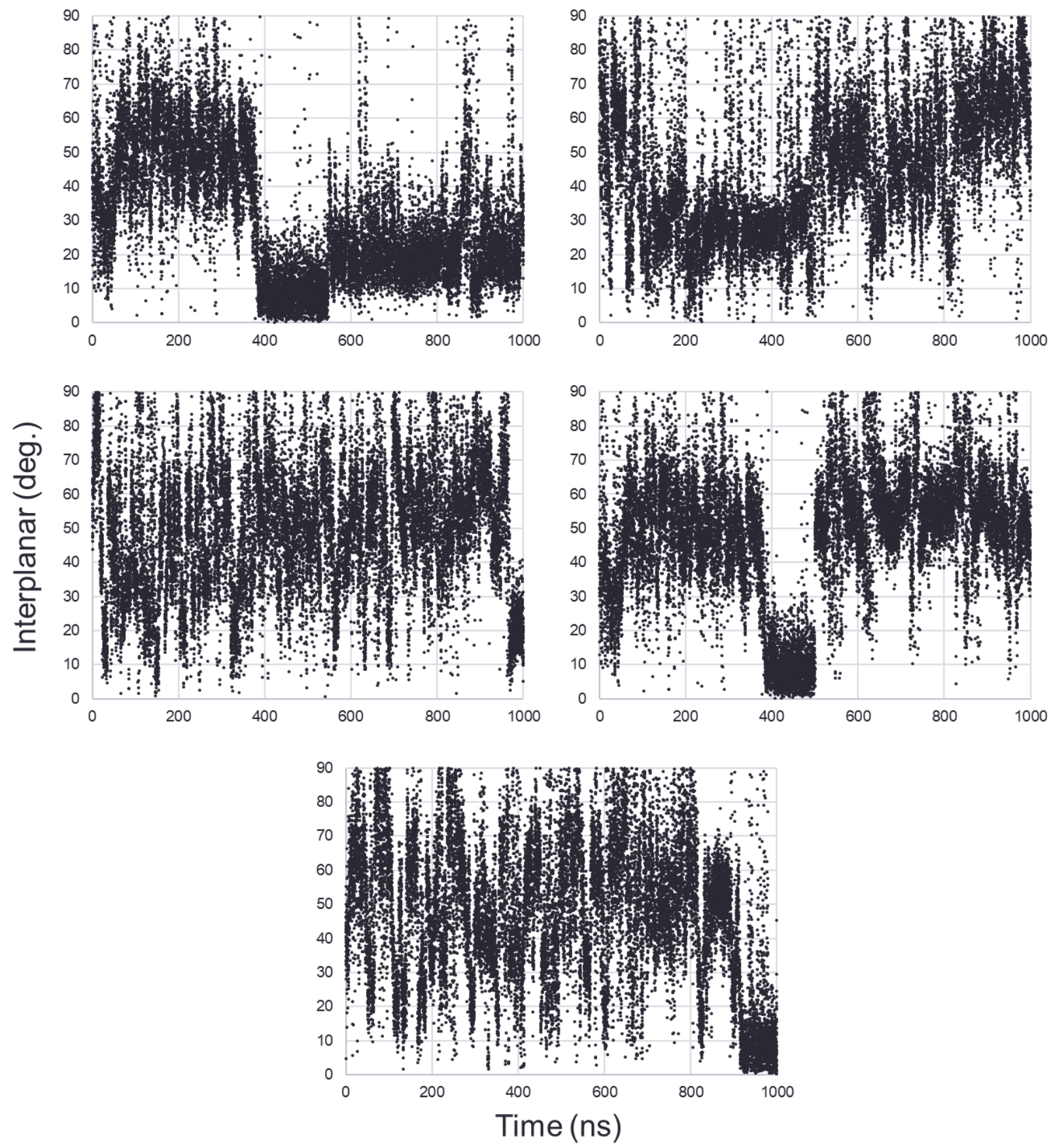

Figure S33: Interplanar angle between the base-pairs flanking the lesion site in the SMI containing syn adduct 2 over the course of the five MD replicate simulations. 


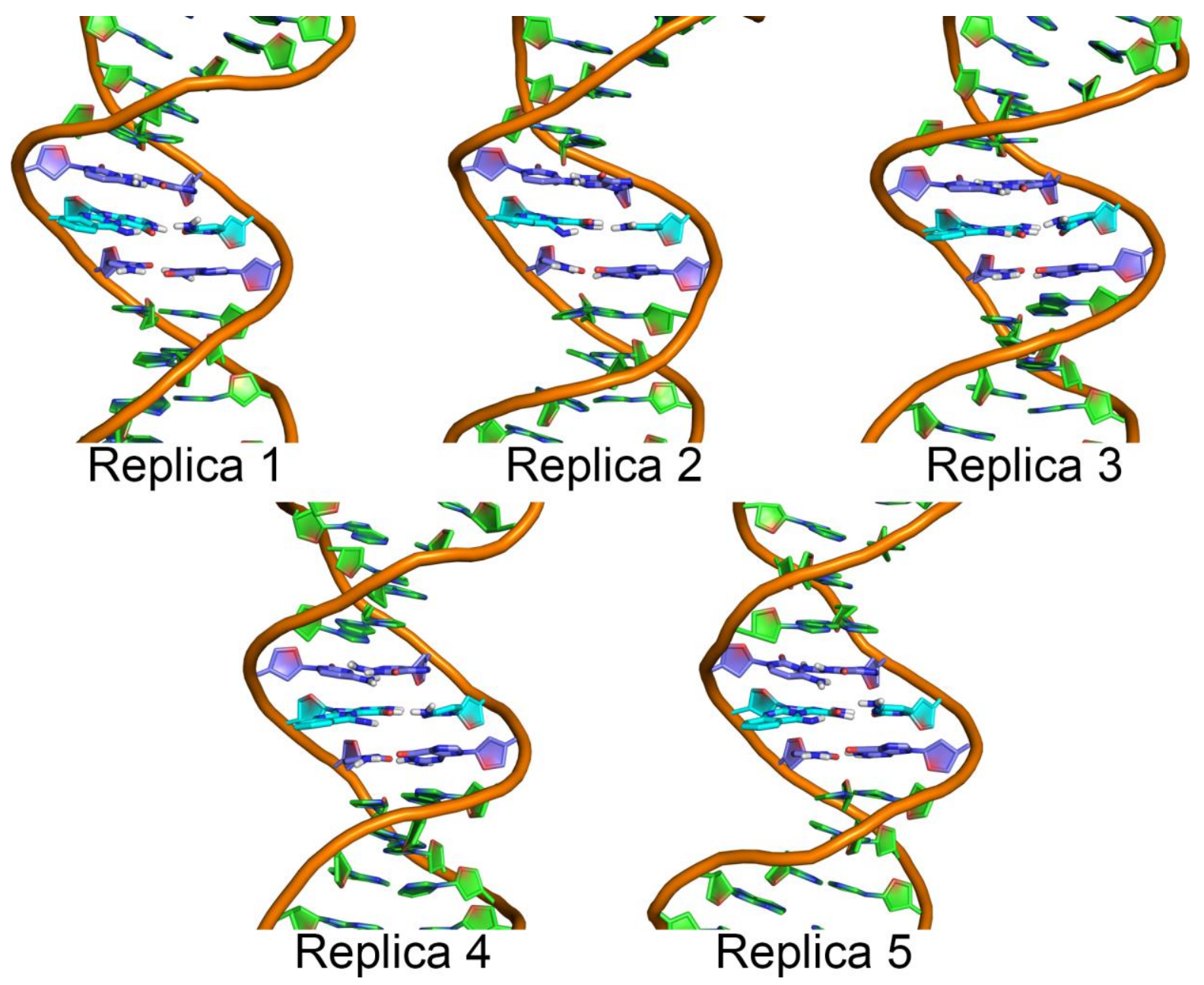

Figure S34: Representative structures obtained from MD simulations for the five $1 \mu$ seplicas of 1 adducted FP duplex in the $B$ conformation. The adducted base and pairing $C$ are shown in cyan and the flanking bases are shown in purple. 


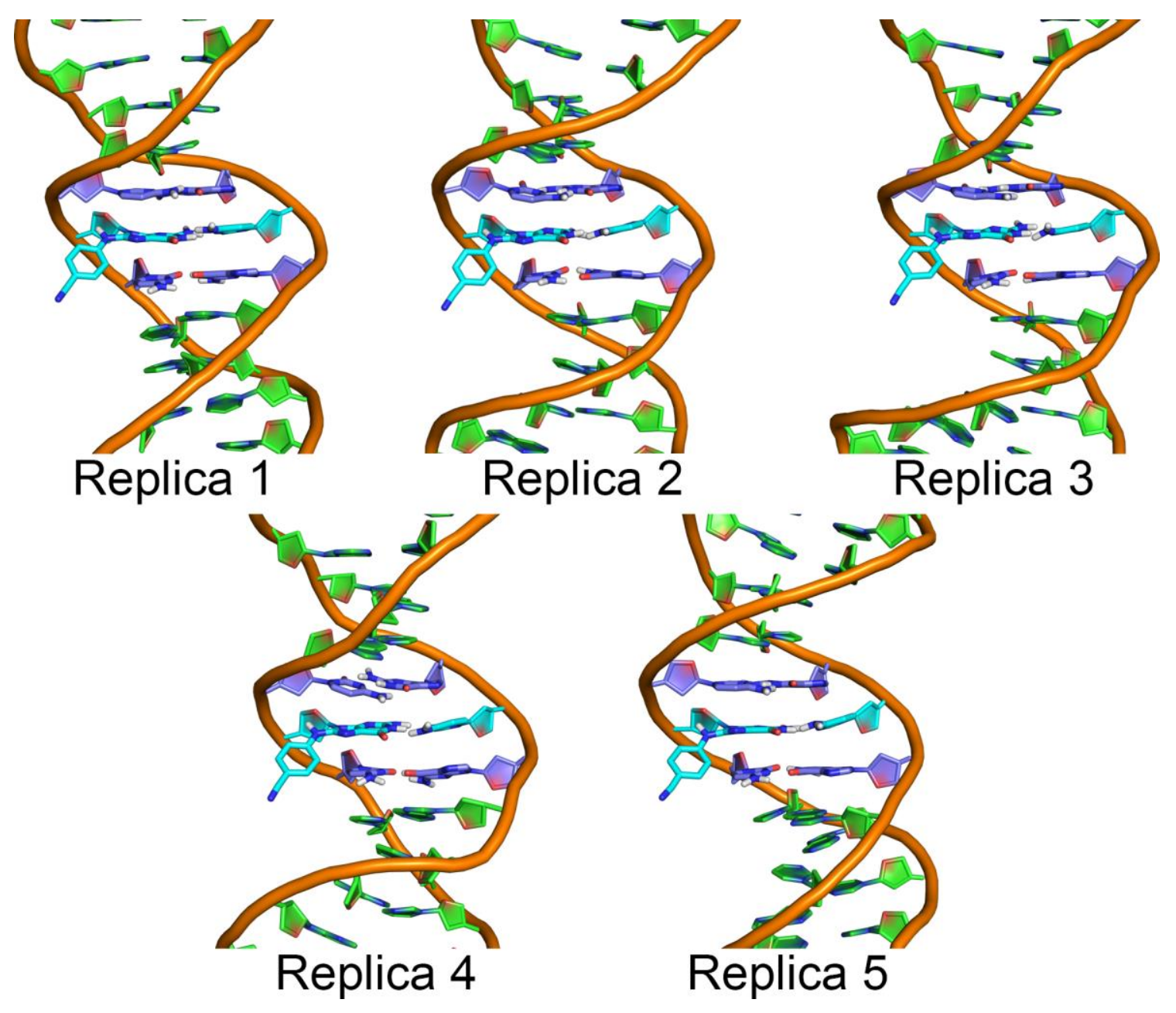

Figure S35: Representative structures obtained from MD simulations for the five $1 \mu$ s replicas of 2 adducted FP duplex in the $B$ conformation. The adducted base and pairing $\mathrm{C}$ are shown in cyan and the flanking bases are shown in purple. 

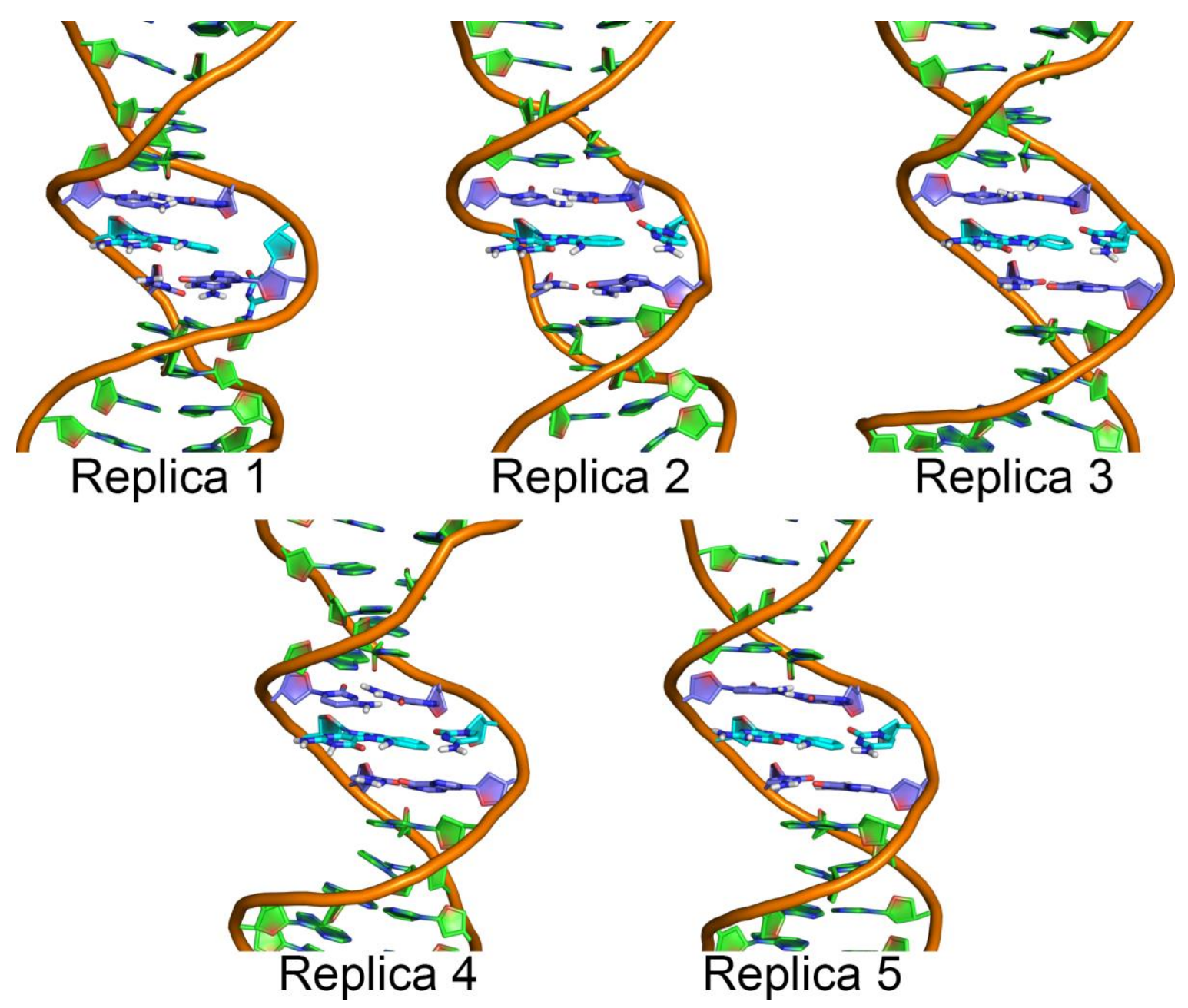

Figure S36: Representative structures obtained from MD simulations for the five $1 \mu$ seplicas of 1 adducted FP duplex in the $S$ conformation. The adducted base and pairing $\mathrm{C}$ are shown in cyan and the flanking bases are shown in purple. 

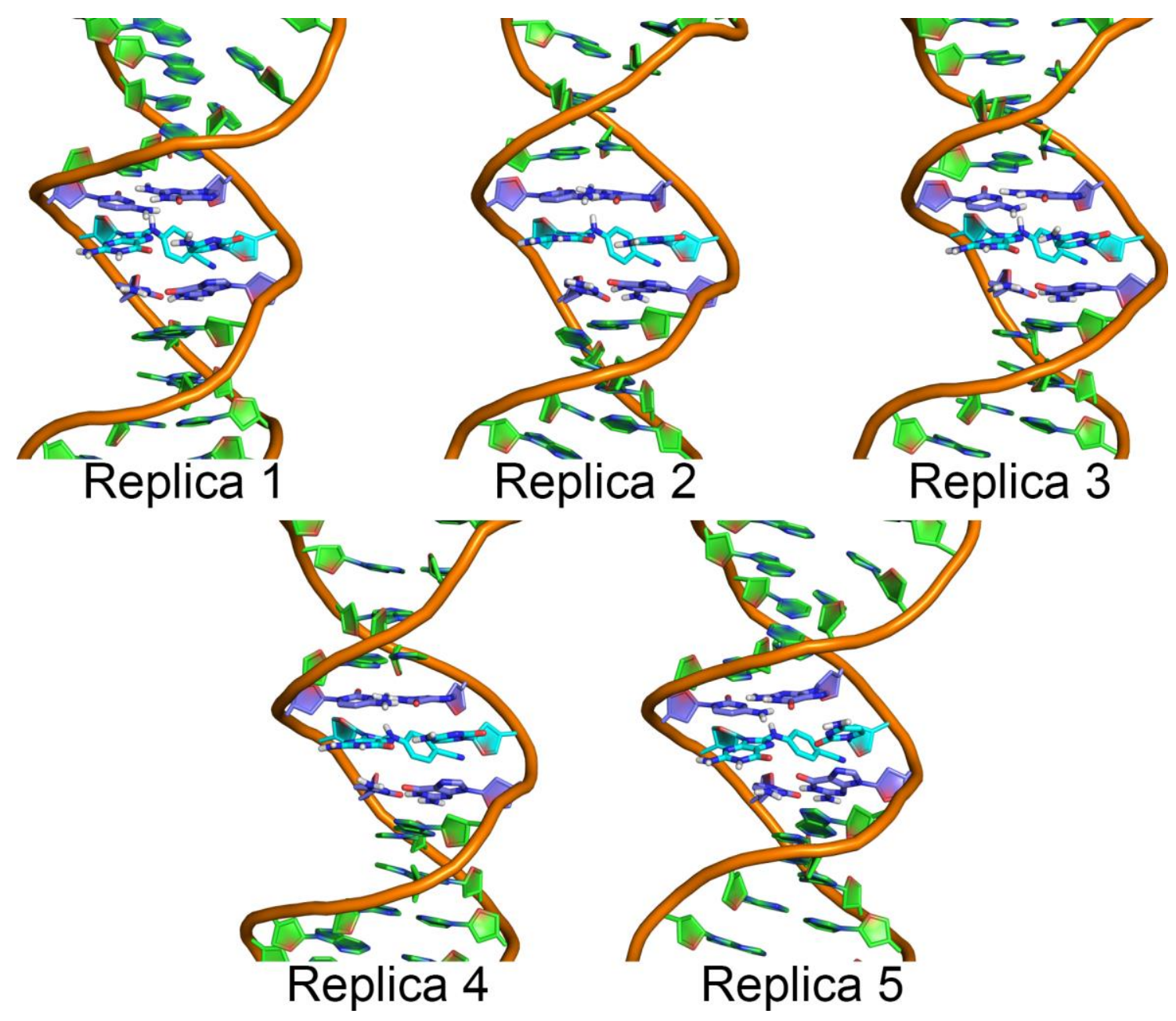

Figure S37: Representative structures obtained from MD simulations for the five $1 \mu$ s replicas of 2 adducted FP duplex in the $S$ conformation. The adducted base and pairing $C$ are shown in cyan and the flanking bases are shown in purple. 

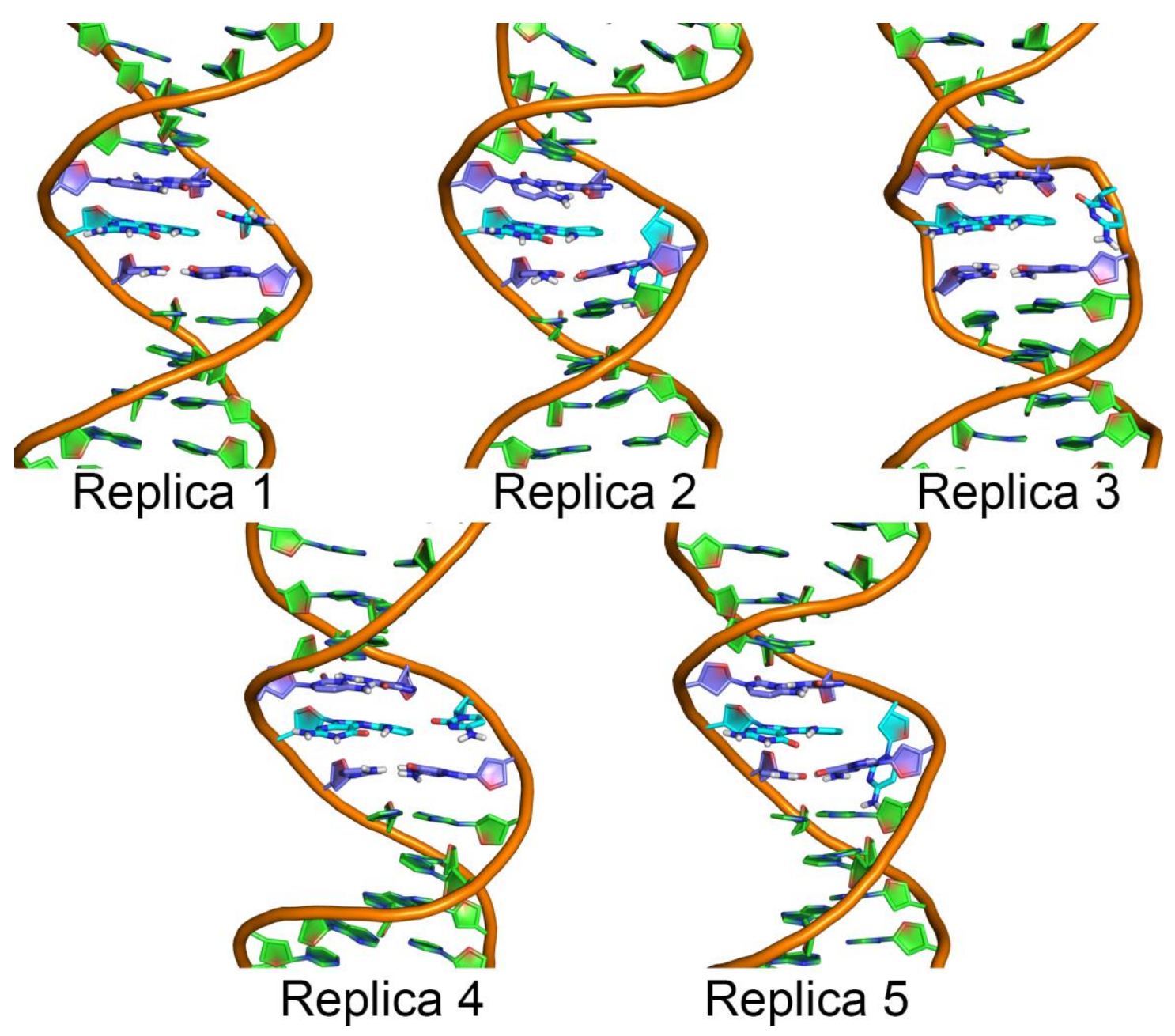

Replica 5

Figure S38: Representative structures obtained from MD simulations for the five $1 \mu$ s replicas of 1 adducted FP duplex in the $\mathrm{W}$ conformation. The adducted base and pairing $\mathrm{C}$ are shown in cyan and the flanking bases are shown in purple. 

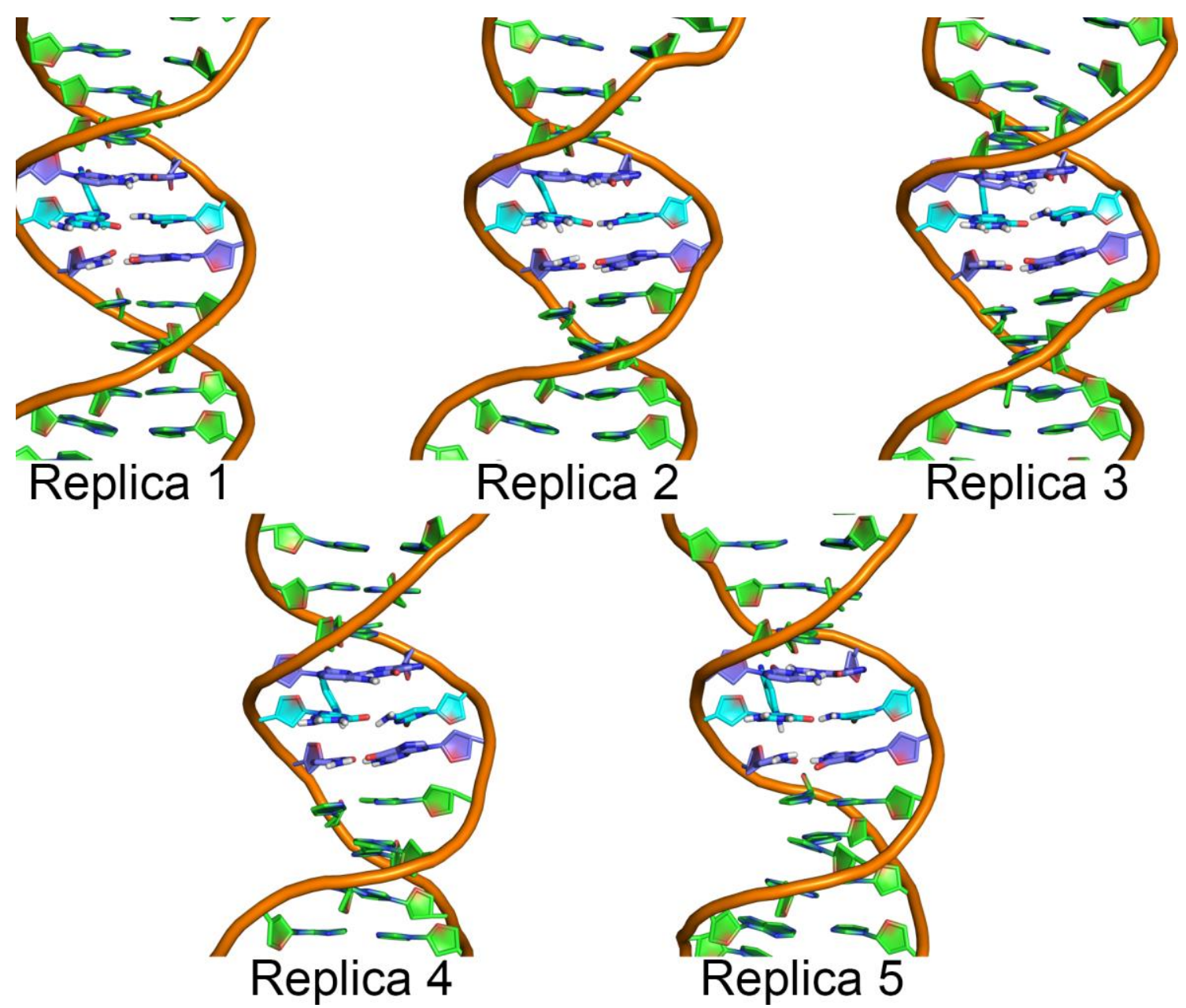

Figure S39: Representative structures obtained from MD simulations for the five $1 \mu$ s replicas of 2 adducted FP duplex in the $\mathrm{W}$ conformation. The adducted base and pairing $\mathrm{C}$ are shown in cyan and the flanking bases are shown in purple. 

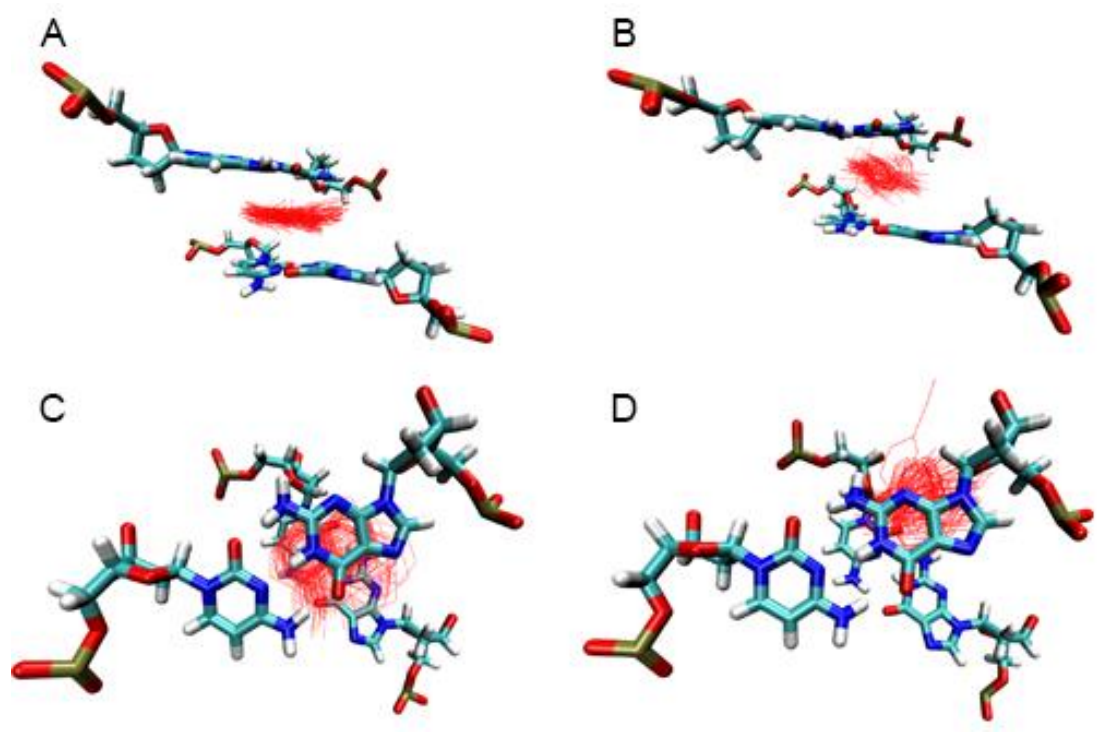

Figure S40: Positions of the bulky moieties (red) with respect to the flanking base-pairs in the FP duplexes in the $S$ conformation for $\mathbf{1}(A$ and $C$ ) and $\mathbf{2}(B$ and $D)$. Figures were generated by overlaying 1000 frames across the trajectories based on the atoms of the flanking base pairs.

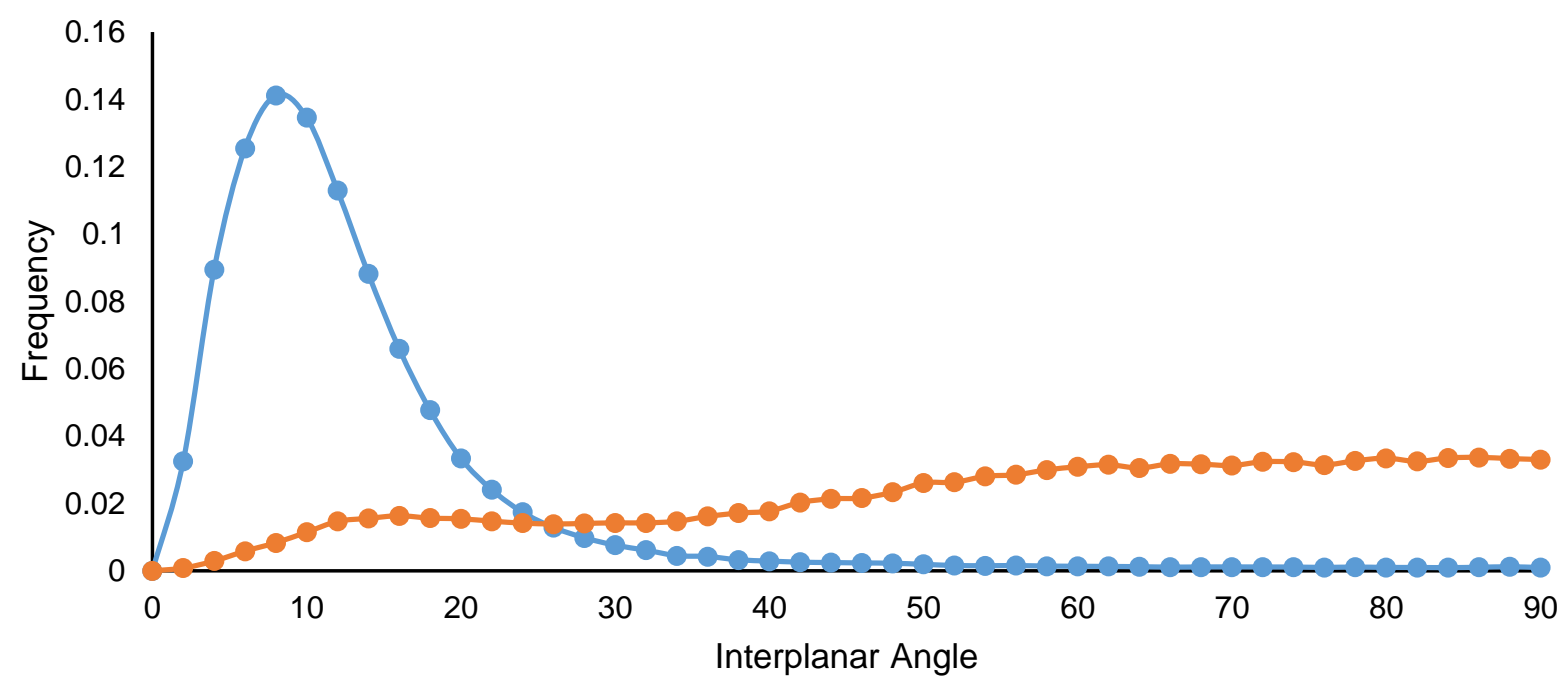

Figure S41: Histogram of the interplanar angles (deg) between the aromatic portion of the bulky moiety of syn 1 (blue) and 2 (orange) and the 5'- or 3'-base pairs from the five MD replicate simulations of the FP duplex. 
Table S1. Comparisons between gas-phase and implicit solvent B3LYP-D3(BJ)/6-

$311++\mathrm{G}(2 \mathrm{df}, 2 \mathrm{p})$ relative energies $(\mathrm{kJ} / \mathrm{mol})$ for the anti and syn conformations of the 1 and 2 nucleosides.

\begin{tabular}{|c|c|c|c|c|}
\hline Adduct & $5^{\prime} \mathrm{OH}$ & Structure & $\begin{array}{c}\text { Gas } \\
\text { Phase }\end{array}$ & $\begin{array}{c}\text { Implicit } \\
\text { Water }\end{array}$ \\
\hline \multirow{8}{*}{1} & \multirow{4}{*}{ Frozen } & anti & 0.8 & 2.9 \\
\hline & & syn & 0.0 & 0.0 \\
\hline & & TS1 & 17.9 & 17.5 \\
\hline & & TS2 & 26.6 & 20.3 \\
\hline & \multirow{4}{*}{ Free } & anti & 0.0 & 0.0 \\
\hline & & syn & 1.0 & 3.2 \\
\hline & & TS1 & 50.8 & 48.1 \\
\hline & & TS2 & 60.3 & 50.0 \\
\hline \multirow{6}{*}{2} & \multirow{2}{*}{ Frozen } & anti & 0.0 & 0.0 \\
\hline & & TS & 46.8 & 38.9 \\
\hline & \multirow{4}{*}{ Free } & anti & 13.2 & 15.2 \\
\hline & & syn & 0.0 & 0.0 \\
\hline & & TS1 & 50.4 & 42.6 \\
\hline & & TS2 & 19.7 & 19.5 \\
\hline
\end{tabular}

Table S2: Average and standard deviations (parentheses) of the sugar pucker occupancies over all windows during umbrella sampling on the adduct nucleosides.

\begin{tabular}{|c|c|c|c|c|c|}
\hline Adduct & C3'-endo & C4'-exo & O4'-endo & C1'-exo & C2'-endo \\
\hline $\mathbf{1}$ & $4.8(3.4)$ & $10.5(8.7)$ & $11.6(3.2)$ & $32.0(11.5)$ & $26.1(6.2)$ \\
\hline $\mathbf{2}$ & $3.6(3.2)$ & $9.6(8.4)$ & $13.0(4.4)$ & $35.3(11.2)$ & $25.5(5.6)$ \\
\hline & C3'-exo & C4'-endo & O4'-exo & C1'-endo & C2'-exo \\
\hline $\mathbf{1}$ & $8.5(7.1)$ & $3.3(4.9)$ & $0.7(0.7)$ & $2.3(3.1)$ & $1.5(1.7)$ \\
\hline $\mathbf{2}$ & $7.6(7.6)$ & $3.0(4.5)$ & $0.6(0.7)$ & $2.3(3.2)$ & $1.3(1.7)$ \\
\hline
\end{tabular}

Table S3: Average and standard deviations (parentheses) of the DNA backbone RMSDs ( $\AA$ ) across 1 us MD simulations.

\begin{tabular}{|c|c|c|c|c|c|c|c|}
\hline Adduct & Strand Length & Conformation & Replica 1 & Replica 2 & Replica 3 & Replica 4 & Replica 5 \\
\hline \multirow{5}{*}{1} & \multirow{2}{*}{ SMI } & anti & $5.8(1.0)$ & $5.1(0.9)$ & $2.6(0.6)$ & $4.6(1.7)$ & $5.4(1.3)$ \\
\hline & & syn & $3.4(0.6)$ & $2.9(0.9)$ & $4.6(1.5)$ & $3.1(1.1)$ & $3.4(1.1)$ \\
\hline & \multirow{3}{*}{ FP } & $B$ & $3.0(0.6)$ & $2.8(0.6)$ & $3.1(0.6)$ & $2.6(0.6)$ & $2.7(0.6)$ \\
\hline & & $S$ & $2.5(0.5)$ & $3.1(0.7)$ & $3.2(0.7)$ & $3.5(0.6)$ & $2.5(0.6)$ \\
\hline & & W & $2.5(0.7)$ & $3.3(0.7)$ & $3.3(0.7)$ & $2.6(0.6)$ & $2.6(0.6)$ \\
\hline \multirow{5}{*}{2} & \multirow{2}{*}{ SMI } & anti & $5.8(0.8)$ & $6.2(1.5)$ & $3.6(0.8)$ & $3.9(0.6)$ & $6.1(0.8)$ \\
\hline & & syn & $3.6(0.7)$ & $3.2(0.7)$ & $3.2(0.7)$ & $3.9(0.9)$ & $3.9(1.0)$ \\
\hline & \multirow{3}{*}{ FP } & B & $2.3(0.5)$ & $2.9(0.6)$ & $2.6(0.5)$ & $2.9(0.7)$ & $2.9(0.6)$ \\
\hline & & $S$ & $3.4(0.8)$ & $2.5(0.7)$ & $3.3(0.8)$ & $3.8(1.0)$ & $2.8(0.6)$ \\
\hline & & W & $3.2(0.7)$ & $2.5(0.5)$ & $2.6(0.7)$ & $2.9(0.7)$ & $3.4(0.7)$ \\
\hline
\end{tabular}


Table S4: Average and standard deviations (parentheses) of the key dihedral angles (deg) for the positioning of the adduct with respect to the DNA backbone across $1 \mu \mathrm{s}$ MD simulations.

\begin{tabular}{|c|c|c|c|c|c|c|c|c|c|}
\hline Adduct & $\begin{array}{l}\text { Strand } \\
\text { Length }\end{array}$ & Conformation & Dihedral & Replica 1 & Replica 2 & Replica 3 & Replica 4 & Replica 5 & $\begin{array}{c}\text { Average over } \\
\text { Replicas }\end{array}$ \\
\hline \multirow{5}{*}{1} & \multirow{2}{*}{ SMI } & anti & $x$ & $231.7(47.9)$ & $218.2(22.8)$ & $240.9(22.1)$ & $242.2(18.8)$ & $220.3(20.8)$ & $230.6(10.0)$ \\
\hline & & syn & $x$ & $53.2(70.5)$ & $61.2(24.7)$ & $24.0(24.5)$ & $57.4(12.0)$ & $50.1(17.1)$ & $49.2(13.1)$ \\
\hline & \multirow{3}{*}{ FP } & $\mathrm{B}$ & $x$ & $222.9(12.3)$ & $222.0(13.0)$ & 221.5 (12.2) & $221.8(12.1)$ & $221.9(12.4)$ & $222.0(0.5)$ \\
\hline & & $S$ & $x$ & $41.1(11.2)$ & $42.6(11.8)$ & $41.2(11.7)$ & $40.7(11.4)$ & $41.3(11.5)$ & $41.4(0.7)$ \\
\hline & & $W$ & $x$ & $42.0(11.6)$ & $41.4(11.7)$ & $43.7(11.6)$ & $42.1(12.0)$ & $41.3(11.3)$ & $42.1(0.9)$ \\
\hline \multirow{15}{*}{2} & \multirow{6}{*}{ SMI } & \multirow{3}{*}{ anti } & $x$ & $203.3(12.8)$ & $204.1(15.4)$ & $195.7(15.1)$ & $202.2(11.9)$ & $200.3(12.5)$ & $201.1(3.0)$ \\
\hline & & & $\theta$ & 200.7 (21.2) & $200.3(31.1)$ & $196.5(30.9)$ & $202.3(19.4)$ & $199.6(22.6)$ & $199.9(1.9)$ \\
\hline & & & $\varphi$ & $180.0(10.3)$ & $180.5(10.6)$ & $180.0(10.5)$ & $179.4(10.5)$ & $180.4(10.4)$ & $180.1(0.4)$ \\
\hline & & \multirow{3}{*}{ syn } & $x$ & $177.0(39.7)$ & $77.3(35.1)$ & $84.7(39.8)$ & $125.5(46.4)$ & $91.8(52.1)$ & $111.2(36.8)$ \\
\hline & & & $\theta$ & $207.9(24.7)$ & $188.4(80.3)$ & 236.8 (39.2) & $200.2(43.9)$ & $229.5(41.1)$ & $212.6(18.1)$ \\
\hline & & & $\varphi$ & $356.5(13.2)$ & $359.4(11.1)$ & $358.0(11.6)$ & $3.9(12.8)$ & $357.4(11.4)$ & $359.0(2.6)$ \\
\hline & \multirow{9}{*}{ FP } & \multirow{3}{*}{ B } & $x$ & $230.3(13.4)$ & $230.8(13.0)$ & $231.5(12.9)$ & $230.0(14.3)$ & $230.7(13.1)$ & $230.7(0.5)$ \\
\hline & & & $\theta$ & $137.3(24.9)$ & $136.9(24.3)$ & $136.6(24.2)$ & $137.3(25.8)$ & $136.9(24.9)$ & $137.0(0.3)$ \\
\hline & & & $\varphi$ & $2.9(12.0)$ & $2.9(12.0)$ & 2.7 (11.9) & $2.7(11.8)$ & $3.0(11.9)$ & $2.8(0.1)$ \\
\hline & & \multirow{3}{*}{$S$} & $x$ & $47.0(15.3)$ & $46.9(15.4)$ & $48.2(15.4)$ & $49.3(15.1)$ & $43.8(14.8)$ & $47.1(1.8)$ \\
\hline & & & $\theta$ & $235.7(34.5)$ & $227.5(39.4)$ & $232.9(34.1)$ & 250.8 (35.5) & $217.1(28.7)$ & $232.8(11.0)$ \\
\hline & & & $\varphi$ & $183.0(10.8)$ & $181.6(10.9)$ & $181.3(10.9)$ & $182.3(10.3)$ & $178.5(10.4)$ & $181.4(1.5)$ \\
\hline & & \multirow{3}{*}{ W } & $x$ & $54.2(17.4)$ & $60.3(15.8)$ & $59.0(15.9)$ & $57.5(17.2)$ & $57.7(16.0)$ & $57.7(2.0)$ \\
\hline & & & $\theta$ & $123.9(66.3)$ & $87.4(54.7)$ & $107.4(61.1)$ & $121.1(66.2)$ & $103.3(65.0)$ & $108.6(13.2)$ \\
\hline & & & $\varphi$ & 359.1 (11.2) & $1.5(10.1)$ & $0.4(10.7)$ & $359.7(11.0)$ & $0.6(10.7)$ & $0.2(0.8)$ \\
\hline
\end{tabular}


Table S5: Average and standard deviations (parentheses) of the sugar pucker occupancies over all replicas for each SMI and FP containing adducts 1 and 2.

\begin{tabular}{|c|c|c|c|c|c|c|}
\hline Adduct & System & C3'-endo & C4'-exo & O4'-endo & C1'-exo & C2'-endo \\
\hline \multirow{5}{*}{1} & SMI - anti & $1.1(1.1)$ & $3.9(1.4)$ & $21.9(11.3)$ & $28.4(4.3)$ & $33.8(11.1)$ \\
\hline & SMI - syn & $7.5(4.2)$ & $29.7(15.0)$ & $12.7(9.0)$ & $17.6(9.5)$ & $14.8(8.1)$ \\
\hline & $F P-B$ & $0.0(0.0)$ & $4.5(0.2)$ & $69.0(0.5)$ & $24.7(0.4)$ & $1.3(0.5)$ \\
\hline & $F P-S$ & $0.0(0.0)$ & $4.3(0.6)$ & $62.4(4.7)$ & $33.0(5.3)$ & $0.3(0.0)$ \\
\hline & $F P-W$ & $0.0(0.0)$ & $4.0(0.9)$ & $59.0(7.6)$ & $35.3(9.0)$ & $1.4(0.6)$ \\
\hline \multirow{5}{*}{2} & SMI - anti & $0.6(0.2)$ & $1.7(0.5)$ & $9.0(2.7)$ & $33.6(2.4)$ & $51.8(4.5)$ \\
\hline & SMI-syn & $8.1(4.1)$ & $14.5(8.6)$ & $4.3(1.9)$ & $34.3(4.4)$ & $34.5(11.3)$ \\
\hline & $F P-B$ & $0.1(0.0)$ & $10.6(0.2)$ & $65.2(1.1)$ & $23.1(0.3)$ & $1.1(0.7)$ \\
\hline & $F P-S$ & $0.2(0.0)$ & $6.9(0.9)$ & $44.3(7.9)$ & $44.6(8.0)$ & $3.6(1.2)$ \\
\hline & $F P-W$ & $0.0(0.0)$ & $1.5(2.1)$ & $9.1(6.4)$ & $70.2(5.6)$ & $18.3(2.9)$ \\
\hline \multirow{6}{*}{1} & & C3'-exo & C4'-endo & 04'-exo & C1'-endo & C2'-exo \\
\hline & $\mathrm{SMI}-a n t i$ & $10.5(4.8)$ & $0.2(0.2)$ & $0.0(0.0)$ & $0.0(0.0)$ & $0.0(0.0)$ \\
\hline & SMI-syn & $13.8(15.5)$ & $2.8(3.9)$ & $0.0(0.0)$ & $0.2(0.2)$ & $0.8(0.3)$ \\
\hline & $F P-B$ & $0.5(0.3)$ & $0.0(0.0)$ & $0.0(0.0)$ & $0.0(0.0)$ & $0.0(0.0)$ \\
\hline & $F P-S$ & $0.0(0.0)$ & $0.0(0.0)$ & $0.0(0.0)$ & $0.0(0.0)$ & $0.0(0.0)$ \\
\hline & $F P-W$ & $0.3(0.2)$ & $0.0(0.0)$ & $0.0(0.0)$ & $0.0(0.0)$ & $0.0(0.0)$ \\
\hline \multirow{5}{*}{2} & SMI - anti & $2.8(1.2)$ & $0.2(0.4)$ & $0.0(0.1)$ & $0.1(0.0)$ & $0.3(0.2)$ \\
\hline & SMI - syn & $3.0(1.5)$ & $0.1(0.0)$ & $0.1(0.0)$ & $0.1(0.1)$ & $1.1(0.6)$ \\
\hline & $F P-B$ & $0.0(0.0)$ & $0.0(0.0)$ & $0.0(0.0)$ & $0.0(0.0)$ & $0.0(0.0)$ \\
\hline & $F P-S$ & $0.3(0.3)$ & $0.0(0.0)$ & $0.0(0.0)$ & $0.0(0.0)$ & $0.0(0.0)$ \\
\hline & $F P-W$ & $0.9(0.3)$ & $0.0(0.0)$ & $0.0(0.0)$ & $0.0(0.0)$ & $0.0(0.0)$ \\
\hline
\end{tabular}


Table S6: Occupancies (\%) of the hydrogen bonds of the adduct and unpaired $\mathrm{C}$ when the damaged $\mathrm{G}$ is in the anti conformation for the SMI models. ${ }^{a}$

\begin{tabular}{|c|c|c|c|c|c|c|c|c|c|}
\hline Donor & Acceptor & Adduct & $\begin{array}{c}\text { Replica } \\
1\end{array}$ & $\begin{array}{c}\text { Replica } \\
2\end{array}$ & $\begin{array}{c}\text { Replica } \\
3\end{array}$ & $\begin{array}{c}\text { Replica } \\
4\end{array}$ & $\begin{array}{c}\text { Replica } \\
5\end{array}$ & Average & $\begin{array}{l}\text { Standard } \\
\text { Deviation }\end{array}$ \\
\hline \multirow{2}{*}{ dC24:N4H } & \multirow{2}{*}{ Lesion:O6 } & 1 & $77.3 \%$ & $94.1 \%$ & $95.8 \%$ & $97.1 \%$ & $97.6 \%$ & $92.4 \%$ & $7.7 \%$ \\
\hline & & 2 & $97.3 \%$ & $93.9 \%$ & $59.9 \%$ & $98.5 \%$ & $98.1 \%$ & $89.5 \%$ & $14.9 \%$ \\
\hline \multirow{2}{*}{ Lesion:N1H } & \multirow{2}{*}{$\mathrm{dC24:N3}$} & 1 & $78.1 \%$ & $95.1 \%$ & $96.8 \%$ & $98.4 \%$ & $98.4 \%$ & $93.3 \%$ & $7.7 \%$ \\
\hline & & 2 & $98.2 \%$ & $95.7 \%$ & $60.5 \%$ & $99.4 \%$ & $99.6 \%$ & $90.7 \%$ & $15.2 \%$ \\
\hline \multirow{2}{*}{ Lesion:N2H } & \multirow{2}{*}{ dC24:O2 } & 1 & $78.1 \%$ & $95.4 \%$ & $97.8 \%$ & $98.5 \%$ & $99.4 \%$ & $93.8 \%$ & $8.0 \%$ \\
\hline & & 2 & $99.2 \%$ & $98.5 \%$ & $60.6 \%$ & $99.5 \%$ & $99.6 \%$ & $91.5 \%$ & $15.4 \%$ \\
\hline dC8:N4H & dA27:OP1 & 1 & $0.8 \%$ & $0.0 \%$ & $0.0 \%$ & $0.0 \%$ & $27.8 \%$ & $5.7 \%$ & $11.1 \%$ \\
\hline dC8:N4H & dG6:N3 & 1 & $39.5 \%$ & $0.0 \%$ & $0.1 \%$ & $0.0 \%$ & $40.0 \%$ & $15.9 \%$ & $19.5 \%$ \\
\hline dC8:N4H & dG7:OP2 & 1 & $0.0 \%$ & $0.0 \%$ & $46.1 \%$ & $32.1 \%$ & $40.0 \%$ & $23.7 \%$ & $19.8 \%$ \\
\hline Lesion:N17H & Lesion:06 & 1 & $99.0 \%$ & $98.8 \%$ & $98.4 \%$ & $96.4 \%$ & $99.2 \%$ & $98.4 \%$ & $1.0 \%$ \\
\hline Lesion:N1H & dC24:02 & 1 & $23.7 \%$ & $21.2 \%$ & $27.8 \%$ & $28.3 \%$ & $32.0 \%$ & $26.6 \%$ & $3.8 \%$ \\
\hline Lesion:N10H & dC10:O4' & 2 & $35.0 \%$ & $33.8 \%$ & $40.0 \%$ & $37.7 \%$ & $42.1 \%$ & $37.7 \%$ & $3.1 \%$ \\
\hline Lesion:N10H & dC10:05' & 2 & $48.5 \%$ & $38.5 \%$ & $37.7 \%$ & $48.0 \%$ & $35.8 \%$ & $41.7 \%$ & $5.4 \%$ \\
\hline Lesion:N2H & dC10:04' & 2 & $32.8 \%$ & $25.6 \%$ & $19.6 \%$ & $32.8 \%$ & $27.8 \%$ & $27.7 \%$ & $4.9 \%$ \\
\hline Lesion:N1H & dC24:O4' & 2 & $0.0 \%$ & $0.0 \%$ & $27.4 \%$ & $0.0 \%$ & $0.0 \%$ & $5.5 \%$ & $11.0 \%$ \\
\hline Lesion:N2H & dC24:04' & 2 & $0.0 \%$ & $0.0 \%$ & $26.5 \%$ & $0.0 \%$ & $0.0 \%$ & $5.3 \%$ & $10.6 \%$ \\
\hline
\end{tabular}

aHydrogen-bonding interactions were determined using a cut-off of $3.4 \AA$ for the donor-acceptor distance and $120^{\circ}$ for the donor-hydrogen-acceptor angle. 
Table S7: Occupancies (\%) of the hydrogen bonds of the flanking bases when the lesion is started from the anti conformation for the SMI models. ${ }^{a}$

\begin{tabular}{|c|c|c|c|c|c|c|c|c|c|}
\hline Donor & Acceptor & Adduct & $\begin{array}{c}\text { Replica } \\
1\end{array}$ & $\begin{array}{c}\text { Replica } \\
2 \\
\end{array}$ & $\begin{array}{c}\text { Replica } \\
3\end{array}$ & $\begin{array}{c}\text { Replica } \\
4\end{array}$ & $\begin{array}{c}\text { Replica } \\
5\end{array}$ & Average & $\begin{array}{l}\text { Standard } \\
\text { Deviation }\end{array}$ \\
\hline \multirow{2}{*}{ dG23:N1H } & \multirow{2}{*}{ dC10:N3 } & 1 & $99.9 \%$ & $99.9 \%$ & $99.8 \%$ & $99.9 \%$ & $99.9 \%$ & $99.9 \%$ & $0.0 \%$ \\
\hline & & 2 & $100.0 \%$ & $99.9 \%$ & $100.0 \%$ & $99.9 \%$ & $100.0 \%$ & $99.9 \%$ & $0.0 \%$ \\
\hline \multirow{2}{*}{ dG23:N2H } & \multirow{2}{*}{ dC10:02 } & 1 & $99.8 \%$ & $99.8 \%$ & $99.8 \%$ & $99.8 \%$ & $99.8 \%$ & $99.8 \%$ & $0.0 \%$ \\
\hline & & 2 & $99.7 \%$ & $99.9 \%$ & $99.8 \%$ & $99.7 \%$ & $99.8 \%$ & $99.8 \%$ & $0.1 \%$ \\
\hline \multirow{2}{*}{$\mathrm{dC10:N4H}$} & \multirow{2}{*}{ dG23:06 } & 1 & $98.7 \%$ & $98.7 \%$ & $98.5 \%$ & $98.7 \%$ & $98.6 \%$ & $98.6 \%$ & $0.1 \%$ \\
\hline & & 2 & $98.9 \%$ & $98.8 \%$ & $98.9 \%$ & $98.9 \%$ & $98.7 \%$ & $98.8 \%$ & $0.1 \%$ \\
\hline \multirow{2}{*}{ dG7:N1H } & \multirow{2}{*}{ dC25:N3 } & 1 & $68.4 \%$ & $84.8 \%$ & $21.4 \%$ & $4.9 \%$ & $79.0 \%$ & $51.7 \%$ & $32.3 \%$ \\
\hline & & 2 & $92.7 \%$ & $74.0 \%$ & $56.8 \%$ & $95.8 \%$ & $89.2 \%$ & $81.7 \%$ & $14.5 \%$ \\
\hline \multirow{2}{*}{ dG7:N2H } & \multirow{2}{*}{ dC25:02 } & 1 & $73.6 \%$ & $86.7 \%$ & $22.1 \%$ & $4.9 \%$ & $81.2 \%$ & $53.7 \%$ & $33.5 \%$ \\
\hline & & 2 & $93.2 \%$ & $79.5 \%$ & $58.2 \%$ & $96.6 \%$ & $94.2 \%$ & $84.3 \%$ & $14.4 \%$ \\
\hline \multirow{2}{*}{ dC25:N4H } & \multirow{2}{*}{ dG7:06 } & 1 & $65.5 \%$ & $82.9 \%$ & $20.4 \%$ & $4.7 \%$ & $76.9 \%$ & $50.1 \%$ & $31.6 \%$ \\
\hline & & 2 & $90.2 \%$ & $64.4 \%$ & $54.8 \%$ & $92.8 \%$ & $84.1 \%$ & $77.2 \%$ & $15.0 \%$ \\
\hline dG7:N1H & dC24:N3 & 2 & $2.2 \%$ & $5.9 \%$ & $39.6 \%$ & $0.9 \%$ & $0.7 \%$ & $9.9 \%$ & $15.0 \%$ \\
\hline $\mathrm{dG7:N2H}$ & $\mathrm{dC24:02}$ & 2 & $2.1 \%$ & $5.6 \%$ & $39.5 \%$ & $0.8 \%$ & $0.7 \%$ & $9.7 \%$ & $15.0 \%$ \\
\hline $\mathrm{dC24:N4H}$ & dG7:06 & 2 & $1.8 \%$ & $4.8 \%$ & $38.4 \%$ & $0.8 \%$ & $0.8 \%$ & $9.3 \%$ & $14.6 \%$ \\
\hline
\end{tabular}

aHydrogen-bonding interactions were determined using a cut-off of $3.4 \AA$ for the donor-acceptor distance and $120^{\circ}$ for the donor-hydrogen-acceptor angle.

Table S8: Occupancies (\%) of the hydrogen bonds of the adduct and unpaired $\mathrm{C}$ when the damaged $\mathrm{G}$ is in the syn conformation for the SMI models. ${ }^{a}$

\begin{tabular}{|c|c|c|c|c|c|c|c|c|c|}
\hline Donor & Acceptor & Adduct & $\begin{array}{c}\text { Replica } \\
1\end{array}$ & $\begin{array}{c}\text { Replica } \\
2\end{array}$ & $\begin{array}{c}\text { Replica } \\
3\end{array}$ & $\begin{array}{c}\text { Replica } \\
4\end{array}$ & $\begin{array}{c}\text { Replica } \\
5\end{array}$ & Average & $\begin{array}{l}\text { Standard } \\
\text { Deviation }\end{array}$ \\
\hline \multirow{2}{*}{ dC8:N4H } & \multirow{2}{*}{ dG7:OP2 } & 1 & $1.1 \%$ & $31.3 \%$ & $14.7 \%$ & $52.2 \%$ & $5.5 \%$ & $21.0 \%$ & $18.7 \%$ \\
\hline & & 2 & $28.2 \%$ & $64.1 \%$ & $73.2 \%$ & $82.3 \%$ & $65.0 \%$ & $62.5 \%$ & $18.4 \%$ \\
\hline dC8:N4H & dG7:N3 & 1 & $0.0 \%$ & $1.0 \%$ & $0.0 \%$ & $0.0 \%$ & $30.0 \%$ & $6.2 \%$ & $11.9 \%$ \\
\hline Lesion:N1H & dC8:02 & 1 & $0.5 \%$ & $16.2 \%$ & $7.2 \%$ & $27.4 \%$ & $3.0 \%$ & $10.8 \%$ & $9.8 \%$ \\
\hline Lesion:N17H & Lesion:06 & 1 & $93.1 \%$ & $98.2 \%$ & $92.2 \%$ & $98.9 \%$ & $97.9 \%$ & $96.0 \%$ & $2.8 \%$ \\
\hline dC8:N4H & :6@N3 & 2 & $27.9 \%$ & $0.0 \%$ & $0.0 \%$ & $0.0 \%$ & $0.9 \%$ & $5.8 \%$ & $11.1 \%$ \\
\hline dC8:N4H & :6@O4' & 2 & $28.5 \%$ & $0.0 \%$ & $0.0 \%$ & $0.0 \%$ & $2.9 \%$ & $6.3 \%$ & $11.2 \%$ \\
\hline Lesion:N10H & dC10:O4' & 2 & $56.2 \%$ & $13.0 \%$ & $20.2 \%$ & $59.6 \%$ & $25.6 \%$ & $34.9 \%$ & $19.2 \%$ \\
\hline Lesion: $\mathrm{N} 10 \mathrm{H}$ & dC10:05' & 2 & $28.2 \%$ & $0.1 \%$ & $0.0 \%$ & $0.0 \%$ & $1.4 \%$ & $5.9 \%$ & $11.1 \%$ \\
\hline dG7:N2H & Lesion:OP1 & 2 & $60.8 \%$ & $0.0 \%$ & $0.0 \%$ & $0.0 \%$ & $8.5 \%$ & $13.9 \%$ & $23.7 \%$ \\
\hline
\end{tabular}

aHydrogen-bonding interactions were determined using a cut-off of $3.4 \AA$ for the donor-acceptor distance and $120^{\circ}$ for the donor-hydrogen-acceptor angle. 
Table S9: Occupancies (\%) of the hydrogen bonds of the flanking bases when the lesion is started from the syn conformation for the SMI models. ${ }^{a}$

\begin{tabular}{|c|c|c|c|c|c|c|c|c|c|}
\hline Donor & Acceptor & Adduct & $\begin{array}{c}\text { Replica } \\
1\end{array}$ & $\begin{array}{c}\text { Replica } \\
2 \\
\end{array}$ & $\begin{array}{c}\text { Replica } \\
3 \\
\end{array}$ & $\begin{array}{c}\text { Replica } \\
4\end{array}$ & $\begin{array}{c}\text { Replica } \\
5\end{array}$ & Average & $\begin{array}{l}\text { Standard } \\
\text { Deviation }\end{array}$ \\
\hline \multirow{2}{*}{ dG7:N1H } & \multirow{2}{*}{ dC24:N3 } & 1 & $99.8 \%$ & $99.3 \%$ & $99.8 \%$ & $99.6 \%$ & $99.8 \%$ & $99.7 \%$ & $0.2 \%$ \\
\hline & & 2 & $99.3 \%$ & $99.0 \%$ & $99.1 \%$ & $41.1 \%$ & $99.7 \%$ & $87.6 \%$ & $23.3 \%$ \\
\hline \multirow{2}{*}{$\mathrm{dG7}$ :N2H } & \multirow{2}{*}{ dC24:O2 } & 1 & $99.4 \%$ & $99.0 \%$ & $99.7 \%$ & $98.2 \%$ & $99.4 \%$ & $99.2 \%$ & $0.5 \%$ \\
\hline & & 2 & $99.5 \%$ & $98.0 \%$ & $98.7 \%$ & $41.1 \%$ & $99.4 \%$ & $87.3 \%$ & $23.1 \%$ \\
\hline \multirow{2}{*}{ dC24:N4H } & \multirow{2}{*}{ dG7:06 } & 1 & $97.7 \%$ & $97.4 \%$ & $97.8 \%$ & $98.4 \%$ & $98.1 \%$ & $97.9 \%$ & $0.3 \%$ \\
\hline & & 2 & $95.0 \%$ & $96.4 \%$ & $95.7 \%$ & $39.8 \%$ & $96.6 \%$ & $84.7 \%$ & $22.4 \%$ \\
\hline \multirow{2}{*}{ dG23:N1H } & \multirow{2}{*}{ dC10:N3 } & 1 & $99.5 \%$ & $99.9 \%$ & $100.0 \%$ & $99.9 \%$ & $99.3 \%$ & $99.7 \%$ & $0.3 \%$ \\
\hline & & 2 & $98.5 \%$ & $94.9 \%$ & $97.7 \%$ & $99.2 \%$ & $99.1 \%$ & $97.9 \%$ & $1.6 \%$ \\
\hline \multirow{2}{*}{ dG23:N2H } & \multirow{2}{*}{ dC10:02 } & 1 & $99.8 \%$ & $99.7 \%$ & $99.9 \%$ & $99.8 \%$ & $99.8 \%$ & $99.8 \%$ & $0.1 \%$ \\
\hline & & 2 & $98.2 \%$ & $97.6 \%$ & $98.7 \%$ & $99.1 \%$ & $99.2 \%$ & $98.6 \%$ & $0.6 \%$ \\
\hline \multirow{2}{*}{$\mathrm{dC10:N4H}$} & \multirow{2}{*}{ dG23:06 } & 1 & $98.4 \%$ & $98.2 \%$ & $99.1 \%$ & $98.9 \%$ & $98.1 \%$ & $98.5 \%$ & $0.4 \%$ \\
\hline & & 2 & $96.5 \%$ & $90.4 \%$ & $94.2 \%$ & $97.6 \%$ & $96.1 \%$ & $95.0 \%$ & $2.5 \%$ \\
\hline \multirow{2}{*}{ dC24:NH4 } & \multirow{2}{*}{ dG23:OP2 } & 1 & $2.1 \%$ & $61.3 \%$ & $18.3 \%$ & $63.8 \%$ & $43.9 \%$ & $37.9 \%$ & $24.1 \%$ \\
\hline & & 2 & $16.0 \%$ & $26.7 \%$ & $31.7 \%$ & $6.7 \%$ & $29.4 \%$ & $22.1 \%$ & $9.4 \%$ \\
\hline dG7:N1H & dG23:OP2 & 2 & $0.0 \%$ & $0.0 \%$ & $0.0 \%$ & $55.5 \%$ & $0.0 \%$ & $11.1 \%$ & $22.2 \%$ \\
\hline dG7:N2H & dG23:OP2 & 2 & $0.0 \%$ & $0.0 \%$ & $0.0 \%$ & $55.7 \%$ & $0.0 \%$ & $11.1 \%$ & $22.3 \%$ \\
\hline dC24:NH4 & dG7:N3 & 2 & $0.0 \%$ & $0.0 \%$ & $0.0 \%$ & $38.6 \%$ & $0.0 \%$ & $7.7 \%$ & $15.5 \%$ \\
\hline dG7:N2H & dC24:N3 & 2 & $26.0 \%$ & $17.6 \%$ & $19.1 \%$ & $9.3 \%$ & $20.9 \%$ & $18.6 \%$ & $5.4 \%$ \\
\hline
\end{tabular}

aHydrogen-bonding interactions were determined using a cut-off of $3.4 \AA$ for the donor-acceptor distance and $120^{\circ}$ for the donor-hydrogen-acceptor angle. 
Table S10: Average residence times (ps, amount of time the helix adopts one conformation before switching conformations) for the planar and bent conformations of the syn SMI structures. ${ }^{a}$

\begin{tabular}{|c|c|c|c|c|c|c|c|}
\hline Adduct & Conformation & Replica 1 & Replica 2 & Replica 3 & Replica 4 & Replica 5 & Average \\
\hline \multirow{2}{*}{$\mathbf{1}$} & Planar & 1167 & 137 & 1136 & 138 & 402 & $596 \pm 464$ \\
\cline { 2 - 7 } & Bent & 99 & 556 & 363 & 639 & 683 & $468 \pm 215$ \\
\hline \multirow{2}{*}{$\mathbf{2}$} & Planar & 587 & 291 & 207 & 200 & 242 & $306 \pm 144$ \\
\cline { 2 - 8 } & Bent & 275 & 348 & 434 & 548 & 425 & $406 \pm 91$ \\
\hline
\end{tabular}

${ }^{2}$ Structures were classified as planar or bent according to whether the interplanar angle between the base pairs flanking the lesion site is less than or greater than $40^{\circ}$, respectively.

Table S11: Histogram of residence times for the SMI adducts switching between the planar and bent conformations for all five replicas. ${ }^{a}$

\begin{tabular}{|c|c|c|}
\hline $\begin{array}{c}\text { Residence } \\
\text { time (ns) }\end{array}$ & $\mathbf{1}$ & $\mathbf{2}$ \\
\hline$<0.5$ & 8785 & 12609 \\
\hline 0.5 to 1.0 & 574 & 715 \\
\hline 1.0 to 1.5 & 243 & 294 \\
\hline 1.5 to 2.0 & 133 & 160 \\
\hline 2.0 to 2.5 & 87 & 115 \\
\hline 2.5 to 3.0 & 75 & 68 \\
\hline 3.0 to 3.5 & 52 & 54 \\
\hline 3.5 to 4.0 & 45 & 39 \\
\hline 4.0 to 4.5 & 21 & 27 \\
\hline 4.5 to 5.0 & 34 & 16 \\
\hline$>5.0$ & 164 & 140 \\
\hline
\end{tabular}

${ }^{a}$ Each simulation was sampled every $50 \mathrm{ps}$ and classified as planar or bent according to whether the interplanar angle between the base pairs flanking the lesion site is less than or greater than $40^{\circ}$, respectively. 
Table S12: Occupancies (\%) of the hydrogen bonds at the lesion site containing the lesion pair in the B conformation for the FP models. ${ }^{a}$

\begin{tabular}{|c|c|c|c|c|c|c|c|c|c|}
\hline \multirow{2}{*}{ Donor } & \multirow{2}{*}{ Acceptor } & Adduct & $\begin{array}{c}\text { Replica } \\
1\end{array}$ & $\begin{array}{c}\text { Replica } \\
2\end{array}$ & $\begin{array}{c}\text { Replica } \\
3\end{array}$ & $\begin{array}{c}\text { Replica } \\
4\end{array}$ & $\begin{array}{c}\text { Replica } \\
5\end{array}$ & Average & $\begin{array}{c}\text { Standard } \\
\text { Deviation }\end{array}$ \\
\hline \multirow{2}{*}{ Lesion:N1H } & \multirow{2}{*}{$\mathrm{d}$ dC24:N3 } & $\mathbf{1}$ & $99.9 \%$ & $99.9 \%$ & $99.9 \%$ & $99.9 \%$ & $99.8 \%$ & $99.9 \%$ & $0.0 \%$ \\
\cline { 3 - 9 } & $\mathbf{2}$ & $99.8 \%$ & $99.8 \%$ & $99.8 \%$ & $99.8 \%$ & $99.6 \%$ & $99.8 \%$ & $0.1 \%$ \\
\hline \multirow{2}{*}{ Lesion:N2H } & \multirow{2}{*}{$\mathrm{dC24:O2}$} & $\mathbf{1}$ & $99.9 \%$ & $99.9 \%$ & $99.9 \%$ & $99.9 \%$ & $99.9 \%$ & $99.9 \%$ & $0.0 \%$ \\
\cline { 3 - 9 } & $\mathbf{2}$ & $100.0 \%$ & $99.9 \%$ & $99.9 \%$ & $99.9 \%$ & $99.9 \%$ & $99.9 \%$ & $0.0 \%$ \\
\hline \multirow{2}{*}{$\mathrm{dC24:N4H}$} & \multirow{2}{*}{ Lesion:O6 } & $\mathbf{1}$ & $99.3 \%$ & $99.4 \%$ & $99.2 \%$ & $99.4 \%$ & $99.3 \%$ & $99.3 \%$ & $0.1 \%$ \\
\cline { 3 - 9 } & $\mathbf{2}$ & $98.3 \%$ & $98.0 \%$ & $98.1 \%$ & $98.1 \%$ & $98.1 \%$ & $98.1 \%$ & $0.1 \%$ \\
\hline Lesion: $\mathrm{N} 17 \mathrm{H}$ & Lesion:O6 & $\mathbf{1}$ & $98.9 \%$ & $98.9 \%$ & $98.8 \%$ & $98.7 \%$ & $98.8 \%$ & $98.8 \%$ & $0.1 \%$ \\
\hline Lesion: $\mathrm{N} 10 \mathrm{H}$ & Lesion:O4' & $\mathbf{2}$ & $61.8 \%$ & $61.6 \%$ & $61.4 \%$ & $60.4 \%$ & $60.8 \%$ & $61.2 \%$ & $0.6 \%$ \\
\hline
\end{tabular}

aHydrogen-bonding interactions were determined using a cut-off of $3.4 \AA$ for the donor-acceptor distance and $120^{\circ}$ for the donor-hydrogen-acceptor angle.

Table S13: Occupancies (\%) of the hydrogen bonds of the flanking bases in the B Conformation for the FP models. ${ }^{a}$

\begin{tabular}{|c|c|c|c|c|c|c|c|c|c|}
\hline Donor & Acceptor & Adduct & $\begin{array}{c}\text { Replica } \\
1 \\
\end{array}$ & $\begin{array}{c}\text { Replica } \\
2 \\
\end{array}$ & $\begin{array}{c}\text { Replica } \\
3 \\
\end{array}$ & $\begin{array}{c}\text { Replica } \\
4 \\
\end{array}$ & $\begin{array}{c}\text { Replica } \\
5 \\
\end{array}$ & Average & $\begin{array}{l}\text { Standard } \\
\text { Deviation }\end{array}$ \\
\hline \multirow{2}{*}{ dG25:N1H } & \multirow{2}{*}{ dC8:N3 } & 1 & $99.9 \%$ & $99.9 \%$ & $99.9 \%$ & $99.9 \%$ & $99.9 \%$ & $99.9 \%$ & $0.0 \%$ \\
\hline & & 2 & $100.0 \%$ & $100.0 \%$ & $100.0 \%$ & $100.0 \%$ & $100.0 \%$ & $100.0 \%$ & $0.0 \%$ \\
\hline \multirow{2}{*}{ dG25:N2H } & \multirow{2}{*}{ dC8:02 } & 1 & $99.9 \%$ & $99.8 \%$ & $99.9 \%$ & $99.9 \%$ & $99.9 \%$ & $99.9 \%$ & $0.0 \%$ \\
\hline & & 2 & $99.8 \%$ & $99.8 \%$ & $99.8 \%$ & $99.7 \%$ & $99.8 \%$ & $99.8 \%$ & $0.1 \%$ \\
\hline \multirow{2}{*}{$\mathrm{dC8}: \mathrm{N} 4 \mathrm{H}$} & \multirow{2}{*}{ dG25:06 } & 1 & $98.6 \%$ & $98.3 \%$ & $98.6 \%$ & $98.5 \%$ & $98.6 \%$ & $98.5 \%$ & $0.1 \%$ \\
\hline & & 2 & $98.8 \%$ & $99.1 \%$ & $99.0 \%$ & $98.9 \%$ & $99.0 \%$ & $98.9 \%$ & $0.1 \%$ \\
\hline \multirow{2}{*}{ dG23:N1H } & \multirow{2}{*}{ dC10:N3 } & 1 & $99.9 \%$ & $99.9 \%$ & $99.9 \%$ & $99.8 \%$ & $99.9 \%$ & $99.9 \%$ & $0.0 \%$ \\
\hline & & 2 & $99.9 \%$ & $100.0 \%$ & $100.0 \%$ & $99.9 \%$ & $99.9 \%$ & $100.0 \%$ & $0.0 \%$ \\
\hline \multirow{2}{*}{ dG23:N2H } & \multirow{2}{*}{ dC10:O2 } & 1 & $99.5 \%$ & $99.7 \%$ & $99.7 \%$ & $99.8 \%$ & $99.7 \%$ & $99.7 \%$ & $0.1 \%$ \\
\hline & & 2 & $99.5 \%$ & $99.2 \%$ & $99.4 \%$ & $99.4 \%$ & $99.4 \%$ & $99.4 \%$ & $0.1 \%$ \\
\hline \multirow{2}{*}{$\mathrm{dC10:N4H}$} & \multirow{2}{*}{ dG23:06 } & 1 & $98.3 \%$ & $98.5 \%$ & $98.3 \%$ & $98.3 \%$ & $98.5 \%$ & $98.4 \%$ & $0.1 \%$ \\
\hline & & 2 & $99.1 \%$ & $99.2 \%$ & $98.9 \%$ & $99.0 \%$ & $99.0 \%$ & $99.0 \%$ & $0.1 \%$ \\
\hline
\end{tabular}

aHydrogen-bonding interactions were determined using a cut-off of $3.4 \AA$ for the donor-acceptor distance and $120^{\circ}$ for the donor-hydrogen-acceptor angle. 
Table S14: Occupancies (\%) of the hydrogen bonds at the lesion site containing the lesion pair in the $\mathrm{S}$ conformation for the FP models. ${ }^{a}$

\begin{tabular}{|c|c|c|c|c|c|c|c|c|c|}
\hline Donor & Acceptor & Adduct & $\begin{array}{c}\text { Replica } \\
1\end{array}$ & $\begin{array}{c}\text { Replica } \\
2\end{array}$ & $\begin{array}{c}\text { Replica } \\
3\end{array}$ & $\begin{array}{c}\text { Replica } \\
4\end{array}$ & $\begin{array}{c}\text { Replica } \\
5\end{array}$ & Average & $\begin{array}{c}\text { Standard } \\
\text { Deviation }\end{array}$ \\
\hline dC24:NH4 & dG23:OP2 & $\mathbf{1}$ & $5.8 \%$ & $31.2 \%$ & $16.1 \%$ & $10.4 \%$ & $14.8 \%$ & $15.7 \%$ & $8.5 \%$ \\
\hline Lesion:N17H & Lesion:O6 & $\mathbf{1}$ & $96.2 \%$ & $95.7 \%$ & $95.0 \%$ & $95.9 \%$ & $94.6 \%$ & $95.5 \%$ & $0.6 \%$ \\
\hline Lesion:N10H & dG25:N2 & $\mathbf{2}$ & $44.7 \%$ & $38.5 \%$ & $40.7 \%$ & $38.2 \%$ & $26.8 \%$ & $37.8 \%$ & $5.9 \%$ \\
\hline dC24:NH4 & Lesion:O6 & $\mathbf{2}$ & $56.7 \%$ & $43.9 \%$ & $45.2 \%$ & $42.8 \%$ & $16.6 \%$ & $41.0 \%$ & $13.2 \%$ \\
\hline
\end{tabular}

aHydrogen-bonding interactions were determined using a cut-off of $3.4 \AA$ for the donor-acceptor distance and $120^{\circ}$ for the donor-hydrogen-acceptor angle.

Table S15: Occupancies (\%) of the hydrogen bonds of the flanking bases when the helix containing a lesion is started from the $S$ conformation for the FP models. ${ }^{a}$

\begin{tabular}{|c|c|c|c|c|c|c|c|c|c|}
\hline Donor & Acceptor & Adduct & $\begin{array}{c}\text { Replica } \\
1\end{array}$ & $\begin{array}{c}\text { Replica } \\
2 \\
\end{array}$ & $\begin{array}{c}\text { Replica } \\
3 \\
\end{array}$ & $\begin{array}{c}\text { Replica } \\
4\end{array}$ & $\begin{array}{c}\text { Replica } \\
5\end{array}$ & Average & $\begin{array}{l}\text { Standard } \\
\text { Deviation }\end{array}$ \\
\hline \multirow{2}{*}{ dG25:N1H } & \multirow{2}{*}{ dC8:N3 } & 1 & $100.0 \%$ & $100.0 \%$ & $100.0 \%$ & $99.9 \%$ & $100.0 \%$ & $100.0 \%$ & $0.0 \%$ \\
\hline & & 2 & $100.0 \%$ & $99.9 \%$ & $100.0 \%$ & $100.0 \%$ & $100.0 \%$ & $100.0 \%$ & $0.0 \%$ \\
\hline \multirow{2}{*}{ dG25:N2H } & \multirow{2}{*}{ dC8:02 } & 1 & $99.9 \%$ & $99.9 \%$ & $99.9 \%$ & $99.9 \%$ & $99.9 \%$ & $99.9 \%$ & $0.0 \%$ \\
\hline & & 2 & $100.0 \%$ & $100.0 \%$ & $99.9 \%$ & $100.0 \%$ & $100.0 \%$ & $99.9 \%$ & $0.0 \%$ \\
\hline \multirow{2}{*}{ dC8:N4H } & \multirow{2}{*}{ dG25:06 } & 1 & $98.8 \%$ & $98.9 \%$ & $98.9 \%$ & $99.1 \%$ & $98.9 \%$ & $98.9 \%$ & $0.1 \%$ \\
\hline & & 2 & $99.2 \%$ & $99.0 \%$ & $99.2 \%$ & $98.7 \%$ & $99.2 \%$ & $99.1 \%$ & $0.2 \%$ \\
\hline \multirow{2}{*}{ dG23:N1H } & \multirow{2}{*}{$\mathrm{dC10:N3}$} & 1 & $99.7 \%$ & $99.6 \%$ & $99.7 \%$ & $99.7 \%$ & $99.7 \%$ & $99.7 \%$ & $0.0 \%$ \\
\hline & & 2 & $93.7 \%$ & $94.3 \%$ & $74.8 \%$ & $69.9 \%$ & $98.3 \%$ & $86.2 \%$ & $11.5 \%$ \\
\hline \multirow{2}{*}{ dG23:N2H } & \multirow{2}{*}{ dC10:02 } & 1 & $99.9 \%$ & $99.8 \%$ & $99.9 \%$ & $99.9 \%$ & $99.8 \%$ & $99.9 \%$ & $0.0 \%$ \\
\hline & & 2 & $94.1 \%$ & $97.2 \%$ & $75.4 \%$ & $70.4 \%$ & $99.7 \%$ & $87.4 \%$ & $12.0 \%$ \\
\hline \multirow{2}{*}{ dC10:N4H } & \multirow{2}{*}{ dG23:06 } & 1 & $97.3 \%$ & $97.4 \%$ & $97.1 \%$ & $97.4 \%$ & $96.5 \%$ & $97.1 \%$ & $0.3 \%$ \\
\hline & & 2 & $92.0 \%$ & $91.9 \%$ & $73.2 \%$ & $67.7 \%$ & $92.2 \%$ & $83.4 \%$ & $10.7 \%$ \\
\hline
\end{tabular}

aHydrogen-bonding interactions were determined using a cut-off of $3.4 \AA$ for the donor-acceptor distance and $120^{\circ}$ for the donor-hydrogen-acceptor angle. 
Table S16: Occupancies (\%) of the hydrogen bonds at the lesion site containing the lesion pair in the $\mathrm{W}$ conformation for the FP models. ${ }^{\mathrm{a}}$

\begin{tabular}{|c|c|c|c|c|c|c|c|c|c|}
\hline Donor & Acceptor & Adduct & $\begin{array}{c}\text { Replica } \\
1\end{array}$ & $\begin{array}{c}\text { Replica } \\
2\end{array}$ & $\begin{array}{c}\text { Replica } \\
3\end{array}$ & $\begin{array}{c}\text { Replica } \\
4\end{array}$ & $\begin{array}{c}\text { Replica } \\
5\end{array}$ & Average & $\begin{array}{c}\text { Standard } \\
\text { Deviation }\end{array}$ \\
\hline Lesion:N17H & Lesion:O6 & $\mathbf{1}$ & $94.4 \%$ & $97.1 \%$ & $95.1 \%$ & $94.8 \%$ & $98.3 \%$ & $95.9 \%$ & $1.5 \%$ \\
\hline $\mathrm{dC24:NH4}$ & dG23:OP2 & $\mathbf{1}$ & $21.6 \%$ & $2.2 \%$ & $38.0 \%$ & $21.2 \%$ & $0.0 \%$ & $16.6 \%$ & $14.0 \%$ \\
\hline $\mathrm{dC24}: \mathrm{N} 4 \mathrm{H}$ & Lesion:O6 & $\mathbf{2}$ & $38.6 \%$ & $63.2 \%$ & $51.1 \%$ & $38.4 \%$ & $47.0 \%$ & $47.7 \%$ & $9.2 \%$ \\
\hline $\mathrm{dC24}: \mathrm{N} 4 \mathrm{H}$ & Lesion:N7 & $\mathbf{2}$ & $37.8 \%$ & $60.9 \%$ & $49.0 \%$ & $37.4 \%$ & $48.3 \%$ & $46.7 \%$ & $8.7 \%$ \\
\hline Lesion: $\mathrm{N10H}$ & $\mathrm{dC10:O4}$ & $\mathbf{2}$ & $24.2 \%$ & $37.3 \%$ & $41.7 \%$ & $45.1 \%$ & $43.5 \%$ & $38.4 \%$ & $7.5 \%$ \\
\hline $\mathrm{dC} 24: \mathrm{N} 4 \mathrm{H}$ & $\mathrm{dC} 10: \mathrm{O} 2$ & $\mathbf{2}$ & $10.0 \%$ & $8.3 \%$ & $18.2 \%$ & $32.5 \%$ & $22.4 \%$ & $18.3 \%$ & $8.8 \%$ \\
\hline
\end{tabular}

${ }^{a}$ Hydrogen-bonding interactions were determined using a cut-off of $3.4 \AA$ for the donor-acceptor distance and $120^{\circ}$ for the donor-hydrogen-acceptor angle.

Table S17: Occupancies (\%) of the hydrogen bonds of the flanking bases when the helix containing a lesion is started from the $\mathrm{W}$ conformation for the FP models. ${ }^{\mathrm{a}}$

\begin{tabular}{|c|c|c|c|c|c|c|c|c|c|}
\hline Donor & Acceptor & Adduct & $\begin{array}{c}\text { Replica } \\
1\end{array}$ & $\begin{array}{c}\text { Replica } \\
2\end{array}$ & $\begin{array}{c}\text { Replica } \\
3\end{array}$ & $\begin{array}{c}\text { Replica } \\
4\end{array}$ & $\begin{array}{c}\text { Replica } \\
5\end{array}$ & Average & $\begin{array}{l}\text { Standard } \\
\text { Deviation }\end{array}$ \\
\hline \multirow{2}{*}{ dG25:N1H } & \multirow{2}{*}{ dC8:N3 } & 1 & $100.0 \%$ & $99.9 \%$ & $100.0 \%$ & $100.0 \%$ & $99.9 \%$ & $100.0 \%$ & $0.0 \%$ \\
\hline & & 2 & $99.9 \%$ & $99.9 \%$ & $99.9 \%$ & $99.9 \%$ & $99.9 \%$ & $99.9 \%$ & $0.0 \%$ \\
\hline \multirow{2}{*}{ dG25:N2H } & \multirow{2}{*}{ dC8:02 } & 1 & $99.9 \%$ & $99.9 \%$ & $99.8 \%$ & $99.9 \%$ & $99.9 \%$ & $99.9 \%$ & $0.0 \%$ \\
\hline & & 2 & $99.7 \%$ & $99.6 \%$ & $99.7 \%$ & $99.5 \%$ & $99.8 \%$ & $99.6 \%$ & $0.1 \%$ \\
\hline \multirow{2}{*}{ dC8:N4H } & \multirow{2}{*}{ dG25:06 } & 1 & $99.1 \%$ & $98.8 \%$ & $98.6 \%$ & $99.2 \%$ & $98.4 \%$ & $98.8 \%$ & $0.3 \%$ \\
\hline & & 2 & $98.7 \%$ & $99.0 \%$ & $98.5 \%$ & $98.4 \%$ & $98.6 \%$ & $98.6 \%$ & $0.2 \%$ \\
\hline \multirow{2}{*}{ dG23:N1H } & \multirow{2}{*}{ dC10:N3 } & 1 & $99.5 \%$ & $99.8 \%$ & $99.8 \%$ & $99.6 \%$ & $99.6 \%$ & $99.7 \%$ & $0.1 \%$ \\
\hline & & 2 & $99.0 \%$ & $99.6 \%$ & $99.3 \%$ & $99.5 \%$ & $99.5 \%$ & $99.4 \%$ & $0.2 \%$ \\
\hline \multirow{2}{*}{ dG23:N2H } & \multirow{2}{*}{ dC10:O2 } & 1 & $99.8 \%$ & $99.8 \%$ & $99.9 \%$ & $99.8 \%$ & $99.7 \%$ & $99.8 \%$ & $0.1 \%$ \\
\hline & & 2 & $98.7 \%$ & $97.4 \%$ & $97.1 \%$ & $97.8 \%$ & $97.9 \%$ & $97.8 \%$ & $0.5 \%$ \\
\hline \multirow{2}{*}{$\mathrm{dC10:N4H}$} & \multirow{2}{*}{ dG23:06 } & 1 & $96.4 \%$ & $98.2 \%$ & $98.1 \%$ & $97.0 \%$ & $98.7 \%$ & $97.7 \%$ & $0.8 \%$ \\
\hline & & 2 & $97.2 \%$ & $98.2 \%$ & $98.4 \%$ & $98.3 \%$ & $98.2 \%$ & $98.1 \%$ & $0.5 \%$ \\
\hline
\end{tabular}

aHydrogen-bonding interactions were determined using a cut-off of $3.4 \AA$ for the donor-acceptor distance and $120^{\circ}$ for the donor-hydrogen-acceptor angle. 
Table S18: Average and standard deviations (in parenthesis) of the interplanar angle (deg) between the aromatic portion of the bulky moiety and the $5^{\prime}$ or $3^{\prime}$ base-pairs for the FP duplexes with the adduct in the syn orientation. ${ }^{a}$

\begin{tabular}{|c|c|c|c|c|c|c|c|}
\hline Direction & Adduct & Replica 1 & Replica 2 & Replica 3 & Replica 4 & Replica 5 & Average \\
\hline \multirow{2}{*}{$\begin{array}{c}\text { ' base- } \\
\text { pair }\end{array}$} & $\mathbf{1}$ & $11.0(12.2)$ & $9.6(11.2)$ & $10.0(10.4)$ & $10.1(10.8)$ & $11.4(13.0)$ & $10.4(0.7)$ \\
\cline { 2 - 8 } & $\mathbf{2}$ & $56.7(20.7)$ & $50.9(23.5)$ & $53.9(21.0)$ & $60.9(19.1)$ & $37.8(23.8)$ & $52.0(7.8)$ \\
\hline $\begin{array}{c}\text { 3' base- } \\
\text { pair }\end{array}$ & $\mathbf{1}$ & $16.1(13.1)$ & $13.6(9.3)$ & $14.0(11.3)$ & $14.7(11.5)$ & $15.0(12.1)$ & $14.7(0.9)$ \\
\hline \multirow{2}{*}{ Both } & $\mathbf{2}$ & $55.2(20.5)$ & $59.7(23.6)$ & $63.9(18.9)$ & $66.9(17.5)$ & $49.1(27.3)$ & $58.9(6.3)$ \\
\cline { 2 - 8 } & $\mathbf{1}$ & $13.6(12.9)$ & $11.6(10.5)$ & $12.0(11.1)$ & $12.4(11.4)$ & $13.2(12.7)$ & $12.5(0.7)$ \\
\hline
\end{tabular}

anterplanar angle calculated between the ring atoms of either the 5 ' or 3 ' flanking bases and the aromatic rings of the bulky group using an in-house script.

Table S19. MOL2 file containing partial charges and atom types of the 1 adduct used for MD simulations (atom numbers are provided in the associated figure).

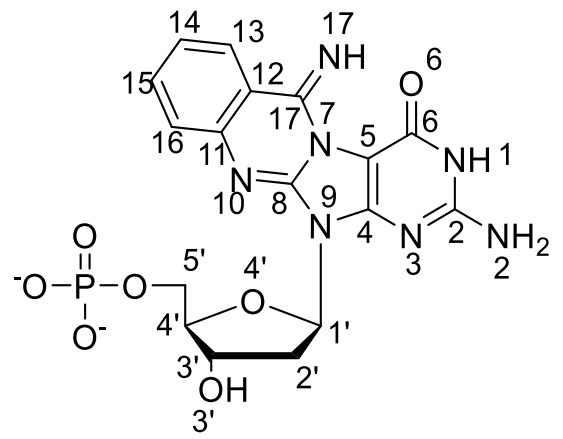

\begin{tabular}{|c|c|c|c|c|c|c|c|c|}
\hline 1 & $\mathrm{P}$ & 5.238 & 2.263 & 0.407 & $\mathrm{P}$ & 1 & LIG & 1.2091 \\
\hline 2 & O5' & 3.926 & 1.364 & 0.000 & OS & 1 & LIG & -0.4826 \\
\hline 3 & OP1 & 4.795 & 3.635 & 0.696 & O2 & 1 & LIG & -0.7854 \\
\hline 4 & OP2 & 6.043 & 1.432 & 1.314 & $\mathrm{O} 2$ & 1 & LIG & -0.7966 \\
\hline 5 & O3' & 0.000 & 0.000 & 0.000 & OS & 1 & LIG & -0.5525 \\
\hline 6 & C5' & 2.896 & 1.974 & -0.733 & $\mathrm{Cl}$ & 1 & LIG & -0.0043 \\
\hline 7 & $\mathrm{H}^{\prime}$ & 2.408 & 2.742 & -0.135 & $\mathrm{H} 1$ & 1 & LIG & 0.0792 \\
\hline 8 & H5" & 3.282 & 2.438 & -1.635 & $\mathrm{H} 1$ & 1 & LIG & 0.0792 \\
\hline 9 & C4' & 1.855 & 0.949 & -1.131 & CT & 1 & LIG & 0.1315 \\
\hline 10 & $\mathrm{H} 4^{\prime}$ & 0.980 & 1.480 & -1.489 & $\mathrm{H} 1$ & 1 & LIG & 0.1007 \\
\hline 11 & O4' & 2.356 & 0.135 & -2.168 & OS & 1 & LIG & -0.3713 \\
\hline 12 & $\mathrm{C} 1^{\prime}$ & 1.961 & -1.189 & -1.952 & CT & 1 & LIG & 0.1256 \\
\hline 13 & $\mathrm{H} 1^{\prime}$ & 0.969 & -1.356 & -2.338 & $\mathrm{H} 2$ & 1 & LIG & 0.0846 \\
\hline 14 & C3' & 1.408 & 0.000 & 0.000 & CT & 1 & LIG & 0.1727 \\
\hline 15 & $\mathrm{H}^{\prime}$ & 1.784 & 0.318 & 0.964 & $\mathrm{H} 1$ & 1 & LIG & 0.0582 \\
\hline 16 & C2' & 1.987 & -1.344 & -0.436 & CT & 1 & LIG & -0.0313 \\
\hline 17 & $\mathrm{H}^{\prime}$ & 3.005 & -1.441 & -0.088 & $\mathrm{HC}$ & 1 & LIG & 0.0330 \\
\hline 18 & H2" & 1.400 & -2.188 & -0.092 & $\mathrm{HC}$ & 1 & LIG & 0.0330 \\
\hline
\end{tabular}




$\begin{array}{lcccccccc}19 & \text { N9 } & 2.814 & -2.077 & -2.709 & N^{*} & 1 & \text { LIG } & -0.0620 \\ 20 & \mathrm{C} 8 & 2.351 & -2.810 & -3.788 & \mathrm{CB} & 1 & \text { LIG } & 0.2835 \\ 21 & \mathrm{~N} 7 & 3.431 & -3.415 & -4.375 & \mathrm{~N}^{*} & 1 & \text { LIG } & -0.0363 \\ 22 & \mathrm{C} 5 & 4.589 & -3.029 & -3.648 & \mathrm{CB} & 1 & \text { LIG } & -0.2219 \\ 23 & \mathrm{C} 6 & 5.978 & -3.308 & -3.781 & \mathrm{C} & 1 & \text { LIG } & 0.5360 \\ 24 & \mathrm{O} 6 & 6.588 & -3.978 & -4.572 & \mathrm{O} & 1 & \text { LIG } & -0.5808 \\ 25 & \mathrm{~N} 1 & 6.711 & -2.644 & -2.778 & \mathrm{NA} & 1 & \text { LIG } & -0.4165 \\ 26 & \mathrm{H} 1 & 7.699 & -2.753 & -2.866 & \mathrm{H} & 1 & \text { LIG } & 0.3444 \\ 27 & \mathrm{C} 2 & 6.191 & -1.852 & -1.816 & \mathrm{CA} & 1 & \text { LIG } & 0.6281 \\ 28 & \mathrm{~N} 2 & 7.057 & -1.259 & -0.959 & \mathrm{~N} 2 & 1 & \text { LIG } & -0.8567 \\ 29 & \mathrm{H} 21 & 7.929 & -1.697 & -0.764 & \mathrm{H} & 1 & \text { LIG } & 0.3949 \\ 30 & \mathrm{H} 22 & 6.621 & -0.790 & -0.196 & \mathrm{H} & 1 & \text { LIG } & 0.3949 \\ 31 & \mathrm{~N} 3 & 4.927 & -1.617 & -1.704 & \mathrm{NC} & 1 & \text { LIG } & -0.5009 \\ 32 & \mathrm{C} 4 & 4.171 & -2.205 & -2.644 & \mathrm{CB} & 1 & \text { LIG } & 0.3147 \\ 33 & \mathrm{~N} 10 & 1.132 & -2.890 & -4.123 & \mathrm{NC} & 1 & \text { LIG } & -0.4245 \\ 34 & \mathrm{C} 17 & 3.279 & -4.257 & -5.500 & \mathrm{CM} & 1 & \text { LIG } & 0.4418 \\ 35 & \mathrm{~N} 17 & 4.198 & -4.859 & -6.100 & \mathrm{~N} 2 & 1 & \text { LIG } & -0.8649 \\ 36 & \mathrm{H} 17 & 5.115 & -4.706 & -5.728 & \mathrm{H} & 1 & \text { LIG } & 0.4607 \\ 37 & \mathrm{C} 11 & 0.864 & -3.684 & -5.229 & \mathrm{CA} & 1 & \text { LIG } & 0.1305 \\ 38 & \mathrm{C} 12 & -0.464 & -3.803 & -5.653 & \mathrm{CA} & 1 & \text { LIG } & -0.1441 \\ 39 & \mathrm{H} 12 & -1.221 & -3.271 & -5.108 & \mathrm{HA} & 1 & \text { LIG } & 0.1073 \\ 40 & \mathrm{C} 16 & 1.865 & -4.363 & -5.921 & \mathrm{CA} & 1 & \text { LIG } & -0.0028 \\ 41 & \mathrm{C} 13 & -0.775 & -4.581 & -6.741 & \mathrm{CA} & 1 & \text { LIG } & -0.1299 \\ 42 & \mathrm{H} 13 & -1.799 & -4.665 & -7.059 & \mathrm{HA} & 1 & \text { LIG } & 0.1477 \\ 43 & \mathrm{C} 14 & 0.227 & -5.262 & -7.437 & \mathrm{CA} & 1 & \text { LIG } & -0.2012 \\ 44 & \mathrm{H} 14 & -0.024 & -5.870 & -8.288 & \mathrm{HA} & 1 & \text { LIG } & 0.1464 \\ 45 & \mathrm{C} 15 & 1.533 & -5.151 & -7.027 & \mathrm{CA} & 1 & \text { LIG } & -0.1279 \\ 46 & \mathrm{H} 15 & 2.323 & -5.662 & -7.541 & \mathrm{HA} & 1 & \text { LIG } & 0.1564\end{array}$


Table S20. MOL2 file containing partial charges and atom types of the $\mathbf{2}$ adduct used for MD simulations (atom numbers are provided in the associated figure).

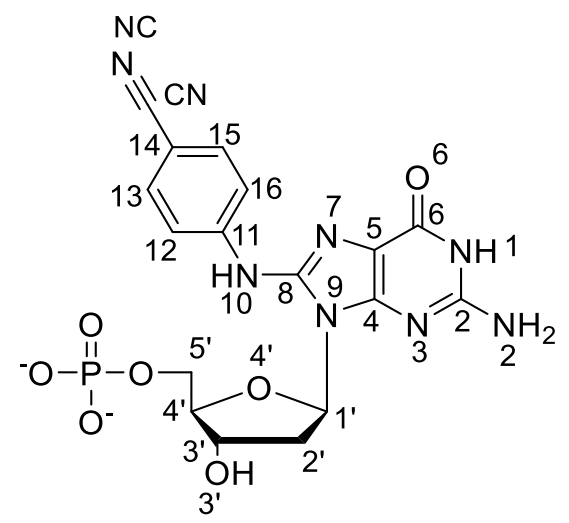

\begin{tabular}{|c|c|c|c|c|c|c|c|c|}
\hline 1 & $P$ & 4.929 & 0.561 & -1.290 & $P$ & 1 & LIG & 1.2091 \\
\hline 2 & O5' & 4.126 & 1.182 & 0.000 & os & 1 & LIG & -0.4826 \\
\hline 3 & OP1 & 4.917 & 1.555 & -2.373 & O2 & 1 & LIG & -0.7854 \\
\hline 4 & OP2 & 6.138 & -0.082 & -0.753 & O2 & 1 & LIG & -0.7966 \\
\hline 5 & O3' & 0.000 & 0.000 & 0.000 & OS & 1 & LIG & -0.5525 \\
\hline 6 & C5' & 3.014 & 1.997 & -0.235 & $\mathrm{Cl}$ & 1 & LIG & -0.0043 \\
\hline 7 & $\mathrm{H}^{\prime}$ & 2.720 & 2.416 & 0.719 & $\mathrm{H} 1$ & 1 & LIG & 0.0792 \\
\hline 8 & H5" & 3.265 & 2.819 & -0.899 & $\mathrm{H} 1$ & 1 & LIG & 0.0792 \\
\hline 9 & C4' & 1.855 & 1.216 & -0.825 & $\mathrm{CT}$ & 1 & LIG & 0.1315 \\
\hline 10 & $\mathrm{H}^{\prime}$ & 1.005 & 1.870 & -0.975 & $\mathrm{H} 1$ & 1 & LIG & 0.1007 \\
\hline 11 & O4' & 2.278 & 0.694 & -2.080 & os & 1 & LIG & -0.3713 \\
\hline 12 & $\mathrm{C} 1^{\prime}$ & 1.896 & -0.657 & -2.200 & CT & 1 & LIG & 0.2759 \\
\hline 13 & $\mathrm{H} 1^{\prime}$ & 0.874 & -0.697 & -2.557 & $\mathrm{H} 2$ & 1 & LIG & 0.0289 \\
\hline 14 & $\mathrm{C}^{\prime}$ & 1.407 & 0.000 & 0.000 & $\mathrm{CT}$ & 1 & LIG & 0.1727 \\
\hline 15 & $\mathrm{H}^{\prime}$ & 1.787 & 0.044 & 1.014 & $\mathrm{H} 1$ & 1 & LIG & 0.0582 \\
\hline 16 & C2' & 1.983 & -1.182 & -0.775 & CT & 1 & LIG & -0.0313 \\
\hline 17 & $\mathrm{H}^{\prime}$ & 3.013 & -1.341 & -0.497 & $\mathrm{HC}$ & 1 & LIG & 0.0330 \\
\hline 18 & H2" & 1.434 & -2.101 & -0.623 & $\mathrm{HC}$ & 1 & LIG & 0.0330 \\
\hline 19 & N9 & 2.741 & -1.278 & -3.195 & $\mathrm{~N}^{*}$ & 1 & LIG & -0.0566 \\
\hline 20 & C8 & 2.801 & -0.867 & -4.521 & $\mathrm{CR}$ & 1 & LIG & 0.2579 \\
\hline 21 & N7 & 3.488 & -1.645 & -5.266 & NB & 1 & LIG & -0.4147 \\
\hline 22 & C5 & 3.912 & -2.651 & -4.421 & CB & 1 & LIG & 0.0338 \\
\hline 23 & C6 & 4.721 & -3.800 & -4.704 & C & 1 & LIG & 0.4880 \\
\hline 24 & O6 & 5.220 & -4.171 & -5.723 & 0 & 1 & LIG & -0.5423 \\
\hline 25 & N1 & 4.910 & -4.556 & -3.524 & NA & 1 & LIG & -0.3889 \\
\hline 26 & $\mathrm{H} 1$ & 5.522 & -5.337 & -3.633 & $\mathrm{H}$ & 1 & LIG & 0.3280 \\
\hline 27 & $\mathrm{C} 2$ & 4.405 & -4.259 & -2.302 & $\mathrm{CA}$ & 1 & LIG & 0.5609 \\
\hline 28 & N2 & 4.744 & -5.102 & -1.287 & N2 & 1 & LIG & -0.8603 \\
\hline
\end{tabular}




$\begin{array}{lcccccccc}29 & \mathrm{H} 21 & 4.900 & -6.061 & -1.505 & \mathrm{H} & 1 & \text { LIG } & 0.3910 \\ 30 & \mathrm{H} 22 & 4.236 & -4.947 & -0.444 & \mathrm{H} & 1 & \text { LIG } & 0.3910 \\ 31 & \mathrm{~N} 3 & 3.672 & -3.226 & -2.061 & \mathrm{NC} & 1 & \text { LIG } & -0.4977 \\ 32 & \mathrm{C} 4 & 3.469 & -2.445 & -3.152 & \mathrm{CB} & 1 & \text { LIG } & 0.1794 \\ 33 & \mathrm{~N} 10 & 2.135 & 0.277 & -4.881 & \mathrm{~N} 2 & 1 & \text { LIG } & -0.2892 \\ 34 & \mathrm{H} 10 & 1.983 & 0.919 & -4.135 & \mathrm{H} & 1 & \text { LIG } & 0.2402 \\ 35 & \mathrm{C} 11 & 1.944 & 0.790 & -6.162 & \mathrm{CA} & 1 & \text { LIG } & 0.1738 \\ 36 & \mathrm{C} 12 & 1.354 & 2.054 & -6.249 & \mathrm{CA} & 1 & \text { LIG } & -0.2411 \\ 37 & \mathrm{H} 12 & 1.090 & 2.582 & -5.350 & \mathrm{HA} & 1 & \text { LIG } & 0.1622 \\ 38 & \mathrm{C} 16 & 2.278 & 0.112 & -7.333 & \mathrm{CA} & 1 & \text { LIG } & -0.0856 \\ 39 & \mathrm{H} 16 & 2.749 & -0.847 & -7.285 & \mathrm{HA} & 1 & \text { LIG } & 0.1125 \\ 40 & \mathrm{C} 13 & 1.100 & 2.629 & -7.472 & \mathrm{CA} & 1 & \text { LIG } & -0.1466 \\ 41 & \mathrm{H} 13 & 0.645 & 3.601 & -7.524 & \mathrm{HA} & 1 & \text { LIG } & 0.1693 \\ 42 & \mathrm{C} 15 & 2.016 & 0.697 & -8.557 & \mathrm{CA} & 1 & \text { LIG } & -0.1947 \\ 43 & \mathrm{H} 15 & 2.278 & 0.171 & -9.456 & \mathrm{HA} & 1 & \text { LIG } & 0.1870 \\ 44 & \mathrm{C} 14 & 1.429 & 1.953 & -8.643 & \mathrm{CA} & 1 & \text { LIG } & 0.0003 \\ 45 & \mathrm{CN} & 1.163 & 2.552 & -9.927 & \mathrm{C} 1 & 1 & \text { LIG } & 0.3527 \\ 46 & \mathrm{NC} & 0.950 & 3.027 & -10.938 & \mathrm{~N} 1 & 1 & \text { LIG } & -0.4879\end{array}$

